\author{
Universidade de São Paulo \\ Escola de Engenharia de São Carlos \\ Programa de Pós-graduação em Engenharia Elétrica
}

Leandro José de Medeiros

\title{
Hidrofone Ultrassônico com \\ Piezoeletreto como Elemento \\ Transdutor
}



Leandro José de Medeiros

\section{Hidrofone Ultrassônico com}

\section{Piezoeletreto como Elemento}

\section{Transdutor}

Dissertação apresentada à Escola de Engenharia de São Carlos da Universidade de São Paulo, como parte dos requisitos para a obtenção do título de Mestre em Ciências, Programa de Engenharia Elétrica.

Área de Concentração: Sistemas Elétricos de Potência.

Orientador: Professor Titular Ruy Alberto Corrêa Altafim

Trata-se da versão corrigida da dissertação. A versão original se encontra disponível na EESC/USP que aloja o Programa de Pós-Graduação de Engenharia Elétrica.

São Carlos 
AUTORIZO A REPRODUÇÃO TOTAL OU PARCIAL DESTE TRABALHO, POR QUALQUER MEIO CONVENCIONAL OU ELETRÔNICO, PARA FINS DE ESTUDO E PESQUISA, DESDE QUE CITADA A FONTE.

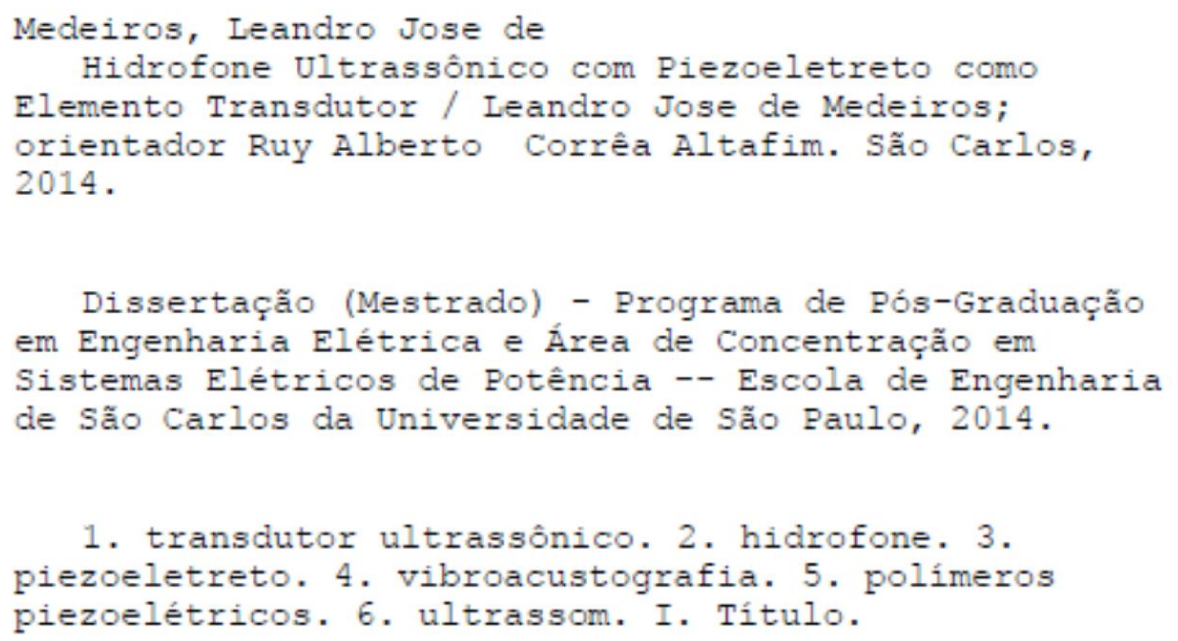




\section{FOLHA DE JULGAMENTO}

\section{Candidato: Engenheiro LEANDRO JOSÉ DE MEDEIROS.}

Título da dissertação: "Hidrofone ultrassônico com piezoeletreto como elemento transdutor".

Data da defesa: 14/03/2014

\section{Comissão Julgadora:}

Prof. Titular Ruy Alberto Corrêa Altafim (Orientador) (Escola de Engenharia de São Carlos/EESC)

Prof. Associado Antonio Adilton Oliveira Carneiro (Faculdade de Filosofia, Ciência e Letras de Ribeirão Preto/FFCLRP-USP)

Prof. Dr. Mardson Freitas de Amorim (Universidade Federal da Paraiba/UFPB)
Resultado:

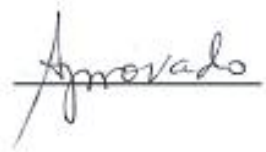

Aprovado

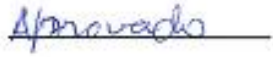

Coordenador do Programa de Pós-Graduação em Engenharia Elétrica e Presidente da Comissão de Pós-Graduação:

Prof. Titular Denis Vinicius Coury 

Esse trabalho é dedicado aos meus pais, Martoni e Ivone, pelo esforço e dedicação para garantir minha formação acadêmica e pessoal. E aos meus irmãos, João $e$ Maria Júlia, pelo carinho e atenção incondicionais nessa jornada. 

Primeiramente a Deus, por me iluminar em mais essa jornada da vida e pela Fé que me acompanha.

À minha família e a minha namorada Jéssica Santiago, por conceder energia positiva tão necessária para vencer os obstáculos encontrados e pela paciência nas horas mais difíceis.

Ao Prof. Dr. Ruy Alberto Corrêa Altafim, pela orientação e dedicação no desenvolvimento desse trabalho, sempre motivando quando nada parecia dar certo. Sou grato também pelas nossas conversas e conselhos que muito contribuíram para meu crescimento pessoal e científico nesses dois anos de convivência.

Ao Prof. Dr. Ruy Alberto P. Altafim, pela imensa contribuição e suporte no desenvolvimento de todas as atividades, estando sempre presente, sem medir esforços, para enriquecer essa pesquisa.

Ao Prof. Dr. Antonio A. Oliveira Carneiro, pela disponibilização de toda estrutura laboratorial do seu grupo (GIIMUS), fundamental na caracterização do protótipo TRU-1. Agradeço também pela grande contribuição nas publicações e pelos ensinamentos sobre acústica e instrumentação.

Ao GIIMUS, da Faculdade de Física Ciência e Letras de Ribeirão Preto, da USP, em especial ao Mestre Hermes Kamimura, pelo suporte nos experimentos práticos, pela vivência e ensinamentos científicos, pelo companheirismo, paciência e incansável dedicação em gerar imagens com o TRU. E também ao técnico Agnelo Bastos, pela atenção dada na realização destes experimentos e demais atividades correlatas.

Aos Mestres Daniel Falconi, Daniel Ferreira, Geraldo Luppi Filho, Reginal Leopoldino e Yuri Olivato; ao mestrando Yvan Gutnik e ao aluno de Iniciação Científica Felipe Carvalho, membros do Grupo de Alta Tensão e Materiais, pelas incansáveis discussões e companheirismo na pesquisa.

Aos técnicos Rui Bertho e Odair, pelo atencioso trabalho de usinagem.

Ao Prof. Dr. Veronese, pelas soluções e projetos em eletrônica.

Ao Conselho de Aperfeiçoamento de Pessoal de Nível Superior (CAPES), pelo apoio financeiro e concessão da bolsa de mestrado.

À Escola de Engenharia de São Carlos (EESC-USP), pela oportunidade de realização do curso de mestrado, pelos seis meses de bolsa do Programa de Aperfeiçoamento de Ensino (PAE) e por todos os outros auxílios disponibilizados. 
Aos funcionários do Departamento de Engenharia Elétrica: administrativo e secretariado (Daniel Manjini, Jussara, Leonardo, Marcelo Xaraba, Marisa) e às funcionárias da limpeza, por manter o ambiente de trabalho organizado e agradável.

Aos membros da República Engenheiros da Cana em São Carlos, Alex (Thompson), Alexandre (Piriquito), Henrique (Goiás), Javier (Mexicano) e Remy (Pançudo), pela amizade, companheirismo e momentos de descontração.

Às verdadeiras amizades cultivadas em São Carlos, pelos momentos de lazer e apoio em momentos mais complicados.

Enfim, MUITO OBRIGADO a todas essas pessoas, de coração! 


\section{Resumo}

MEDEIROS, L. J. Hidrofone Ultrassônico com Piezoeletreto como Elemento Transdutor. 2014. Dissertação (Mestrado: Programa de Pós Graduação em Engenharia Elétrica) - Escola de Engenharia de São Carlos, Universidade de São Paulo, São Carlos, 2014.

Desde o ano 2000, o Grupo de Alta Tensão e Materiais (GATM) tem contribuído com suas pesquisas no desenvolvimento de processos para produção de novos transdutores piezoelétricos de materiais poliméricos, baseados na tecnologia dos piezoeletretos. Essa intensa investigação se justifica pelas excelentes propriedades piezoelétricas desses dispositivos, com atividade na ordem de centenas e até milhares de $\mathrm{pC} / \mathrm{N}$, ultrapassando o desempenho de algumas tradicionais cerâmicas. Destacam-se também nestes sensores, sua estrutura flexível e robusta, sua resposta na faixa de frequências ultrassônicas e seu baixo custo. Características estas que os tornam muito competitivos com os transdutores convencionais, cerâmicos e poliméricos, a exemplo do PZT e PVDF, respectivamente. Neste contexto, desenvolveu-se em 2009 no GATM um novo arranjo polimérico de múltiplos canais, em que filmes de teflon FEP foram termicamente moldados e depois expostos a um intenso campo elétrico (na ordem de $\mathrm{kV}$ ), criando sensores com elevado coeficiente piezoelétrico. Esse novo dispositivo, batizado de Piezoeletreto de Canais Tubulares (PCT) foi construído por meio de um processo de fabricação organizado e controlado, diferentemente dos piezoeletretos vistos até então. No presente trabalho construiu-se um protótipo de hidrofone com elemento ativo dado por um filme de PCT, para aplicações de até $100 \mathrm{kHz}$ e com uma eletrônica de pré-amplificação em $24 \mathrm{~dB}$. O primeiro teste com o protótipo restringiu-se à obtenção da sua sensibilidade. Realizaram-se ainda testes de caracterização quanto ao padrão de diretividade e a relação sinal-ruído. A calibração foi feita em três diferentes modalidades de geração do sinal: AM, CW e Burst, todas de maneira comparativa com o auxílio de um hidrofone comercial. A sensibilidade média encontrada nas medidas foi de $0,142 \mathrm{mV} / \mathrm{Pa}(-196,93 \mathrm{~dB}$ re $1 \mathrm{~V} / \mu \mathrm{Pa})$ e, na ressonância $(40 \mathrm{kHz}) \mathrm{de}$ $1,698 \mathrm{mV} / \mathrm{Pa}(-175,4 \mathrm{~dB}$ re $1 \mathrm{~V} / \mu \mathrm{Pa})$. A segunda fase de testes destinou-se a geração de imagens para diagnóstico clínico, baseada na técnica de Vibroacustografia (VA). Verificou-se a viabilidade do uso da VA com o mapeamento de dois objetos distintos, uma pequena esfera metálica de $1 \mathrm{~mm}$ de diâmetro e uma estrutura óssea. 
Palavras-chave: transdutor ultrassônico, hidrofone, piezoeletreto, vibroacustografia, polímeros piezoelétricos, ultrassom. 


\section{Abstract}

MEDEIROS, L. J. Ultrasonic Hydrophone with Piezoelectret as Transducer Element. 2014. Dissertation (Master's Degree: Program of Post-Graduation in Electrical Engineering) - Engineering School of Sao Carlos, University of Sao Paulo, Sao Carlos, 2014.

Since 2000, the High-Voltage and Materials Group (GATM) has focused its research on developing new processes for manufacture piezoelectric transducers, from polymeric materials based on the piezoelectret technology. This intense research is justified by the excellent electromechanical properties of these devices, with piezoelectric coefficient in the order of hundreds up to thousands of $\mathrm{pC} / \mathrm{N}$, exceeding the performance of the most traditional ceramics. Other highlights of these sensors are the flexible and robust structure, its wide range response in ultrasonic frequencies and low cost. These characteristics make them very competitive with those conventional ceramic and polymeric transducers, such as the PZT and PVDF, respectively. In this context, in 2009 a new polymeric multiple film arrangement was laminated to create an open channel structure that after been exposed to an intense electric field (on the order of $\mathrm{kV}$ ), produces a piezoelectric sensor with high piezoelectricity. This new device was built by an organized and controlled process, unlike the piezoelectrets seen so far. The main features inherent to tubular channels piezoelectret are the constructive uniformity, control of the resonance frequency and greater thermal stability, when compared to other piezoelectric polymers. Based on these tubular piezoelectrets, in the current study, a prototype of a $24 \mathrm{~dB}$ preamplifier ultrasonic hydrophone was built. The first test with the prototype restricted to obtaining its sensitivity. Further tests were performed to characterize the pattern of directivity and signal-to-noise ratio. The calibration tests were conducted on three different approaches to signal generation AM, CW and Burst; all in a comparative manner with the aid of a calibration standard hydrophone. The results showed a transducer with average sensitivity of $0.142 \mathrm{mV} / \mathrm{Pa}(-196.93 \mathrm{~dB}$ re $1 \mathrm{~V} / \mu \mathrm{Pa})$, and the resonance region at $40 \mathrm{kHz}$ with a sensitivity of $1,698 \mathrm{mV} / \mathrm{Pa}(-175.4 \mathrm{~dB}$ re $1 \mathrm{~V} / \mathrm{\mu Pa})$ and a unidirectional sensitive region. The feasibility of producing images by VA has been verified by mapping two distinct objects, a small metal sphere of $1 \mathrm{~mm}$ diameter and a bone structure. 
Keywords: ultrasonic transducer, hydrophone, piezoelectret, vibroacoustography, piezoelectric polymers, ultrasound. 


\section{Lista de Figuras}

Figura 2.1-(a) Sonar de Langevin (LANGEVIN, 1918) e (b) Sonar de Boyle (MANBACHI; COBBOLD, 2011).

Figura 2.2 - Diagrama esquemático da vibroacustografia. Adaptado de (KAMIMURA, 2011)..... 12 Figura 2.3 - Imagens microscópicas de filmes celulares: PP (lado esquerdo) e PETP (lado direito) (HILLENBRAND et al., 2003). 16

Figura 2.4 - Esquema ilustrativo das cargas elétricas aprisionadas nos polímeros celulares após carregamento elétrico e a deformação das cavidades pela aplicação de uma pressão externa na estrutura (GERHARD-MULTHAUPT, 2002). 17

Figura 2.5 - (a) Micrografia por escaneamento eletrônico da seção transversal de um filme EMFi de $70 \mu \mathrm{m}$ de espessura. (b) distribuição das cargas no interior do filme (SESSLER; HILLENBRAND, 1999). 18

Figura 2.6 - Amplitude do deslocamento versus frequência de um filme EMFi para diferentes tensões de excitação (RUPITSCH et al., 2011). 27

Figura 2.7 - Valores normalizados da $f_{R}$ no modo espessura e do coeficiente $d_{33}$, plotados em função da relação geométrica $\left(D_{g} / h_{g}\right)$ da cavidade lenticular (RUPITSCH et al., 2011). 27

Figura 2.8 - Camadas empilhadas de filmes de Teflon®-FEP e alumínio (ALTAFIM et al., 2003).

29

Figura 2.9 - Configuração do dispositivo utilizado para formação de amostra termo-formadas, com distribuição homogênea das bolhas de ar (ALTAFIM et al., 2006). 31

Figura 2.10 - Configuração do dispositivo utilizado para formação de amostra termo-formadas, com distribuição homogênea das bolhas de ar (ALTAFIM et al., 2006) 31

Figura 2.11 - Esquema do procedimento para moldar bolhas de ar de filmes empilhados em 3 camadas (lado esquerdo) e representação gráfica da seção transversal desses filmes (lado direito)(ZHANG; HILLENBRAND; SESSLER, 2006). 32

Figura 2.12 - Esquema do procedimento para moldar bolhas de ar de filmes empilhados em 5 camadas (lado esquerdo) e imagem da seção transversal desses filmes (lado direito) (ZHANG; HILLENBRAND; SESSLER, 2007). 33

Figura 2.13 - Esquema do procedimento de fabricação em laboratório de piezoeletretos com estruturas padronizadas em canaletas (acima) e micrografia ótica da seção transversal dessa estrutura (abaixo). (ALTAFIM et al., 2009). 
Figura 2.14 - Capacitância real (C') e imaginária (C') da amostra de ferroeletretos produzidos em

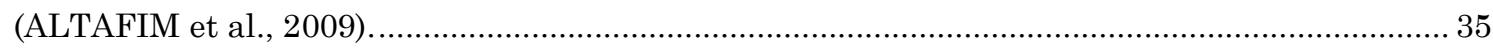

Figura 2.15 - Ilustração do procedimento para produção de domos em filmes FEP. (FALCONI et al., 2010) 36

Figura 2.16 - Esquema laminação de filmes FEP, previamente moldado em domos (esquerda) e amostra moldada e metalizada (direita). (FALCONI et al., 2010). 37

Figura 2.17 - Representação esquemática das camadas do piezoeletreto moldadas a frio (esquerda). À direita, imagens da template e da superfície da amostra. (FALCONI et al., 2011).. 38 Figura 3.1 - Transdutor confocal: a) disposição das cerâmica e b) esquema gráfico do feixe acústico. Adaptado de (BAGGIO, 2011). 41

Figura 3.2 - (a) Coordenadas de orientação da aplicação da tensão mecânica e polarização em um material piezoelétrico. (b) Modo espessura. 44

Figura 4.1 - Projeto do hidrofone proposto no trabalho. 50

Figura 4.2 - Primeiro protótipo do hidrofone e o compartimento de interface e baterias................ 51

Figura 4.3 - Amostra das medidas e flexibilidade do elemento sensor polimérico do hidrofone.... 52

Figura 4.4 - Material de retaguarda. Imagem de projeto (superior) e real com o circuito eletrônico

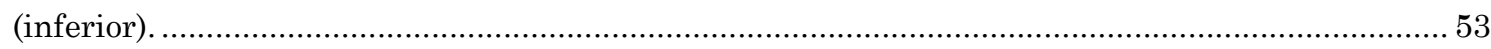

Figura 4.5 - Circuito eletrônico de pré-amplificação. ……………………………............................... 54

Figura 4.6 - Resposta em frequências do circuito de pré-amplificação do TRU-1. Teste em modo

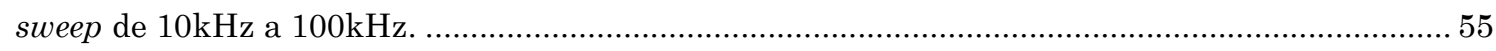

Figura 4.7 - Curvas típicas de hidrofones de membrana (COSTA-FÉLIX; MACHADO, 2007)..... 56

Figura 4.8 - Tanque de experimentos com sistemas de rastreio (FIGLABS PESQUISA E

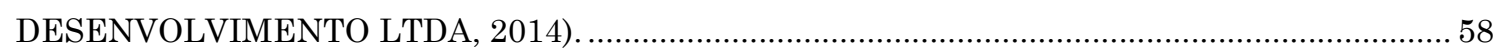

Figura 4.9 - Morfologia do Hidrofone ITC-6050C, utilizado no projeto como padrão de calibração (INTERNATIONAL TRANSDUCER CORPORATION, 2014). 59

Figura 4.10 - Curva de calibração do hidrofone comercial utilizado nos experimentos de caracterização do protótipo TRU-1 60

Figura 4.11 - Curva com a frequência de ressonância do transdutor PZT confocal........................ 61

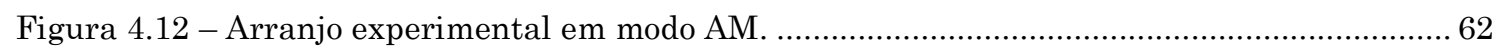

Figura 4.13 - Espumas acústicas atrás do alvo esférico e metálico. .................................................. 63

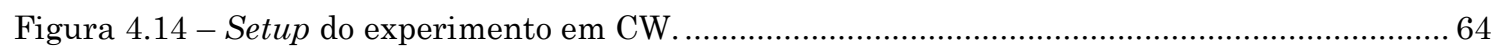


Figura 4.15 - Posicionamento do atuador e dos sensores, no mesmo eixo. O alvo fixado em outra base em frente aos transdutores. 65

Figura 4.16 - Configuração das formas de onda com sinais em modo burst. A frequência desejada é resultante do batimento entre as ondas 1 e 2. Os três "pacotes" apresentam as mesmas dimensões. 67

Figura 4.17 - Setup do experimento em burst. 69

Figura 4.18 - TRU-1 acoplado no eixo de rotação do goniômetro e instalado no arranjo experimental 70

Figura 4.19 - Arranjo do experimento em modo burst para obter o padrão de diretividade do TRU1 . 71

Figura 4.20 - Esfera com $1 \mathrm{~mm}$ de diâmetro, dada como objeto de imagem. 74

Figura 4.21 - Diagrama experimental do ensaio de vibroacustografia com o uso de um hidrofone comercial (ITC-6050C) e do hidrofone de piezoeletreto (TRU-1). 75

Figura 4.22 - Aquisição de imagem por VA de uma esfera com 1mm de diâmetro com o TRU-1, fixadada por fios de cabelo e centralizada em um aro de PVC. 76

Figura 4.23 - Vibroacustografia de uma estrutura óssea. Na fotografia é exibido o posicionamento da região sensível do ITC-6050C, frente ao objeto de imagem excitado pelo transdutor confocal. O mesmo rastreio foi realizado com o TRU-1, com a região sensível em igual posicionamento......... 78

Figura 5.1 - Gráficos da resposta elétrica dos hidrofones, nas aquisições em modo AM. 80

Figura 5.2 - Sensibilidade do TRU-1 em modo AM, em 40kHz e 50kHz.... 81

Figura 5.3 - Resposta em frequências do sinal elétrico gerado pelo TRU-1 (1) e, a sensibilidade do protótipo também em frequências (2). 82

Figura 5.4 - Gráficos comparativos entre o TRU-1 e o ITC-6050C no modo CW: (1) Valores normalizados da resposta elétrica (u.a.) e (2) sensibilidade em $\mathrm{mV} / \mathrm{Pa}$. 83

Figura 5.5 - Sinal Burst completo (1). Seleção da região de interesse para análise da sensibilidade (2). Exemplo correspondente à aquisição feita pelo ITC-6050C em $100 \mathrm{kHz}$. 85

Figura 5.6 - FFT da região de interesse, que apresenta frequência de batimento $(\Delta f)$. 86

Figura 5.7 - Resposta em frequências do TRU-1 no modo burst: sinal elétrico (1); sensibilidade (2). 86

Figura 5.8 - Gráficos comparativos entre o TRU-1 e o ITC-6050C no modo burst: (1) Valores normalizados da resposta elétrica (u.a.) e (2) sensibilidade em SPL (dB re $1 \mathrm{~V} / \mu \mathrm{Pa})$. 87

Figura 5.9 - Análises do transitório na excitação e desligamento do transdutor confocal de PZT, em $\Delta f=30 \mathrm{kHz}$, mapeados com o TRU-1 e o ITC-6050C. 88 
Figura 5.10 - Análises do transitório na excitação e desligamento do transdutor confocal de PZT, em $\Delta f=40 \mathrm{kHz}$, mapeados com o TRU-1 e o ITC-6050C.

Figura 5.11 - Análises do transitório na excitação e desligamento do transdutor confocal de PZT, em $\Delta f=60 \mathrm{kHz}$, mapeados com o TRU-1 e o ITC-6050C.

Figura 5.12 - Análises do transitório na excitação e desligamento do transdutor confocal de PZT, em $\Delta f=70 \mathrm{kHz}$, mapeados com o TRU-1 e o ITC-6050C.

Figura 5.13 - Medidas em burst evidenciando o momento do disparo do conjunto de senoides (dado pelo sinal de trigger) e momento em que o hidrofone começa a captar as primeiras ondas. Exemplo em $50 \mathrm{kHz}$. 92

Figura 5.14 - Curvas representativas do Padrão de Diretividade do TRU-1 em 40 kHz (1) e 50

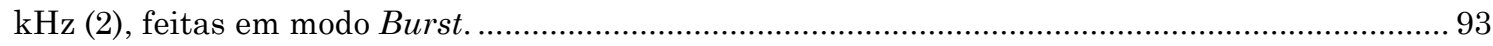

Figura 5.15 - Espectro de frequências do ruído percebido pelo TRU-1, sem fonte de US atuando e dentro de uma sala anecoica totalmente isolada de outras fontes de sinal. .95

Figura 5.16 - Curva da Relação Sinal-Ruído do TRU-1, dado em função das frequências no qual ele foi caracterizado anteriormente. 96

Figura 5.17 - Imagens por VA da esfera de $1 \mathrm{~mm}$ de diâmetro, colada em um filme de PVC. Imagem à esquerda do TRU-1 e à direita do ITC-6050C.................................................. 97

Figura 5.18 - Perfis na linha de centro das imagens adquiridas pelo TRU-1 e ITC-6050C. .........98

Figura 5.19 - Imagens adquiridas pelo TRU-1 e ITC-6050C, em escala de cinza para melhor

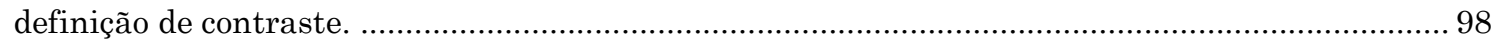

Figura 5.20 - Imagens por VA da esfera de $1 \mathrm{~mm}$ de diâmetro, colada em um filme de PVC. Imagem (1) TRU-1 e (2) ITC-6050C. .99

Figura 5.21 - Imagens por VA da estrutura óssea mapeada pelos hidrofones. Imagem (1) TRU-1 e (2) ITC-6050C. 100 


\section{Lista de Tabelas}

Tabela 2.1 - Principais propriedades de três tipos de materiais transdutores piezoelétricos. Propriedades medidas em discos com $20 \mathrm{~mm}$ de diâmetro e $1 \mathrm{~mm}$ de espessura (QUANLU et al., 2005) 20

Tabela 2.2 - Propriedades do PZT e Single Crystals (RHIM; JUNG, 2007). 21

Tabela 2.3 - Propriedade dos polímeros piezoelétricos de interesse para o projeto de transdutores ultrassônicos de alta frequência. 24

Tabela 2.4 - Frequência de ressonância $\left(f_{R}\right)$ versus a temperatura ambiente $(T a)$, para um material EMFi

Tabela 3.1 - Resumo dos principais parâmetros dielétricos e eletromecânicos envolvidos no estudo e desenvolvimento de transdutores piezoelétricos (BASSI, 2012; SHERMAN; BUTLER, 2007; ZHANG; YU, 2011). 45

Tabela 5.1 - Parâmetros do estudo em modo burst na resposta em frequências de 30 a $100 \mathrm{kHz} .84$ Tabela 5.2 - Parâmetros do modo burst no estudo do Padrão de Diretividade nas frequências de 40 e $50 \mathrm{kHz}$. 93 


\section{Lista de Abreviaturas e Siglas}

$\begin{array}{ll}\text { AM } & \text { Amplitude Modulation } \\ \text { CC } & \text { Corrente Contínua } \\ \text { CW } & \text { Continuous Wave } \\ \text { EESC } & \text { Escola de Engenharia de São Carlos } \\ \text { EMFi } & \text { ElectroMechanical Film } \\ \text { END } & \text { Ensaio Não Destrutivo } \\ \text { FEP } & \text { Etileno Propileno Fluorado } \\ \text { FFT } & \text { Fast Fourier Transform } \\ \text { FFCLRP } & \text { Faculdade de Física Ciências e Letras de Ribeirão Preto } \\ \text { GATM } & \text { Grupo de Alta Tensão e Materiais } \\ \text { GIIMUS } & \text { Grupo de Inovação em Instrumentação Médica e Ultrassom } \\ \text { PCT } & \text { Piezoeletreto de Canais Tubulares } \\ \text { PETP } & \text { Pound Pransdutor ultrassônico } \\ \text { PF } & \text { Politereftalato de Etilenglicol } \\ \text { PP } & \text { Ponto de Fusão } \\ \text { PVDF } & \text { Polipropileno } \\ \text { PVDF-TrFE } & \text { Poluoreto de Vinilideno de Vinilideno Tri-Fluoreto de Etileno } \\ \text { SONAR } & \text { Poure }\end{array}$


Universidade de São Paulo

VA

Vibroacustografia 


\section{Lista de Símbolos}

A

C

D

$d B$

$d_{i j}$

E

$f$

F

$g_{i j}$

$k_{i j}$

$K_{T}$

M

$p$

$P$

$Q$

$Q_{m}$

$s^{E}$

$T$

$T_{c}$

$t_{b}$

$\tan \delta$

$u$
Área

Capacitância

Vetor Deslocamento elétrico

Decibel

Coeficiente de carga piezoelé- Coulomb por Newton $(\mathrm{C} / \mathrm{N})$ trico

Vetor campo elétrico

Frequência

Força

Coeficiente de tensão piezoelé-

trico

Acoplamento eletromecânico

Permissividade relativa

Sensibilidade

Pressão acústica

Vetor polarização elétrica

Densidade de carga elétrica

Fator de qualidade mecânica

Constante elástica

Temperatura

Temperatura de Curie

Período do burst

Tangente de perdas dielétricas

Velocidade de uma partícula
Graus Celsius $\left({ }^{\circ} \mathrm{C}\right)$

Metros quadrados $\left(\mathrm{m}^{2}\right)$

Farad (F)

Coulomb por metro ${ }^{2}\left(\mathrm{C} / \mathrm{m}^{2}\right)$

Volt por metro (V/m)

Hertz (Hz)

Newton $(\mathrm{N})$

Volt vezes metro por Newton

(V.m/N)

Volt por Pascal (V/Pa)

Pascal (Pa)

Coulomb vezes metro (C.m)

Coulomb (C)

Graus Celsius $\left({ }^{\circ} \mathrm{C}\right)$

Segundos (s)

Metros por segundo $(\mathrm{m} / \mathrm{s})$ 
$v$

V

$x$

X

Z

$Z_{a}$

$\varepsilon_{i j}$

$\rho$

$\lambda$

$\Lambda_{b}$
Velocidade

Tensão elétrica

Deformação estrutural

Tensão mecânica

Impedância elétrica

Impedância Acústica

Permissividade elétrica

Densidade

Comprimento de onda

Comprimento de onda do burst
Metros por segundo (m/s)

Volt (V)

Milímetro por metro $(\mathrm{mm} / \mathrm{m})$

Newton por metro ${ }^{2}\left(\mathrm{~N} / \mathrm{m}^{2)}\right.$

$\operatorname{Ohm}(\Omega)$

MRayl

Farad por metro $(\mathrm{F} / \mathrm{m})$

Quilograma por metro cúbico

$\left(\mathrm{kg} / \mathrm{m}^{3}\right)$

$\operatorname{Metro}(\mathrm{m})$

Metro (m) 


\section{Sumário}

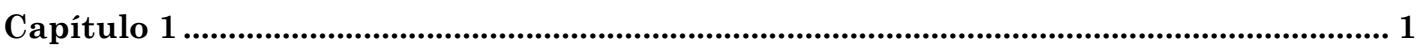

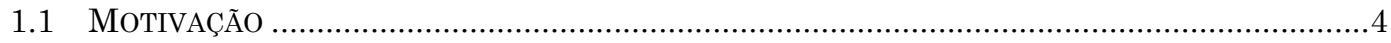

1.2 OBJETIVOS

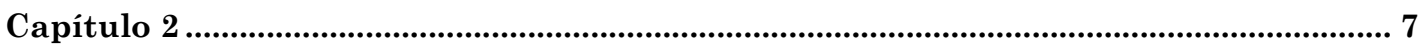

2.1 CONTEXTUALIZAÇÃO HISTÓRICA DO ULTRASSOM..............................................................

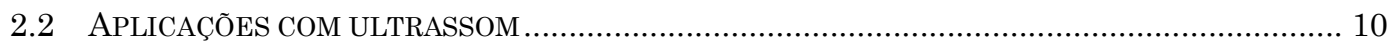

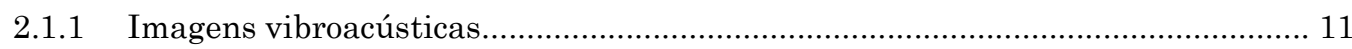

2.1.2 Aspectos gerais da Vibroacustografia ................................................................... 13

2.1.3 A evolução de materiais piezoelétricos .................................................................... 14

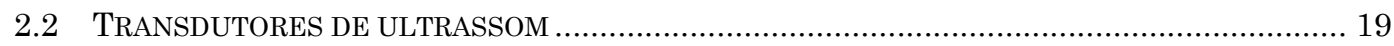

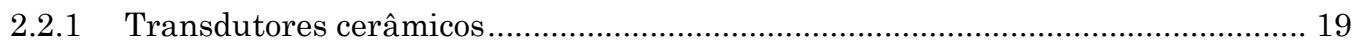

2.2.2 Transdutores de PVDF e seus copolímeros ......................................................... 22

2.2.3 Transdutores a base de piezoeletretos ................................................................ 26

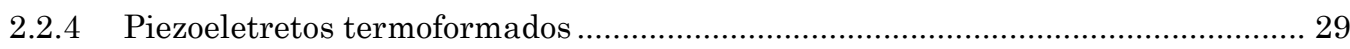

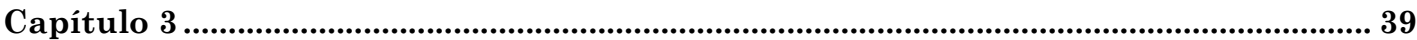

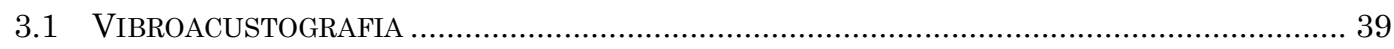

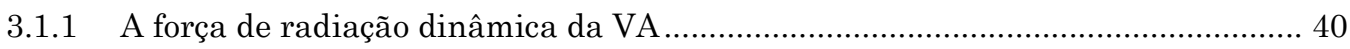

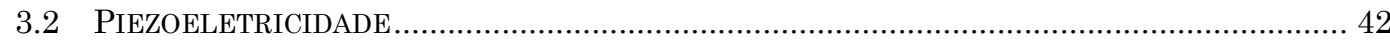

3.2.1 Parâmetros dielétricos e eletromecânicos ................................................................... 44

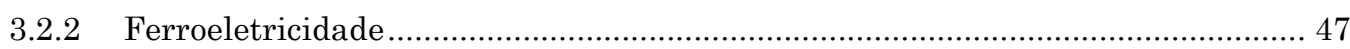

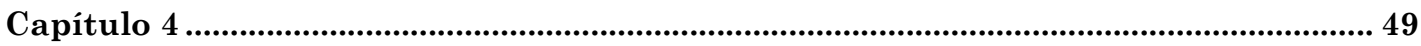

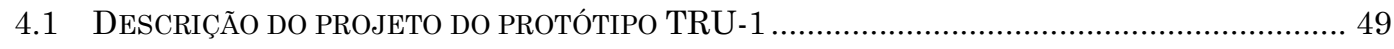

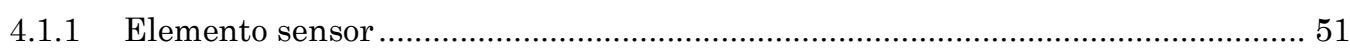

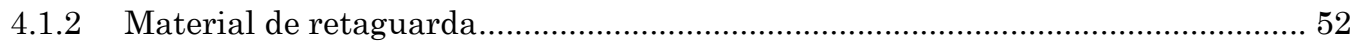

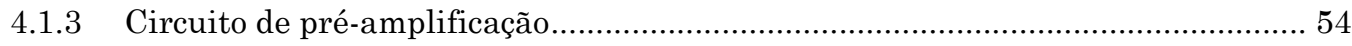

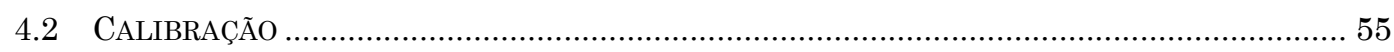

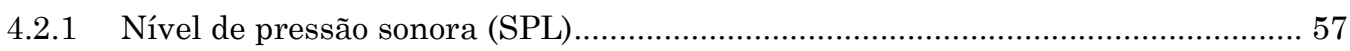

4.3 METOdoloGia dos EXPERIMENTOS DE CALIBRAÇÃO........................................................ 57

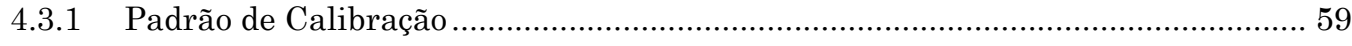

4.3.2 Fonte de Geração das ondas de US ........................................................................ 60

4.3.3 Teste comparativo 1: Modulação em Amplitude (AM) ........................................... 61

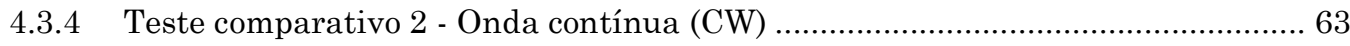




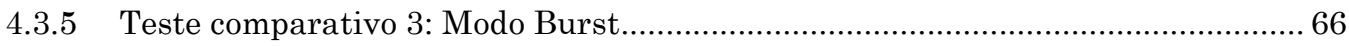

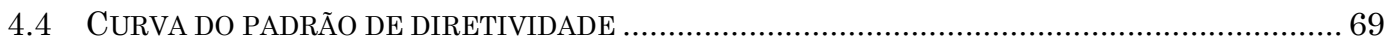

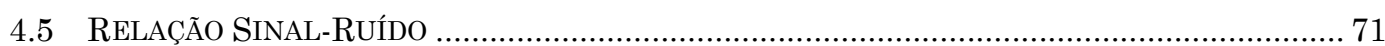

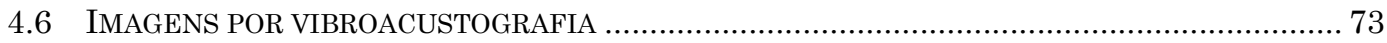

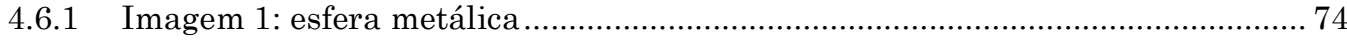

4.6.2 Imagem 2: pequena esfera presa em fios de cabelo............................................ 76

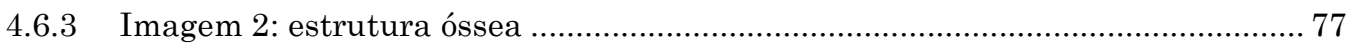

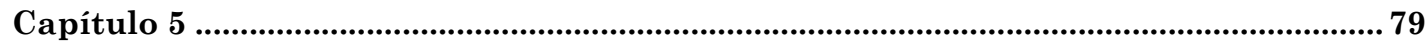

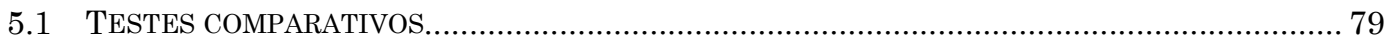

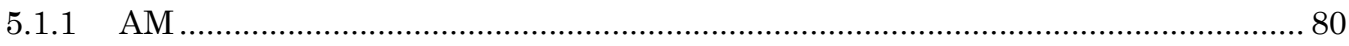

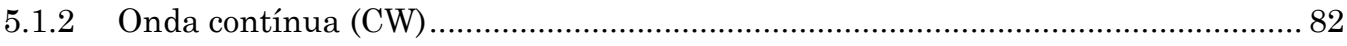

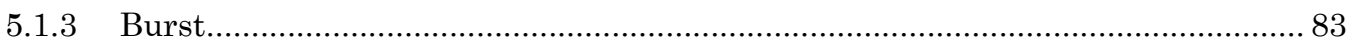

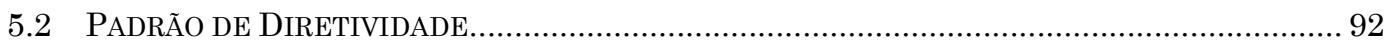

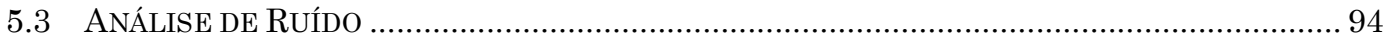

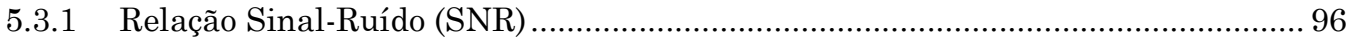

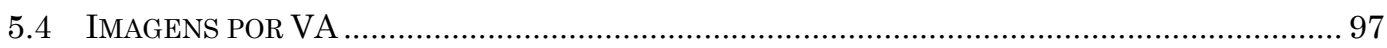

5.4.1 Esfera metálica colada em película ........................................................................ 97

5.4.2 Esfera metálica fixada por fios de cabelo.................................................................. 99

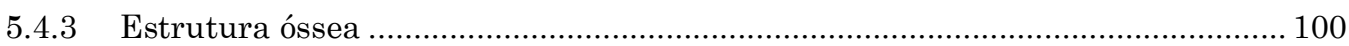

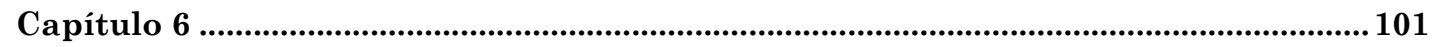

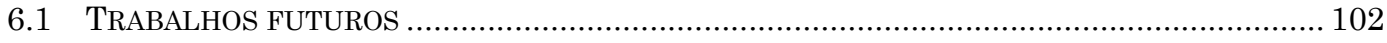

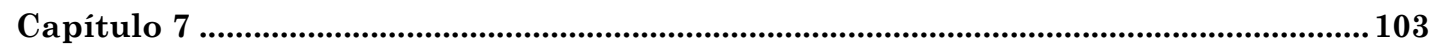

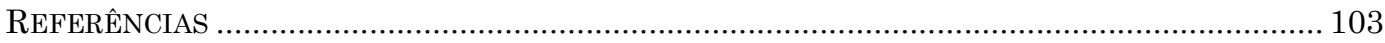




\section{Capítulo 1}

\section{Introdução}

O campo sonoro compreende uma interação de ondas mecânicas viajantes em meio material cujas frequências das oscilações encontram-se tipicamente na ordem de $20 \mathrm{~Hz}$ a $20 \mathrm{kHz}$ (limiares da audição humana). A incidência destas ondas provocam deslocamentos das partículas formadoras do meio desencadeado e, consequentemente uma alteração da densidade de energia do local irradiado. Assim, um campo acústico pode ser perfeitamente caracterizado através de medidas da pressão mecânica gerada, bem como pelas características (velocidade, distância, aceleração) do movimento destas partículas, na região de interação do feixe.

Seguindo os mesmos princípios de propagação das ondas mecânicas e fenômenos físicos do som audível, o ultrassom (US) caracteriza-se por apresentar frequência das oscilações superior ao limiar da audição humana. A energia proveniente de ondas ultrassônicas foi inicialmente verificada em seres vivos dotados de um tipo de sonar biológico para detectar presas e obstáculos. Esse recurso recebeu o nome de eco-localização, e baseia-se na fisiologia desses seres, que os permite emitirem sinais acústicos de alta frequência e os receber de volta na forma de eco.

Essa espécie de biossonar foi sem dúvida uma descoberta norteadora para inúmeras pesquisas e aplicações com ultrassom, tais como sonares marítimos, equipamentos médicos de diagnóstico e terapia e, avaliação de materiais em Ensaios Não Destrutivos (END) (do inglês, Nondestructive Testing).

Uma das principais vantagens do US remete-se às dimensões reduzidas do comprimento de onda $(\lambda)$ do sinal de interesse, que varia inversamente com o aumento da frequência do campo acústico em propagação. Nas aplicações de END e de ecossondagem, por exemplo, o reduzido $\lambda$ possibilita o mapeamento acústico em superfícies muito pequenas. Já no campo de diagnóstico clínico, a importância do comprimento de onda relaciona-se intimamente com a resolução espacial da imagem. 
Equipamentos dotados de sistemas eco-localizadores empregam para essa função uma sonda, que faz o papel de transdutor ${ }^{1}$. Esse dispositivo é responsável por produzir e/ou captar os sinais eletroacústicos. O transdutor pode ser configurado tanto como um sensor acústico, que faz a conversão da energia mecânica (percepção do som) em energia elétrica (sinal a ser interpretado), ou ainda, como um atuador acústico, onde de maneira recíproca, converte energia elétrica (sinal excitador) em energia mecânica.

Geralmente, o elemento ativo incumbido de realizar a conversão eletroacústica funciona com base na atividade piezoelétricas de certos materiais, cujos parâmetros dielétricos e eletromecânicos afetam diretamente nas aplicações com US.

As características piezoelétricas em um transdutor estão diretamente relacionadas com a estabilidade do material nos quesitos vida útil, temperatura, exposição a tensões mecânicas e ao campo elétrico. Além disso, alguns pontos críticos do material (saturação por esforço ou campo elétrico aplicado, fadiga, limites térmicos, etc.) podem servir para estimar o potencial do dispositivo na conversão energética em questão.

Os materiais piezoelétricos atualmente empregados em transdutores ultrassônicos podem ser classificados em cinco principais grupos: cristais de quartzo, monocristais, cerâmicas, polímeros e uma combinação dos últimos dois que formam os compósitos. As piezocerâmicas na composição de Titanato Zirconato de Chumbo (PZT), por sua vez, têmse mostrado um padrão de referência de transdutores por suas fortes propriedades piezoelétricas.

A busca por materiais piezoelétricos complementares aos atributos das piezocerâmicas, essencialmente com relação às características de flexibilidade e impedância acústica, tem ganhado espaço nas investigações em transdutores de US. Esses estudos impulsionaram-se com a descoberta do efeito piezoelétrico em filmes poliméricos, tais como o Poli(Fluoreto de Vinilideno) PVDF e, principalmente, os polímeros não-polares, com polarização remanescente (proveniente da exposição do dielétrico a um intenso campo elétrico). No Capítulo 2 serão descritos alguns piezos materiais, a título de revisão bibliográfica.

Nos transdutores eletroacústicos, a escolha do adequado elemento transdutor deve primeiramente considerar as exigências da aplicação; o meio de sensoriamento (por ex.ar ou água), a influência de interferência eletromagnética, nível de ruído ambiental, intensidade do campo sonoro detectado ou gerador, etc. Esses fatores, por sua vez, determinarão principalmente o método de acomodação do elemento, a necessidade de camadas adi-

\footnotetext{
${ }^{1}$ Qualquer dispositivo que converta uma forma de energia em outra.
} 
cionais de casamento de impedância acústica ao sensor, frequência de operação e o uso circuitos de pré-amplificação.

Definida a morfologia e construção do transdutor, os testes seguintes consistem em obter a sua sensibilidade. Nessa etapa é onde se define o fator de conversão energética do equipamento, ou seja, qual o nível do sinal elétrico gerado, mediante a tensão mecânica incidente, pelo campo acústico, no elemento ativo. Este procedimento é conhecido por calibração ${ }^{2}$ e visa deixar acessível ao usuário, qual a proporção da excitação acústica, de acordo com a leitura por sinais elétricos.

Portanto, a grande importância do emprego de um instrumento calibrado, está em permitir que dados suficientemente coerentes sejam coletados e caracterizem com segurança um campo acústico em determinado estudo.

Os transdutores eletroacústicos ora descritos podem ser construídos para assumir funções independentes de atuador ou de sensor, dependendo da necessidade operacional. Nessa abordagem, contextualiza-se o hidrofone foco de pesquisa deste trabalho.

O hidrofone compreende um transdutor eletromecânico de percepção de som (sensor), para aplicações subaquáticas (como a própria nomenclatura sugere), cujo o nicho principal de aplicações envolve o mapeamento de campo ultrassônico. A sua nomenclatura faz analogia ao microfone (sensor de voz), devido às semelhantes características de funcionamento.

No decorrer dessa pesquisa, posterior às atividades de montagem, calibração e caracterização de um protótipo de hidrofone, os resultados foram avaliados a fim de verificar o potencial do dispositivo como um todo. Esse estudo permitiu julgar as aplicabilidades nas quais esse sensor teria condições significativas de atuar.

Neste contexto, este trabalho de mestrado descreve o desenvolvimento e caracterização de um hidrofone ultrassônico, aqui denominado de TRU-1 (Transdutor Ultrassônico, protótipo 1). O elemento sensor do TRU-1 foi construído com base na tecnologia dos piezoeletretos termo-formados, produzidos pelo Grupo de Alta Tensão e Materiais (GATM), da EESC, USP.

Esse equipamento almejou sua aplicabilidade no campo de diagnósticos médicos, utilizando para tanto uma técnica de sensoriamento acústico, denominada de vibroacustografia (VA). A VA é uma modalidade de imagem elastográfica, ou seja, firmada nas ca-

${ }^{2}$ Calibração é um "conjunto de operações que estabelece em condições especificadas, a relação entre os valores indicados por um instrumento de medição (...) e os valores correspondentes das grandezas estabelecidas por padrões" (Vocabulário, Inmetro). 
racterísticas viscoelásticas de certos materiais, que quando excitados por um feixe acústico direcionado e localizado, emitem vibrações particulares à região irradiada.

Essa técnica de imagem apresenta alta resolução lateral, é não invasiva, apresenta radiação não-ionizante e se fundamenta em uma combinação não-linear de ondas acústica em $\mathrm{MHz}$, gerando uma região focal estreita de baixa frequência $(\mathrm{kHz})$. Detalhes do funcionamento do método são dados no Capítulo 2.

\subsection{Motivação}

As cerâmicas piezoelétricas nos transdutores têm se mostrado muito vantajosas com relação à alta eficiência na conversão eletroacústica e baixas perdas dielétricas, na orientação dos domínios ferroelétricos. No entanto, fatores construtivos e características físicas, tais como serem quebradiças, apresentarem complexo processo de fabricação e elevada impedância acústica, têm motivado a busca por materiais que supram esses inconvenientes.

As constantes investigações sobre atividade eletromecânica em estruturas poliméricas têm colocado esses materiais na condição de serem complementares às cerâmicas piezoelétricas.

Os filmes poliméricos polarizados têm apresentado propriedades com desempenho compatível às cerâmicas de PZT, além das características estruturais exclusivas dos polímeros, tais como baixa impedância acústica, alta flexibilidade, baixa densidade e processos fabris menos complexos e mais ágeis.

As vantagens aliadas a essas propriedades incluem a fabricação de transdutores, cujos elementos sensores podem ser assumir diferentes morfologias, que adequam-se a distintas aplicações e, a possibilidade de empilhamento de filmes ativos, a fim de otimizar o efeito de polarização. A reduzida impedância acústica dos piezo-polímeros, permite ainda, emprego no ar ou água, com menores perdas na troca de energia com o meio, devido a um melhor casamento de impedância.

Neste contexto, tem-se observado comercialmente que, inúmeros dispositivos ultrassônicos já estão sendo fabricados a partir de elementos piezo-poliméricos, com destaque ao PVDF e seus copolímeros. No âmbito nacional, o que se observa é a predominância de equipamentos com tecnologias internacionais, que, além de possuírem custos proibitivos 
para uso em larga escala, são muitas vezes regidos por contratos de uso exclusivo e controlados.

Visando essa linha de pesquisa de transdutores, na última década, o GATM tem focado suas investigações, na implementação de processos para produção de novos transdutores piezoelétricos de materiais poliméricos, baseados na tecnologia dos piezoeletretos (ALTAFIM et al., 2003, 2005, 2006, 2009; FALCONI et al., 2010). O domínio na produção desses piezoeletretos impulsionou recentemente no GATM uma nova fase em suas pesquisas, o desenvolvimento de aplicações tecnológicas para esses sensores.

\subsection{Objetivos}

Os objetivos dessa dissertação abrangem o desenvolvimento, calibração e caracterizações de um dispositivo do tipo hidrofone. Esse protótipo emprega como elemento eletroacústico, os piezoeletretos desenvolvidos pelo GATM. As etapas experimentais posteriores a construção e, aferição do hidrofone TRU-1 devem compreender os tópicos listados abaixo (COSTA-FÉLIX; MACHADO, 2007):

a) Determinar a resposta em frequências do transdutor, verificando como sua sensibilidade varia em função da frequência;

b) Obter a banda de frequência útil na operação do dispositivo, levando em consideração uma faixa de sinal/ruído mínima;

c) Determinar a relação sinal-ruído do equipamento, em função das mesmas frequências do teste de sensibilidade;

d) Verificar a linearidade e faixas de ressonância do elemento ativo ou eletroacústico.

e) Traçar a curva do Padrão de Diretividade desse protótipo

A avaliação de desempenho do TRU-1, nas atividades acima, permitiu orientar suas aplicações ao imageamento clínico, reportado pela técnica vibroacústica. 


\section{Capítulo 2}

\section{Revisão Bibliográfica}

Esta revisão procura apresentar uma visão geral sobre ultrassom, os principais transdutores ultrassônicos existentes e do uso da ultrassonografia na área médica, principal foco de estudo desse trabalho.

\subsection{Contextualização histórica do ultrassom}

$\mathrm{O}$ ultrassom visto como uma modalidade de energia naturalmente gerada por sistemas biológicos complexos mostra-se vital para a sobrevivência de animais, como golfinhos, morcegos, entre outros. Estes seres vivos são dotados de um sistema de ecolocalização que emprega ondas acústicas na deteç̧ão de presas, obstáculos, etc.

Os primeiros estudos de técnicas ultrassônicas datam de 1794 e são creditados ao biólogo italiano Lazzaro Spallanzani, ao demonstrar que a precisa orientação dos morcegos no escuro, quando em voo, deve-se principalmente à sua capacidade de emissão e de recepção de sons em altas frequências, fenômeno este conhecido em acústica por ecoreflexão (WOO, 2002).

Em 1876, com a invenção do cientista inglês Francis Galton, chamada de "Apito de Galton" ou "Apito silencioso" (do inglês, Galton whistle), foi possível emitir ondas sonoras acima do limiar da audição humana. O dispositivo de Galton foi mencionado em 1883 na discussão de seus experimentos para testar a faixa de frequências que poderiam ser sensíveis à audição de alguns animais (GALTON, 1883).

Os irmãos Curie (CURIE; CURIE, 1880) ao demonstrarem os primeiros trabalhos conclusivos sobre a atividade piezoelétrica em alguns cristais, propiciaram um verdadeiro avanço na evolução das técnicas de ecossondagem ou batimetria (do inglês, echosounding $)^{3}$ em alta frequência. Através dos resultados experimentais, eles observaram

\footnotetext{
${ }^{3}$ Determinação de profundidades marítimas.
} 
que um potencial elétrico seria produzido quando uma pressão mecânica fosse exercida, principalmente no quartzo e no Sal de Rochelle (tartarato de sódio e potássio tetrahidratado). (LIPPMAN, 1881) No ano seguinte, propôs que o comportamento inverso, ou seja, a existência de uma deformação mecânica em resposta à uma diferença de potencial, deveria ocorrer nesses materiais, provando matematicamente tal efeito a partir de fundamentos termodinâmicos. No ano seguinte, baseados em observações experimentais, os irmãos Curie comprovaram o efeito piezoelétrico inverso. Pouco tempo depois, Pierre e seu irmão mais velho Jacques colocaram em prática sua descoberta e inventaram o piezoeletrômetro de quartzo. Este dispositivo fora mais tarde utilizado pela esposa de Pierre em seus estudos para medir cargas elétricas emitidas por sais de rádio (MANBACHI; COBBOLD, 2011).

Posteriormente, no início do século XX, Voight (VOIGT, 1910) escreveu a primeira monografia sobre piezoeletricidade e aplicações de cristais, abordando principalmente experimentos laboratoriais e deduções matemáticas que descrevem o fenômeno da piezoeletricidade.

O fato, porém que relaciona a descoberta da piezoeletricidade com a ultrassonografia é que com essa descoberta passou a ser possível emitir sinais acústicos em altas frequências por meio da simples excitação do material piezoelétrico com um sinal elétrico variável.

O naufrágio do transatlântico RMS Titanic, em 1912, motivou o desenvolvimento de um dispositivo cuja operação fosse semelhante ao sistema de ecolocalização biológica de alguns animais, orientando os navegadores sobre a existência de obstáculos no trajeto. Surge com isso, a primeira patente para um SONAR (do inglês, Sound Navigation and Raging) de eco-mapeamento embaixo d'água, protocolada no escritório de patentes britânico pelo meteorologista Inglês, Lewis Richardson. As pesquisas progridem rápido e um mês após o naufrágio do Titanic, no ano de 1913 em Viena, Áustria, o físico e pesquisador alemão Alexander Behm obteve a primeira patente para um dispositivo de ecossondagem subaquática (HILL; ROBINSON, 1962).

No ano seguinte, o primeiro equipamento sonar foi projetado e construído nos Estados Unidos pelo engenheiro canadense Reginald Fessenden. O sonar de Fessenden, como era conhecido, tratava-se de um oscilador eletromagnético com bobina móvel, similar aos alto-falantes atuais, que emitia um ruído de baixa frequência e, este sinal era então enviado a um receptor para ouvir os ecos emitidos. Este equipamento, embora não relacionado com a piezoeletricidade, tinha uma sensibilidade capaz de detectar um iceberg a 
aproximadamente $3 \mathrm{~km}$ de distância, mas não permitia determinar precisamente sua direção, devido à baixa frequência do sinal (aproximadamente $500 \mathrm{~Hz}$ ) e a pequena dimensão da face irradiação do transdutor (menos de 1 metro de diâmetro) (SEITZ, 1999).

Durante a Primeira Guerra Mundial (1914-1918) a necessidade de detecção submarina foi mais acurada, impulsionou as pesquisas em acústica para sistemas de localização. Com esse foco, físico francês Paul Langévin e o cientista russo Constantin Chilowsky, que então residia na França, iniciaram estudos na criação de dispositivos ultrassônicos baseados nas propriedades piezoelétricas do quartzo. Nos primeiros testes eles conseguiram gerar pulsos e receber seus ecos a partir de alvos em curta distancia. Patentes com este dispositivo foram depositadas na França e no EUA (CHILOWSKY; LANGEVIN, 1916, 1917).

Quando os resultados franceses foram comunicados para os britânicos, um grupo sob o comando de Robert William Boyle (Comitê de Investigação de Deteç̧ão submarina) iniciou experimentos semelhantes em 1916. Embora Boyle também tenha evidenciado que o efeito piezoeléctrico em cristais de quartzo tinha o potencial para transdutores melhorados foi Langevin que demonstrou o valor de piezeletricidade, logo que encontrou amostras adequadas de quartzo. Com isso, já em 1917 transdutores com maior alcance foram obtidos (LANGEVIN, 1918). A grande melhoria no projeto consistiu em fazer um ressonador com cristais de quartzo empilhado e entrepostos por placas de aço (Figura 2.1a), uma abordagem ainda utilizada em transdutores modernos. Posteriormente o grupo de Boyle desenvolveu um dispositivo semelhante (Figura 2.1 b).
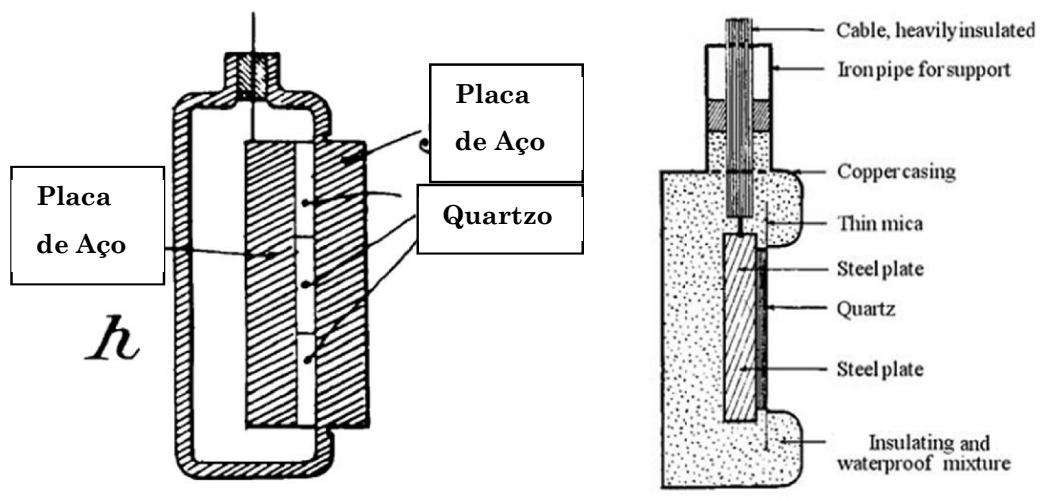

Figura 2.1-(a) Sonar de Langevin (LANGEVIN, 1918) e (b) Sonar de Boyle (MANBACHI; COBBOLD, 2011).

O equipamento de Langevin foi denominado hidrofone e operava com uma frequência de ressonância de $150 \mathrm{kHz}$. Entre os anos de 1915 e 1918, o hidrofone foi aperfeiçoado para uso em atividades de pesquisa (LANGEVIN, 1918) e, foi extensivamente empregado 
em sistemas de localização de alguns submarinos entre eles o da marinha alemã (U-boat) (WOO, 2002).

O primeiro relato de naufrágio, detectado por um hidrofone, ocorreu no Atlântico durante a Primeira Guerra Mundial, em abril de 1916. Os hidrofones de Langevin propiciaram, nos anos seguintes, uma base teórica fundamental aos projetos dos sonares navais de pulso-eco ${ }^{4}$. Em meados de 1930, muitos transatlânticos já estavam equipados com alguma forma de sistema subaquático de monitoramento de alcance por ecossondagem (WOO, 2002).

Acredita-se que estes dispositivos da área naval foram cruciais para a disseminação do US em outras áreas. Hoje, podem-se observar inúmeras aplicações que vão desde ensaios de avaliação não destrutiva à área médica. Nesta última, os equipamentos de ultrassons destinam-se tanto a terapias quanto aos diagnósticos por imagens, em especial à técnica de vibroacústica para geração de imagens médicas, mais bem descritas nos itens subsequentes e um dos principais focos de aplicação desse trabalho.

\subsection{Aplicações com ultrassom}

Em um período próximo ao fim da Primeira Guerra Mundial, Paul Langevin durante o desenvolvimento de seu transdutor de quartzo, notou que, no mar, cardumes mortos em decorrência da exposição dos peixes às ondas ultrassônicas de elevada intensidade geradas por seu dispositivo. Também relatou que quando a mão era colocada diante do feixe acústico do transdutor no interior de um tanque fortes dores eram sentidas (MANBACHI; COBBOLD, 2011).

As análises de Langevin foram princípios norteadores para o desenvolvimento da primeira aplicação do ultrassom na área médica, utilizado com fins terapêuticos, na década de 1930 em Berlin. O equipamento exercia movimentos sobre o tecido humano com o propósito de melhorar o fluxo sanguíneo e a velocidade do metabolismo, bem como reduzir inflamações e aliviar espasmos musculares. $\mathrm{O}$ dispositivo gerava ondas mecânicas com intensidade limitada a 5 W.cm ${ }^{-2}$ e oscilava numa frequência de 1 a $3 \mathrm{MHz}$ (BIERMAN, 1954).

\footnotetext{
${ }_{4}^{4}$ Teste acústico não destrutivo em que pulsos de energia de um campo sonoro são dirigidos para um corpo, e o tempo para o eco retornar, a partir de uma ou mais superfícies, é calculo ou medido.
} 
No ano de 1942, o psiquiatra austríaco Karl Dussik publicou estudos iniciais sobre a ultrassonografia, fruto de um trabalho que iniciou em 1937. Anos depois, em 1948, o mesmo autor apresentou um trabalho intitulado de Hyperphonography of the Brain, tratando-o como o primeiro método de diagnóstico clínico por meio de ultrassom, o qual pretendia localizar tumores cerebrais (DUSSIK, 1948). O artigo, embora muito contestado na época, promoveu as pesquisas com o uso da técnica em diagnósticos por imagem (MANBACHI; COBBOLD, 2011).

Mais tarde 1949, o ultrassom foi utilizado para detectar a presença e a posição de corpos estranhos em tecidos animais, o método de pulso-eco em Modo-A ${ }^{5}$. Depois, em 1952, Wild e Reid (WILD; REID, 1952) descreveram o desenvolvimento e o uso de um transdutor de alta frequência em combinação com um sistema de mapeamento, para criar imagens bidimensionais (2D) por ecografia, atualmente conhecido como imageamento em Modo-B . $^{6}$

Apresentando um sistema de operabilidade diferente das técnicas tradicionais de ecografia descritas anteriormente, surge no final da década de 90 um método promissor de imagens por US que utiliza sinais provenientes da aquisição da resposta mecânica de corpos vibrantes. Entre suas principais características destaca-se: alta resolução lateral, não invasiva, apresenta radiação não-ionizante e se fundamenta em uma combinação não-linear de ondas acústica em $\mathrm{MHz}$, modulada em $\mathrm{kHz}$. Essa técnica é descrita a seguir.

\subsubsection{Imagens vibroacústicas}

Nos trabalhos publicados no final dos anos 90 pelos pesquisadores (FATEMI; GREENLEAF, 1998) e (FATEMI; GREENLEAF, 1999) foi apresentada uma modalidade de imageamento ultrassônico, teoricamente sustentada na elastografia ${ }^{7}$. A técnica ficou conhecida como vibroacustografia (VA) por mapear as características vibracionais de uma amostra, quando esta fosse estimulada por um feixe acústico de alta frequência (na ordem de kHz). O feixe é oriundo de uma soma de interações não lineares entre sinais

${ }^{5}$ Modo mais simples de ecografia que analisa um feixe ultrassônico unidimensional. A imagem consta de uma série de picos que indicam a distância, em função do tempo, de um alvo irradiado pelo pulso do transdutor.

${ }^{6}$ Consta de um conjunto de sinais em Modo-A, formando uma imagem bidimensional, por meio da conversão dos picos em pontos (pixels) cujo brilho varia com a intensidade do sinal.

${ }^{7}$ Qualquer medida ou técnica de imagem que extraia informações, qualitativas e quantitativas, diretamente relacionadas às propriedades mecânicas de uma matéria (OLIPHANT; EHMAN; GREENLEAF, 2002). 
acústicos na ordem de $\mathrm{MHz}$, gerados em frequências ligeiramente diferentes, de modo a permitir uma modulação em kHz, pelo fenômeno de batimento ${ }^{8}$.

Os dois sinais são configurados em sua fonte de modo a apresentarem focos equidistantes, para potencializar o feixe resultante do batimento, que irá exercer remotamente um campo de tensões mecânicas, altamente localizadas sobre pequenas porções do objeto alvo. Em resposta a esta interação entre os feixes, a pequena região do objeto vibra na frequência de modulação previamente configurada. A intensidade dessa oscilação e o padrão de vibração dependem predominantemente das características viscoelásticas da amostra que se deseja mapear. O campo acústico resultante da vibração do objeto foi tratado nos estudos de Fatemi e Greenleaf, como "emissões acústicas" que ao serem detectadas por um hidrofone sensível fornecem dados para que seja formada uma imagem do objeto. O esquema da Figura 2.2 ilustra basicamente o funcionamento VA.

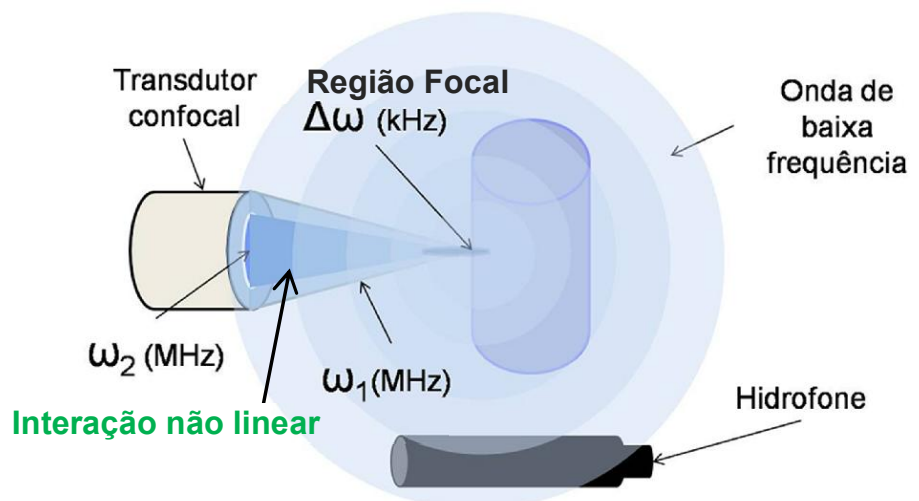

Figura 2.2 - Diagrama esquemático da vibroacustografia. Adaptado de (KAMIMURA, 2011).

A emissão acústica oriunda do objeto alvo é uma função resultante das características mecânicas da estrutura e da localização do ponto de excitação. A imagem é produzida mapeando-se a amplitude ou a fase deste som, que é detectado por um sensível hidrofone em relação ao seu posicionamento. Apesar da imagem gerada pela VA ser bidimensional, ela representa o mapa acústico do volume coberto pelo foco do transdutor confocal.

8 Fenômeno recorrente da existência de uma superposição entre duas fontes emissoras de ondas, tal que elas possuam a mesma direção, amplitude e frequências próximas $f_{1}$ e $f_{2}$. A diferença de frequências implica na existência de momentos de interferência construtiva, onde a amplitude resultante será maior e momentos de interferência destrutiva, acarretando numa amplitude diminuta.

${ }^{9}$ No contexto, o termo descreve o campo acústico originado da vibração cíclica de um objeto material, ou seja, um campo acústico resultante da deformação estrutural de um objeto. 


\subsubsection{Aspectos gerais da Vibroacustografia}

Em uma visão prática, a sensibilidade inerente ao sistema da vibroacustografia tem se mostrado um importante argumento, principalmente em aplicações onde a intensidade do ultrassom permitida é limitada (como no caso de imagens médicas). Conforme pode ser avaliado no artigo de (FATEMI; GREENLEAF, 1998), deslocamentos oscilatórios na ordem de $100 \mathrm{~nm}$ em uma frequência de $10 \mathrm{kHz}$ produziram, em média, uma intensidade

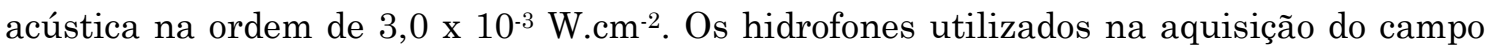
acústico proveniente do objeto irradiado são sensíveis a uma intensidade tão baixa quanto $10^{-15} \mathrm{~W} . \mathrm{cm}^{-2}$. Isso mostra que o sistema tem a capacidade de detectar deslocamentos cíclicos muito pequenos, fator que garante uma alta sensibilidade ao método.

A título de comparação, o tradicional mapeamento por pulso-eco, em frequências ultrassônicas comuns na área médica, apresenta uma sensibilidade a movimentos limitada a alguns micrometros (SUGIMOTO; UEHA; ITOH, 1990).

(FATEMI; GREENLEAF, 1999) também propuseram em seus trabalhos, que o US estimulado por vibroacustografia apresenta potencial para aplicações em duas áreas gerais. A primeira delas é na avaliação não destrutiva de materiais (END), onde falhas mecânicas e características elásticas de materiais podem ser identificadas pela análise e medidas de alterações na resposta mecânica gerada pela vibração estimulada em algum ponto da superfície do corpo avaliado. Estes estímulos mecânicos incidentes no objeto sob testes podem ocorrer remotamente com os feixes sendo propagados tanto na água como no ar, ou também, em pontos internos do objeto, quando o objetivo são emissões acústicas para detecção e falhas.

Na patologia clínica, sabe-se que diferentes enfermidades (tais como o câncer) podem alterar significativamente a rigidez dos tecidos, principalmente os mais moles e, consequentemente, altera-se também o padrão de oscilação ou de amortecimento dos tecidos. Tais respostas mecânicas, por sua vez, podem ser facilmente comparadas utilizando a VA, logo se permite detectar a anormalidade. Pode-se dizer que a VA assemelha-se a uma "palpação" remota (sem contato direto), capaz de perceber pequenas e profundas anormalidades, antes dificilmente verificados com os métodos tradicionais de tato.

No entanto, para aplicações in vivo da VA, limitações devem ser assumidas, tais como um limite de segurança da potência, a atenuação do tecido, ruídos corporais e desvios de fase. A potência solicitada para gerar uma emissão acústica detectável depende do objeto, ruído acústico e sensibilidade do receptor. Resultados experimentais exibidos em 
(FATEMI; GREENLEAF, 1999), demonstram que intensidades tão baixas quanto $30 \mathrm{~mW} . \mathrm{cm}^{-2}$ são suficientes para detectar emissões acústicas vindas de objetos com $1 \mathrm{~mm}$ de diâmetro, com um sensível hidrofone imerso em água. Este valor de potência é muito menor que o limite da $\mathrm{FDA}^{10}$ para a segurança de aplicações em diagnósticos médicos, que fica em torno de $600 \mathrm{~mW} . \mathrm{cm}^{-2}$ (US FOOD AND DRUG ADMINISTRATION (FDA), 2012).

No âmbito desse trabalho de desenvolver um hidrofone com foco de aplicação na vibroacustografia e, visto a necessidade de se utilizar para essa modalidade um sensor acima de tudo sensível, nas seções seguintes foi realizada uma revisão comparativa de elementos transdutores piezoelétricos capazes de compor o elemento de sensoriamento do hidrofone para a aplicação em VA.

\subsubsection{A evolução de materiais piezoelétricos}

O efeito piezoelétrico, que até a Primeira Guerra Mundial era visto como um curioso fenômeno encontrou no funcionamento do equipamento de Paul Langevin (Sonar para detectar submarinos) a primeira aplicação expressiva. Ali, a piezoeletricidade teve realmente seu potencial ressaltado na geração e deteç̧ão de ondas ultrassônicas, desencadeando desenvolvimento de outros dispositivos e impulsionando as pesquisas por outros materiais com características eletromecânicas semelhantes às dos cristais de quartzo.

Já na Segunda Guerra Mundial, as limitadas fontes naturais de cristais piezoelétricos propiciaram o surgimento de outros grupos de pesquisa, como as cerâmicas piezoelétricas e ferroelétricas, estas últimas com propriedades piezoelétricas superiores as dos materiais naturais até então catalogados. A primeira cerâmica ferroelétrica foi sintetizada em 1946, com o titanato de bário $\left(\mathrm{BaTiO}_{3}\right)$. Esta descoberta iniciou uma era de ouro no campo de materiais cerâmicos policristalinos e nas aplicações com transdutores ultrassônicos (MANBACHI; COBBOLD, 2011).

Em 1951 (SHIRANE; SAWAGUCHI; TAKAGI, 1951) no Instituto de Tecnologia de Tóquio, no Japão, na mesma linha das cerâmicas foi sintetizada a cerâmica de titanato zirconato de chumbo (PZT). Este material foi um grande avanço na área das piezocerâmicas devido às suas elevadas e estáveis características piezoelétricas e também por seus amplos parâmetros de operação exigidos pelos transdutores de US, mantendo sua rele-

${ }^{10}$ Food and Drug Administration (FDA) é um órgão governamental dos USA que realiza o controle de alimentos, medicamentos, equipamentos médicos, etc. 
vância e importância mesmo depois de mais de 60 anos de sua primeira descrição (GALLEGO-JUAREZ, 1989). Várias outras variações do PZT, conforme veremos posteriormente, mostraram-se prevalecentes sobre as cerâmicas de $\mathrm{BaTiO}_{3}$, principalmente devido à melhor reprodutibilidade e melhores velocidades de propagação.

As cerâmicas piezoelétricas já haviam se consolidado nas aplicações com efeito piezoelétrico quando em 1969, o professor japonês Heiji Kawai do Kobayasi Institute of Physical Research de Tóquio, descreveu um trabalho sobre a descoberta de uma polarização remanescente em filmes orientados de fluoreto de polivinilideno (PVDF) (KAWAI, 1969). Descoberta esta, embasada em análises preliminares das propriedades piezoelétricas em pedaços de madeira seca e fibras de colágeno, realizadas cerca de dez anos antes, por Yasuda e Fukada. Nos estudos com polímeros apresentados por Kawai, foram detectados coeficientes piezoelétricos $d_{33}$ na ordem de $30 \mathrm{pC} / \mathrm{N}$, valores bastante superiores aos 2 pC/N reportados por Fukada em 1957 (FUKADA, 2000).

A ascensão das pesquisas com polímeros foi permitida devido a características específicas destes materiais, tais como flexibilidade, menor massa específica e maior facilidade de fabricação que as já tradicionais cerâmicas (CAPRON; HESS, 1986). Nas quatro décadas seguintes à primeira publicação de Kawai sobre a atividade piezoelétrica em polímeros, diversos trabalhos foram publicados, descrevendo os mecanismos e diferentes técnicas de preparo de filmes que levam à obtenção da piezoeletricidade nestes materiais, principalmente no PVDF (BROADHURST et al., 1978), (SESSLER, 1981).

Os efeitos ferro e piezoelétricos foram relatados em diversas pesquisas com base em diferentes polímeros, no entanto na maior parte dos casos, os efeitos encontrados foram inferiores aos do PVDF e não despertaram tanto interesse da comunidade científica (NALWA, 1995).

Uma solução de maior interesse foi apresentada para elevar as propriedades piezoelétricas dos polímeros. A proposta seria unir os altos coeficientes piezoelétricos $d_{33}$ das cerâmicas com a flexibilidade dos polímeros. Esses materiais ficaram conhecidos como compósitos e foram formados por partículas de cerâmica piezoelétricas (PZT) misturadas a uma base polimérica de PVDF (FURUKAWA, 1989)

No decorrer das pesquisas com polímeros piezoelétricos publicados nos últimos anos, foi observado que os diferentes polímeros investigados, apresentavam particularidades elétricas restritas à sua composição. Por exemplo, nos polímeros à base de silicone e nos polímeros fluorados, como o politetrafluoroetileno (PTFE), observou-se que estes apresentam uma maior retenção de cargas elétricas, assim como as poliamidas ímpares e 
aromáticas, apresentam coeficientes piezoelétricos mais elevados (GERHARDMULTHAUPT, 2002).

O aprisionamento de cargas elétricas nos polímeros retoma os estudos dos eletretos, que são materiais dielétricos capazes de reterem cargas elétricas por longos períodos, amplamente utilizados em aplicações como capacitores. Embora sejam totalmente diferentes dos polímeros piezoelétricos, por não apresentarem uma estrutura cristalina bipolar, os eletretos também possuem uma polarização remanescente criada pelo aprisionamento de cargas (SESSLER, 1987).

Neste contexto, os pesquisadores Wada e Hayakawa, na década de 70, previram que a polarização remanescente dos eletretos poderia causar a existência de propriedades piezoelétricas. $\mathrm{O}$ efeito piezoelétrico nestes materiais foi verificado experimentalmente os pesquisadores concluíram que o mesmo era fruto das cargas elétricas aprisionadas nos eletretos carregados (WADA; HAYAKAWA, 1976). Entretanto, os testes experimentais realizados na época com estes polímeros polarizados não demonstraram fortes propriedades eletromecânicas, fato que enfraqueceu as pesquisas na época (QIU, 2010).

Cerca de meia década depois, já nos anos 80, este cenário foi completamente modificado, quando foi observado que filmes porosos e celulares, de polipropileno (PP), quando eram eletricamente carregados passaram a apresentar coeficientes piezoelétricos $d_{33}$ similares ou superiores (800 pC/N) aos das cerâmicas (GERHARD-MULTHAUPT, 2002).

Diferente dos eletretos formados por filmes rígidos, a estrutura porosa desses filmes poliméricos, como mostrado na Figura 2.3, apresentam cavidades que aliada a propriedade de armazenamento de cargas de alguns polímeros, permite que grandes dipolos elétricos sejam formados, quando esses materiais fossem submetidos a intensos campos elétricos. Esses macro-dipolos somados à estrutura mais flexível, possibilitam uma maior compressão do material mediante a aplicação de uma força externa, o que normalmente resulta grandes efeitos piezoelétricos (GERHARD-MULTHAUPT, 2002).
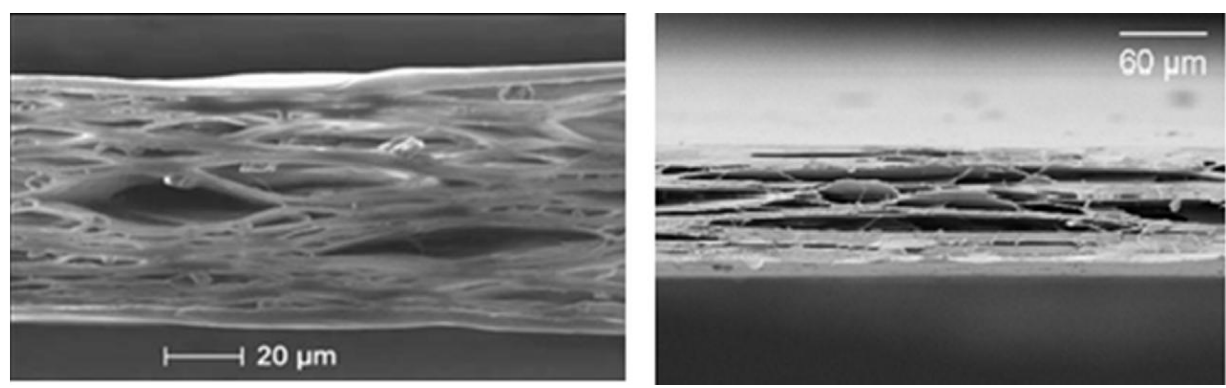

Figura 2.3 - Imagens microscópicas de filmes celulares: PP (lado esquerdo) e PETP (lado direito) (HILLENBRAND et al., 2003). 
Devido à similaridade com os eletretos e ao elevado coeficiente piezoelétrico esses materiais foram chamados de ferroeletretos ou piezoeletretos. E de forma mais detalhada, o efeito piezoelétrico nesses polímeros porosos, pode ser explicado devido a dois fatores principais: as cavidades e ao processo de carregamento. Durante o carregamento elétrico a estrutura celular é exposta à influência de um intenso campo elétrico, que provoca a ruptura do gás dentro das cavidades em forma de descargas elétricas (ALTAFIM et al., 2008), (QIU et al., 2007). Essas descargas promovem a ionização do gás dentro das cavidades e que pela ação do campo elétrico, são deslocadas em direções opostas (positivas e negativas).

Contudo, alguns polímeros como observado, apresentam características de aprisionamento de cargas, e as cargas deslocadas ficam aprisionadas nas superfícies das cavidades, formando dipolos, como ilustrado na Figura 2.4. Quando eletrodos são depositados nas superfícies desses filmes, cargas elétricas de compensação surgem para cancelar a polarização do material. Ao submeter o material a uma força mecânica externa e negativa, na mesma direção da polarização, ocorre uma redução na sua espessura, provocando uma aproximação das cargas aprisionadas nas superfícies internas das cavidades. Isso causa um desequilíbrio nas cargas de compensação externas, que tendem a se reorganizar, gerando uma resposta elétrica instantânea (BAUER et al., 2005).
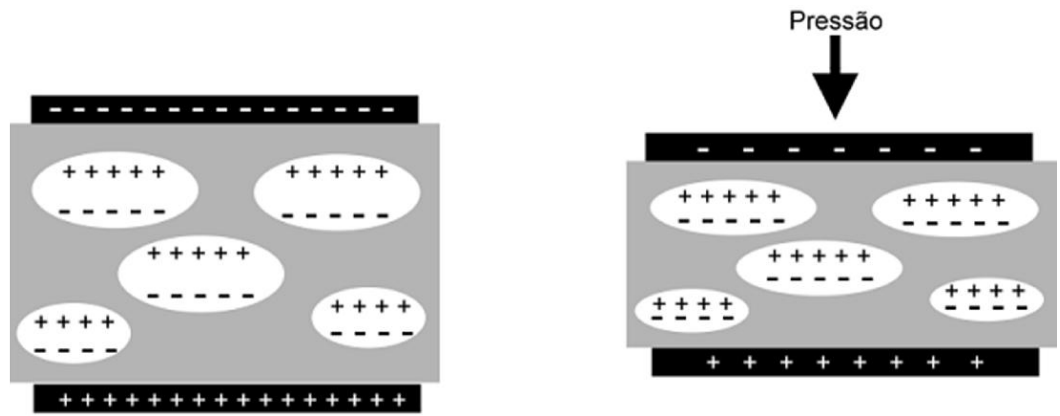

Figura 2.4 - Esquema ilustrativo das cargas elétricas aprisionadas nos polímeros celulares após carregamento elétrico e a deformação das cavidades pela aplicação de uma pressão externa na estrutura (GERHARD-MULTHAUPT, 2002).

O método proposto para a fabricação dos piezoeletretos consiste na injeção de ar ou grãos de areia no interior de uma porção de PP em aquecimento, num processo denominado de aeração. Posteriormente, durante o resfriamento do material, cavidades esféricas com cerca de $10 \mu \mathrm{m}$ de diâmetro são formadas em torno das inclusões (BAUER; GERHARD-MULTHAUPT; SESSLER, 2004). Na sequência, o PP modificado passa por uma etapa de extrusão, onde são moldados filmes com $70 \mu \mathrm{m}$ de espessura. Assim, as cavidades esféricas iniciais, agora deformadas, passam a formar espaços vazios com for- 
mato elipsoidal de 10 a $100 \mu \mathrm{m}$ em diâmetro e 2 a $10 \mu \mathrm{m}$ de altura (PAAJANEN; LEKKALA; KIRJAVAINEN, 2000), conforme Figura 2.5(a). As superfícies superior e inferior do filme, antes com formatos irregulares, devem então ser homogeneizadas por uma selagem de PP. Por fim, o material é exposto à descarga corona a fim de se efetuar o carregamento elétrico (SESSLER; HILLENBRAND, 1999), como ilustra a Figura 2.5(b).
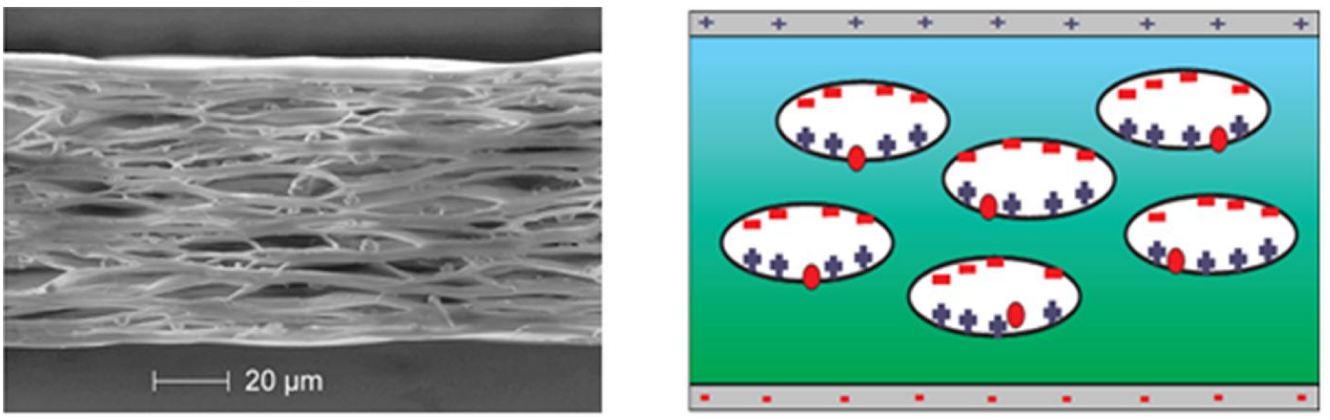

Figura 2.5 - (a) Micrografia por escaneamento eletrônico da seção transversal de um filme EMFi de $70 \mu \mathrm{m}$ de espessura. (b) distribuição das cargas no interior do filme (SESSLER; HILLENBRAND, 1999).

Após o carregamento elétrico é que a estrutura passa a exibir propriedades piezoelétricas e, após a metalização das superfícies externas do material, o filme eletromecânico está apto a aplicações como transdutor. Conforme demonstrado no esquema das cargas na Figura 2.5(b), o alinhamento dos macro-dipolos ocorre somente na mesma direção do campo elétrico aplicado durante o carregamento dos polímeros celulares. Logo, é esperado que o efeito piezoelétrico encontrado nos piezoeletretos só ocorra quando uma excitação externa (mecânica ou elétrica) seja aplicada perpendicularmente ao polímero (BAUER et al., 2003).

Essa forma de orientação dos dipolos, onde a direção da polarização é paralela à direção da tensão mecânica aplicada, tem sido denotada pelo coeficiente piezoelétrico $d_{33}$. Tal simbologia é utilizada por muitos pesquisadores como principal parâmetro de medida da piezoeletricidade, fazendo uma analogia ao coeficiente piezoelétrico utilizados nos cristais e cerâmicas (BAUER et al., 2003), (ZHANG et al., 2005).

Em contraste aos elevados coeficientes piezoelétricos em condições de operação em temperatura ambiente (ZHANG; HILLENBRAND; SESSLER, 2007), o PP possui baixa estabilidade térmica, apresentando um rápido decaimento no coeficiente piezoelétrico quando submetido a temperaturas superiores a $60^{\circ} \mathrm{C}$ (HILLENBRAND et al., 2003). 


\subsection{Transdutores de ultrassom}

Os equipamentos baseados na emissão e/ou recepção de ondas ultrassônicas têm como elementos principais os transdutores piezoelétricos, que atuam na conversão eletromecânica de energia. Nesses dispositivos, as características dos materiais que os compõem são fundamentais para seu rendimento, a exemplo do coeficiente de acoplamento eletromecânico $\left(k_{i j}\right)$, que é um parâmetro indicativo da eficiência da conversão de energia mecânica (proveniente de ondas acústicas) em energia elétrica e, vice-versa. Este fator relaciona-se diretamente à sensibilidade do transdutor. Assim, quanto mais elevado for o $k_{i j}$, melhor será o rendimento.

Um valor alto da constante dielétrica é essencial para permitir que a impedância elétrica do dispositivo seja boa o suficiente para corresponder à impedância dos terminais dos dispositivos eletrônicos, tais como amplificadores, osciloscópios, etc. A tangente de perdas dielétricas também se apresenta como um importante referencial das características do transdutor, pois está intimamente ligada à quantidade de calor gerado por ele na transmissão de ondas e à relação sinal-ruído na recepção de sinais (WALLER; CHEN; GURURAJA, 1996).

Contudo, várias outras considerações pertinentes às propriedades estruturais, elétricas, mecânicas, etc., dos elementos transdutores piezoelétricos devem ser efetuadas. Isso se faz verdade, pois diferentes aplicações e situações de construção dos equipamentos podem exigir propriedades que muitas vezes acabam priorizando a escolha de um material que talvez não seja o mais eficiente em certos quesitos.

Neste cenário, dois tipos de transdutores se destacam os cerâmicos e os poliméricos, mais bem descritos nos itens subsequentes.

\subsubsection{Transdutores cerâmicos}

As cerâmicas ferroelétricas policristalinas, em especial o titanato zirconato de chumbo (PZT), compreendem sistemas estruturais pesquisados há mais de 60 anos por sua vasta aplicação em dispositivos transdutores piezoelétricos. As piezocerâmicas oferecem destacada sensibilidade traduzida por seus coeficientes piezoelétricos, geralmente, maiores que $350 \mathrm{pC} / \mathrm{N}$, com um fator de acoplamento mecânico que supera os 70\% (JAFFE; COOK; JAFFE, 1971). A faixa útil de temperaturas das cerâmicas ferroelétricas é limitada por seu respectivo ponto de Curie $(T c)$, na ordem de $160^{\circ} \mathrm{C}-350^{\circ} \mathrm{C}$, mas devido à ação 
de envelhecimento, as propriedades piezoelétricas das cerâmicas podem ser degradadas sob temperaturas bem inferiores à $T_{c}$ (SHROUT; EITEL; RANDALL, 2002).

Em 2005, Quanlu et al. (QUANLU et al., 2005) contextualizou preparação e a aplicação de transdutores ultrassônicos multifuncionais (diagnóstico e terapêutico) para aplicações médicas, à base de cerâmicas ferroelétricas de PZT. No intuito de melhorar as propriedades piezoelétricas do PZT, foram propostas no artigo três formulações (SF-PZT, $\mathrm{F}_{1}$-PZT e $\mathrm{F}_{2}$-PZT) diferentes da composição química desta cerâmica, cujos prefixos $\mathrm{SF}, \mathrm{F}$ indicam, respectivamente, materiais piezoelétricos para emissão (atuador) e recepção (sensor) de ondas acústicas e apenas emissão. Em todas elas a diferença nas formulações variou em torno da proporção dos elementos padrões (Pb, Zi e Ti). No SF-PZT, houve ainda adição de pequenas quantidades de carbonato de níquel $\left(\mathrm{NiCO}_{3}\right)$, óxido de cromo $\left(\mathrm{Cr}_{2} \mathrm{O}_{3}\right)$ e óxido de chumbo $(\mathrm{PbO})$.

No $\mathrm{F}_{1}$-PZT foram adicionadas pequenas quantidades de trióxido de ferro $\left(\mathrm{Fe}_{2} \mathrm{O}_{3}\right)$, dióxido de manganês $\left(\mathrm{MnO}_{2}\right)$ e também $\mathrm{PbO}$. Logo, medidas das propriedades eletromecânicas e dielétricas destes materiais, feitas no trabalho, chegaram aos dados da tabela abaixo.

Tabela 2.1 - Principais propriedades de três tipos de materiais transdutores piezoelétricos. Propriedades medidas em discos com $20 \mathrm{~mm}$ de diâmetro e $1 \mathrm{~mm}$ de espessura (QUANLU et al., 2005).

\begin{tabular}{llll}
\hline Parâmetros & SF-PZT & F $_{1}$-PZT & F $_{2}$-PZT \\
\hline$\rho\left(\mathrm{kg} / \mathrm{m}^{3}\right)$ & 7600 & 7700 & 7740 \\
$d_{33},(\mathrm{pC} / \mathrm{N})$ & 426 & 370 & 240 \\
$g_{33}(\mathrm{~V} . \mathrm{m} / \mathrm{N})$ & 0,032 & 0,0248 & 0,034 \\
$K_{3} T$ & 1450 & 1200 & 1130 \\
$\tan \delta(\%)$ & 1,1 & 0,19 & 0,23 \\
$Q_{m}$ & 370 & 780 & 1010 \\
$k_{p}$ & 0,54 & 0,50 & 0,52 \\
\hline
\end{tabular}

Considerações importantes feitas pelo autor permitiram alinhar os resultados expostos na Tabela 2.1 às adequadas aplicações em conformidade com as propriedades exibidas por cada material. $\mathrm{O}$ baixo coeficiente de perdas dielétricas (tan $\delta$ ) e os relativamente altos valores de $\left(k_{p}\right)$ e de $\left(Q_{m}\right)$, consideraram a cerâmica $\mathrm{F}_{1}$-PZT apta à construção de aparelhos de US terapêuticos e transdutores piezoelétricos ultrassônicos de média potência. Os elevados valores de $d_{i j}$ e $g_{i j}$ e o mediano valor do acoplamento eletromecânico $\left(k_{i j}\right)$, constataram que o SF-PZT tem potencial para aplicações ultrassônicas de pulso-eco, tais como diagnóstico médico, equipamentos metrológicos e transdutores para testes de avaliação não destrutiva (END). Já o $\mathrm{F}_{2}$-PZT que apresentou relativamente ótimo valor de 
$\left(Q_{m}\right)$, um alto valor de $\left(k_{i j}\right)$ e baixo $(\tan \delta)$, mostrou-se um transdutor adequado para equipamentos de limpeza e dispersão por US; para dispositivos de US de alta potência e também, transdutores de US terapêuticos.

Desde a década de 1980, pesquisas com monocristais piezoelétricos, com estrutura similar ao PZT, vêm sendo realizadas com foco na produção de transdutores de US na área médica (KUWATA; UCHINO; NOMURA, 1982). No desenvolvimento destes trabalhos notou-se que os transdutores utilizando os monocristais mostraram-se mais eficientes que o transdutor de PZT, em aspectos como largura de banda e sensibilidade eletromecânica (RHIM et al., 2005). Os autores (RHIM; JUNG, 2007) por sua vez, fizeram uma revisão da aplicação de cerâmicas monocristalinas (Single Crystal) em transdutores de US médico numa faixa de frequências de 2 a $7 \mathrm{MHz}$, retratando as propriedades piezoelétricas e suas tendências de pesquisa. $\mathrm{O}$ artigo propôs um estudo comparativo entre as cerâmicas monocristalinas (PMN-PT e PZN-PT) e duas convencionais de PZT (PZT-5H e $3203 \mathrm{HD})$, retratando as vantagens e desvantagens com relação às propriedades mecânicas, elétricas e acústicas, fundamentais para a aplicação em transdutores de alta frequência. A Tabela 2.2 mostra os principais parâmetros de interesse.

Tabela 2.2 - Propriedades do PZT e Single Crystals (RHIM; JUNG, 2007).

\begin{tabular}{lllll}
\hline Propriedades & PZT-5H & 3203HDa $^{\text {PMN-PT }}$ & PZN-PT \\
\hline$\rho\left(\mathrm{kg} / \mathrm{m}^{3}\right)$ & 7500 & 7800 & 8000 & 8200 \\
$d_{33}(\mathrm{pC} / \mathrm{N})$ & 593 & 650 & 2000 & 2200 \\
$K_{3}{ }^{T}$ & 3400 & 3800 & 7000 & 7000 \\
$k_{33}$ & 0,75 & 0,75 & 0,92 & 0,93 \\
$\tan \delta(\%)$ & 2 & 2,5 & $<1$ & $<1$ \\
$\operatorname{Tc}\left({ }^{\circ} \mathrm{C}\right)$ & 190 & 225 & 130 & 170 \\
$Z a($ MRayls $)$ & 34 & 32 & 27 & 22 \\
\hline
\end{tabular}

Perante a análise da tabela acima, é notória a superioridade piezoelétrica dos monocristais visto o elevado coeficiente piezoelétrico do PMN-PT (lead magnesium niobatelead titanate) e PZN-PT (lead zinc niobate-lead titanate), bem como o alto fator de acoplamento eletromecânico de ambos, características estas que podem garantir melhor sensibilidade ao transdutor e maior largura de banda. Outro ponto de destaque fica por conta da impedância acústica dos monocristais, bastante inferior ao PZT.

As vantagens das cerâmicas em monoblocos, citadas no trabalho de (RHIM; JUNG, 2007), comprovaram o desempenho superior frente às cerâmicas policristalinas, motivo que explica uma crescente preferência destas em boa parte de aplicações, antes ocupadas pelo PZT. No entanto, estes materiais apresentam sérias desvantagens com relação a sua 
estabilidade térmica. A baixa Temperatura de Curie $(T c)$ é uma fragilidade dos monocristais para aplicações em alta frequência, uma vez que a despolarização destes dispositivos ocorre facilmente, tanto na construção e como na operação destes elementos, quando atuando como transdutores ultrassônicos. Outro fator negativo exposto no artigo trata-se do complexo e lento processo de fabricação destes dispositivos. Portanto, os desafios de pesquisa dos monocristais focam ainda, melhorias em resistência mecânica, fatores dependentes da temperatura e atividade de degradação durante o processo de fabricação.

\subsubsection{Transdutores de PVDF e seus copolímeros}

As propriedades elétricas e mecânicas inerentes aos polímeros piezoelétricos apresentam algumas vantagens que têm justificado a sua utilização em dispositivos ultrassônicos. Dentre estas propriedades, destaca-se a baixa impedância acústica relativamente próxima à impedância dos meios de mais comuns de aplicações, tais como o ar, água e tecidos. Isso proporciona menores perdas na propagação das ondas ultrassônicas, e também no quesito desempenho acústico, pois estes materiais proporcionam aplicações em ampla banda de frequências.

A flexibilidade, que possibilita a acomodação em substratos de variados formatos e a disponibilidade comercial em filmes com áreas relativamente grandes, compreendem os demais fatores positivos, favoráveis à aplicação dos materiais piezoelétricos poliméricos.

As aplicações bem sucedidas da tecnologia da piezoeletricidade em polímeros, têm superado algumas de suas "deficiências" perante outros materiais piezoelétricos mais tradicionais, a exemplo das cerâmicas e compósitos. Nesse contexto, os piezo-polímeros apresentam menores coeficientes piezoelétricos, maiores perdas dielétricas e elásticas, bem como uma baixa constante dielétrica. Estes pontos negativos, porém, representam desafios especiais de pesquisa, em torno da caracterização das propriedades piezoelétricas e modelagem de desempenho acústico (BROWN, 2000).

As pesquisas com novos polímeros piezoelétricos e ferroelétricos foram disseminadas desde a descoberta das fortes propriedades piezoelétricas em filmes orientados de PVDF (KAWAI, 1969). O PVDF, por sua vez, mesmo depois de mais de 40 anos, apresenta-se como um dos mais populares polímeros piezoelétricos disponível no mercado. Mas, este cenário tem sido modificado desde década de 80, a partir de intensos estudos com copolímeros do PVDF, os quais apresentam melhores propriedades ferroelétricas. Em determinadas experiências foi possível obter uma polarização remanescente superior à do 
próprio PVDF. Diante destes copolímeros, os mais pesquisados atualmente são o poli(fluoreto de vinilideno-co-trifluoretileno) (PVDF-TrFE) e poli(fluoreto de vinilideno-cotetrafluoroetileno) (PVDF-TeFE), que são materiais que não exigem nenhum método de estiramento a fim de converter sua estrutura molecular para uma forma polarizada. Já o PVDF comum, necessita ser alongado em aproximadamente 4 a 5 vezes em relação à sua dimensão lateral de origem.

Nesse contexto, o PVDF-TeFE apresentado ao mercado em meados de 1980, como uma alternativa ao PVDF padrão, exibiu propriedades piezoelétricas melhoradas, mas suas propriedades dielétricas não foram muito superiores a ponto de justificar sua ascensão. Apesar das interessantes propriedades quanto à polarização do PVDF-TeFE foi verificado que as suas propriedades dielétricas e eletromecânicas eram facilmente vencidas pelo PVDF-TrFE, também copolímero do PVDF. Este passou a ser comercializado no final da década de 80, e ainda nos dias de hoje é tido como um bem sucedido copolímero ferroelétrico, devido às suas altas propriedades piezoelétricas (BROWN, 2000).

Em 2000, Lewis Brown (BROWN, 2000) fez um trabalho de revisão sobre modelos de transdutores de US baseados em polímeros piezoelétricos, destacando o PVDF e seus copolímeros, onde foram apresentadas sete importantes considerações referentes aos desenvolvimentos destes dispositivos, sendo elas: critérios para seleção de materiais polímeros piezoelétricos; técnicas de construção de transdutores e maneiras de acondicionamento dos mesmos; modelagem e caracterização dos materiais; espessura do filme polimérico e dimensionamento da área ativa do elemento transdutor; seleção de eletrodos; dimensionamento do material da camada retaguarda e da proteção frontal do equipamento, onde é também a camada de "casamento" com o meio. Além destas considerações de projeto foram também representadas novas perspectivas de projeto para transdutores de polímeros piezoelétricos ativos, para aplicações em US.

Foram avaliadas ainda neste estudo propriedades típicas dos seguintes polímeros e copolímeros piezoelétricos comercialmente disponíveis: PVDF, PVDF-TrFE, PVDF-TeFE, poli(cianeto de vinilideno-vinil acetato) PVDF-VAc) e os Nylons “7 e 11”. Estas propriedades, listadas na Tabela 2.3 são consideradas importantes no desenvolvimento de transdutores ultrassônicos de alta frequência. Esta comparação serviu como auxilio na seleção do material transdutor adequado a determinadas aplicações, conforme exigências do autor. 
Tabela 2.3 - Propriedade dos polímeros piezoelétricos de interesse para o projeto de transdutores ultrassônicos de alta frequência.

\begin{tabular}{lllllll}
\hline Parâmetros & PVDF $^{*}$ & P(VDF-TrFE) $^{*}$ & P(VDF-TeFE) $^{* *}$ & P(VDCN-VAc) $^{* *}$ & Nylon-11 $^{*}$ & Nylon-7 $^{*}$ \\
\hline$(\rho),\left[k g / m^{3}\right]$ & 1780 & 1880 & 1900 & 1200 & 1023 & 1115 \\
$(v),[m / s]$ & 2200 & 2400 & 2200 & 2620 & 2000 & 2000 \\
$\left(Z_{a}\right),[$ MRayl] & 3,92 & 4,32 & 4,18 & 3,14 & 2,05 & 2,23 \\
$\left(\varepsilon_{33}\right)$ & 5,0 & 4,0 & 5,5 & 6,0 & 2,2 & 2,5 \\
$\left(\right.$ tan $\left.\delta_{e}\right)$ & 0,25 & 0,12 & 0,19 & $\cdots$ & 0,25 & 0,22 \\
$\left(Q_{m}\right)$ & 13 & 25 & 17 & -- & 8 & 8 \\
$\left(k_{t}\right)$ & 0,15 & 0,30 & 0,21 & 0,22 & 0,11 & 0,10 \\
\hline
\end{tabular}

*(BROWN et al., 1997); ** (WANG; HERBERT; GLASS, 1988)

Os resultados expostos na tabela acima mostraram que, tomando-se por base apenas as propriedades piezoelétricas, o desempenho do PVDF padrão está muito aquém de seus copolímeros, que se destacaram principalmente por apresentarem maior acoplamento eletromecânico. Valores expressivos também foram identificados quanto à baixa impedância acústica $(Z a)$ dos polímeros investigados, fato que os torna bem aceitáveis nas aplicações em água e tecidos. Os polímeros piezoelétricos apresentam impedância acústica correspondentes com diversos produtos e equipamentos poliméricos, tais como materiais de fibras epóxi de grafite, o que incentiva a fabricação de transdutores ultrassônicos de contato visando o ramo das aplicações de avaliação não-destrutiva (BROWN, 1990).

O desempenho eletromecânico e as características dielétricas do $\operatorname{PVDF}_{x}-\operatorname{TrFE}_{1-x}$ são extremamente dependentes de seu processamento químico e elétrico, bem como da proporção de fluoreto de vinilideno (VDF), dado por $x$ em sua nomenclatura. No trabalho de (KOGA; OHIGASHI, 1986) foi analisada a relação entre a proporção de VDF na composição química do copolímero e o fator de acoplamento eletromecânico $\left(k_{t}\right)$ alcançado em modo espessura. Este estudo mostrou que melhores resultados de acoplamento estavam associados com valores de $x$ na faixa de 0,7 a 0,8 (faixa de composição atualmente disponível). Posteriormente, Omote et al. (OMOTE; OHIGASHI; KOGA, 1997) relataram informações sobre a bem sucedida formação dos filmes monocristalinos de $\mathrm{PVDF}_{0,75-}$ $\operatorname{TrFE}_{0,25}$, cuja preparação necessita de um conjuntos de soluções para tratamento térmico, além da necessidade de alongamento uniaxial por 5 vezes o seu comprimento original. Estes filmes monocristalinos exibiram após polarização em temperatura ambiente, um fator de acoplamento em modo espessura $\left(k_{33}\right)$ de aproximadamente 0,292. Tal valor de $k_{33}$ tem pouca variação com temperaturas até $125^{\circ} \mathrm{C}$.

A fração molar de VDF influencia diretamente também na Temperatura de Curie $\left(T_{C}\right)$ dos copolímeros do PVDF. Aproximados $135{ }^{\circ} \mathrm{C}$ é a $T_{C}$ da forma comercial mais comum do copolímero trifluoretado $(x=0,75)$ e, seu ponto de fusão $\left(P_{F}\right)$ fica em torno de 150 ${ }^{\circ} \mathrm{C}$. No entanto, experimentos com o $\mathrm{PVDF}_{0,75}-\mathrm{TrFE}_{0,25}$ apontaram que uma amostra (fil- 
me $32 \mu \mathrm{m}$ de espessura, metalizado a ouro), após 18 horas submetida a $120{ }^{\circ} \mathrm{C}$ de temperatura dentro de uma câmara, sentiu alterações nas suas propriedades dielétricas (ligeiro aumento em $\varepsilon_{33}$ e na $\tan \delta$ ) e também eletromecânicas ( $k_{t}$ reduzido de 0,285 para 0,25 e redução de $Q m$, de 24 para 21). A significante perda de polarização em $120{ }^{\circ} \mathrm{C}$, que evidencia a extrema sensibilidade do $\mathrm{PVDF}_{0,75}-\mathrm{TrFE}_{0,25}$ a determinadas condições de operação, ocorre em razão do grande "encolhimento" que sofre o material nestas temperaturas. Por esta razão, o fabricante recomenda uma temperatura de operação para o copolímero de 90 a $100{ }^{\circ} \mathrm{C}$, mesmo a $T c$ sendo aproximadamente $135^{\circ} \mathrm{C}$.

O tradicional filme de PVDF em um comportamento similar ao de seu polímero trifluoretado, mostrou possuir propriedades piezoelétricas e dielétricas bastante dependentes de variações de temperatura na faixa de -40 a $80{ }^{\circ} \mathrm{C}$, conforme resultados exibidos em (BROWN, 2000). As análises evidenciaram que o fator $k_{t}$ é bastante independente das variações de temperatura, ao contrário das constantes dielétricas e do fator de qualidade $(Q m)$ que demonstram ser fortemente dependentes. Testes com um transdutor de PVDF em aplicações de frequências ultrassônicas na ordem de 1 a $15 \mathrm{MHz}$ informaram, que a frequência central, a largura de banda e as perdas por inserção do polímero sensor, todas, variaram consideravelmente com a temperatura. Como consequência, a velocidade de propagação acústica (que é diretamente proporcional a impedância acústica, $Z_{a}$ ) pode diminuir quase que linearmente com a temperatura, fato que provoca também uma recorrente redução da frequência ressonante do transdutor de US feito de PVDF.

Nas considerações finais da investigação de (BROWN, 2000) foi apontada a superioridade do copolímero PVDF-TrFE, por oferecer superior acoplamento eletromecânico $\left(k_{t}\right)$, menor tangente de perdas dielétricas $\left(\tan \delta_{e}\right)$ e menor tangente de perdas mecânicas $\left(1 / Q_{m}\right)$. A este copolímero foram dedicadas aplicações que requerem um elemento transdutor de filme plano, com mínimas ou nenhuma curvatura, pois devido à sua alta cristalinidade (80\% ou maior), logo não apresentam robustez mecânica necessária para certas aplicações. Enquanto que, para aplicações que dispensam frágeis transdutores de filmes piezoelétricos (tais como transdutores flexíveis e membrana de hidrofones), o PVDF seria o mais indicado, pois apresenta uma menor cristalinidade (em torno de 50\%) e grande flexibilidade. No entanto, ambos os filmes de PVDF e PVDF-TrFE esboçaram dificuldades na construção e acomodação do elemento transdutor, em razão da baixa temperatura de fusão dos filmes e por dificuldades de adesão. 


\subsubsection{Transdutores a base de piezoeletretos}

Em 2011, Rupitsch et al. (RUPITSCH et al., 2011) construíram transdutores eletroacústicos monoelemento e matriciais, baseados em filmes porosos ativos de polipropileno (PP), denominados inicialmente de filmes eletromecânicos (EMFi) e posteriormente de piezoeletretos. Sua estrutura celular, de fácil compressão, possibilitou que estes filmes apresentassem elevados coeficientes piezoelétricos como já apresentado e também um excelente casamento de impedância acústica com o ar e, consequentemente, elevada largura de banda. Essas características tornaram os polímeros celulares de PP apropriados a diversos trabalhos como transdutores de US, que envolveram ainda simulações de projeto com modelagem por elementos finitos e caracterização dos transdutores de US.

Os pontos favoráveis listados em (RUPITSCH et al., 2011) para a utilização do piezoeletreto em transdutores de US, particularmente para aplicações em ar, foram cinco. $\mathrm{O}$ primeiro deles é a sensibilidade piezoelétrica dos ferroeletretos celulares que podem atingir níveis de até $800 \mathrm{pC} / \mathrm{N}$, no modo espessura ( $\left.d_{33}\right)$ (SCHWODIAUER et al., 2000). Outros polímeros convencionais utilizados nestas aplicações, tais como o PVDF, alcançaram coeficientes na ordem de 20 pC/N (LERCH; SESSLER, 1980). Outros pontos fortes estão também associados à composição celular dos filmes eletromecânicos de PP, tais como a baixa rigidez estrutural, baixa impedância acústica (assim como os demais polímeros piezoelétricos), o que garante em um melhor casamento com o ar e, proporciona consequentemente uma melhor largura de banda. Além disso, vale destacar que os materiais porosos podem ser dispostos em filmes finos e flexíveis, tal como o PVDF, por exemplo, permitindo sua fixação em superfícies curvas, muitas vezes úteis em aplicações industriais, principalmente.

Como ponto negativo do piezoeletretos há o baixo acoplamento eletromecânico $\left(k_{33}\right)$, com valores de aproximadamente 0,1 , que em consequência disto, transdutores com estes filmes necessitam de grandes excitações elétricas para apresentarem um bom desempenho mecânico. O gráfico da Figura 2.6 retrata bem esta condição para um transdutor atuando como emissor de ondas acústicas, no qual ao dispositivo foram aplicadas tensões de 100 a $800 \mathrm{~V}$, e sua deformação em (nm) foi avaliada em numa faixa de frequências (20 a $400 \mathrm{kHz})$. 


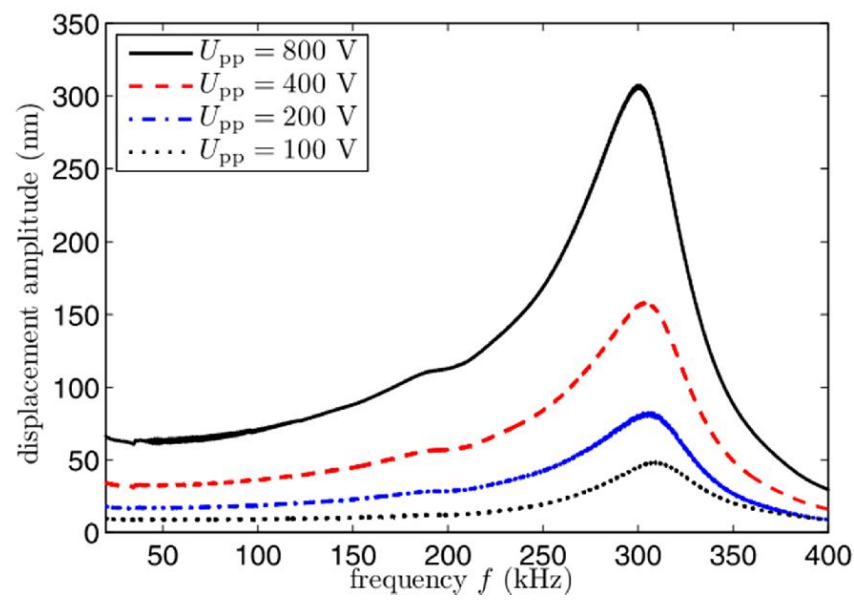

Figura 2.6-Amplitude do deslocamento versus frequência de um filme EMFi para diferentes tensões de excitação (RUPITSCH et al., 2011).

Soluções dadas pelo autor para melhorar a limitação do fator de acoplamento $\left(k_{33}\right)$, sugerem o empilhamento dos transdutores conforme visto em (STREICHER et al., 2003). Apesar da solicitação de menores tensões de excitação, este arranjo acabar por reduzir a $f_{R}$ para vibrações no modo de espessura.

Simulações numéricas também implementadas no estudo de (RUPITSCH et al., 2011), conceberam importantes relações do coeficiente $d_{33}$ e da frequência de ressonância $\left(f_{R}\right)$ em função da geometria das cavidades elipsoidais dos ferroeletretos celulares. No gráfico abaixo são exibidos estes resultados, sendo $D_{g}$ o diâmetro da cavidade gasosa e $h_{g}$ a altura da cavidade.

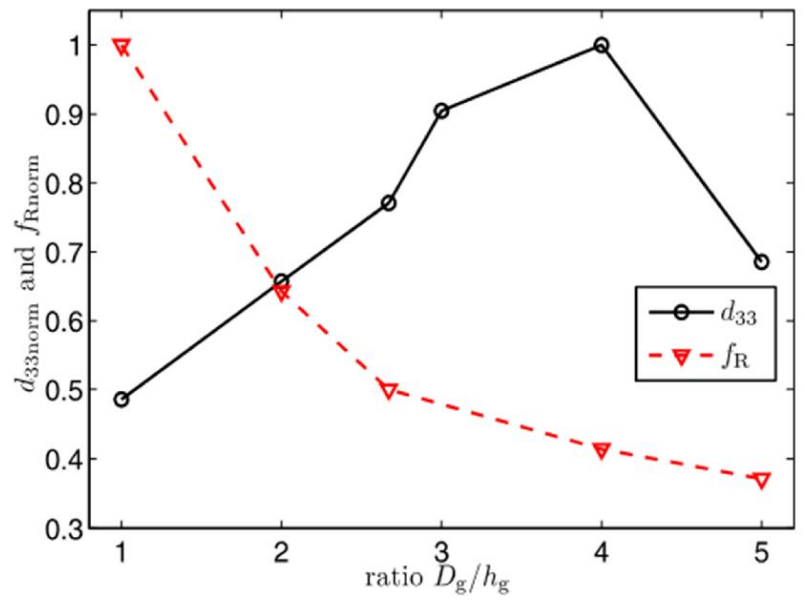

Figura 2.7 - Valores normalizados da $f_{R}$ no modo espessura e do coeficiente $d_{33}$, plotados em função da relação geométrica $\left(D_{g} / h_{g}\right)$ da cavidade lenticular (RUPITSCH et al., 2011). 
Nota-se no gráfico da Figura 2.7 que a $\left(f_{R}\right)$ diminui com o aumento da relação $\left(D_{g} / h_{g}\right)$, valores provavelmente atribuídos à redução do Módulo de Young (módulo de elasticidade) em decorrência dos grandes diâmetros $\left(D_{g}\right)$ das cavidades.

Outro ponto negativo dos piezoeletretos de PP é a baixa estabilidade e sensibilidade térmica inerente, que estão intimamente relacionadas às suas constantes eletromecânicas. Na Tabela 2.4 abaixo pode ser visto a mudança da frequência de ressonância de um filme poroso de PP em relação à temperatura. Destaca-se que quando esses filmes são expostos a temperaturas superiores a $60{ }^{\circ} \mathrm{C}$ ocorrem alterações irreversíveis nas suas propriedades piezoelétricas, pois os elevados níveis do coeficiente $d_{33}$ constatados à temperatura ambiente e que permanecem estáveis por vários anos, decaem rapidamente, em temperatura na faixa de 70 a $90{ }^{\circ} \mathrm{C}$. Essa queda no coeficiente piezoelétrico ocorre principalmente devido à recombinação das cargas elétricas que são liberadas de suas armadilhas energéticas cancelando os macro-dipolos (ZHANG; HILLENBRAND; SESSLER, 2007).

Tabela 2.4 - Frequência de ressonância $\left(f_{R}\right)$ versus a temperatura ambiente $(T a)$, para um material EMFi.

\begin{tabular}{llllll}
\hline$T a\left({ }^{\circ} \mathrm{C}\right)$ & -20 & 0 & 20 & 40 & 60 \\
\hline$f_{R}(\mathrm{kHz})$ & 290 & 270 & 250 & 220 & 200 \\
\hline
\end{tabular}

No campo da aplicação de polímeros ferroelétricos como elementos sensores e atuadores de dispositivos transdutores, a baixa estabilidade térmica apresentada pelo PP tem sido um dos principais motivos para o surgimento de pesquisas com polímeros termicamente mais estáveis.

Como avaliado anteriormente, a resposta eletromecânica dos filmes poliméricos apolares relaciona-se diretamente com o aprisionamento de cargas elétricas nas cavidades destes materiais. Mas, comercialmente, esses polímeros não são encontrados na forma de filmes porosos. Isso incentivou pesquisadores a desenvolverem técnicas convenientes de extrusão e diferentes métodos para se obter polímeros celulares (WEGENER et al., 2005), (BAUER et al., 2005), (QIU et al., 2005).

Nesse âmbito, estruturas poliméricas termoformadas que se assemelhem à estrutura porosa descrita anteriormente, e, que também apresentem a capacidade do aprisionamento de cargas constituindo assim dipolos elétricos, serão discutidas na próxima seção. 


\subsubsection{Piezoeletretos termoformados}

Os piezoeletretos termo-formados são assim como os piezoeletretos porosos, estruturas poliméricas com cavidades internas eletricamente carregadas, que formam macrodipolos de fácil deformação e que, portanto, são capazes de exibir elevados coeficientes piezoelétricos. No entanto, o que difere um piezoeletreto poroso de um termo-formado é o processo de fabricação, que permite que estes apresentem uma estrutura polimérica com cavidades controladas, ou seja, com formas geométricas bem definidas e que podem ser ajustadas conforme à aplicação desejada.

Por curiosidade histórica, os primeiros piezoeletretos termo-formados foram desenvolvidos no (GATM/EESC), da Universidade de São Paulo, coordenado pelo prof. Titular Ruy Alberto Corrêa Altafim (ALTAFIM et al., 2005). Neste trabalho pioneiro, filmes poliméricos foram previamente moldados por uma grade aquecida e unidos por fusão, formando uma estrutura polimérica formada por dois filmes contendo várias bolhas seladas, que foram posteriormente carregadas eletricamente.

Esse processo, melhor descrito a seguir, teve sua origem em um método pouco menos elaborado, mas igualmente importante. Baseado em uma estrutura polimérica composta por dois filmes circulares (75 $\mathrm{m}$ de espessura e 2,5 cm de diâmetro) de Fluoretileno Propileno (Teflon ${ }^{\circledR}$-FEP), os primeiros piezoeletretos do GATM foram desenvolvidos unindose esses filmes com tinta sintética em spray e, posteriormente, metalizados com folha laminada de alumínio, para compor os eletrodos. Detalhes do processo podem ser observados na Figura 2.8 (ALTAFIM et al., 2003).

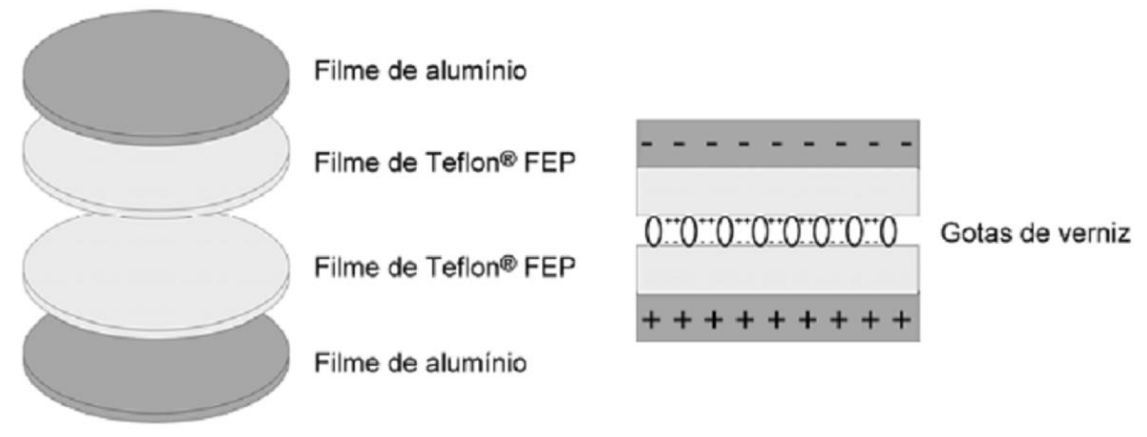

Figura 2.8 - Camadas empilhadas de filmes de Teflon®-FEP e alumínio (ALTAFIM et al., 2003).

A tinta sintética borrifada nas películas implicou na formação de gotículas de tinta com dimensões microscópicas (em média $10 \mu \mathrm{m}$ ) entre os filmes poliméricos, configurando uma estrutura semelhante à dos filmes celulares anteriormente produzidos. $\mathrm{O}$ mesmo 
verniz foi utilizado ainda na fixação dos eletrodos de alumínio aos filmes de FEP. Por fim, as amostras montadas com essa técnica foram carregadas pelo método impulsivo desenvolvido por (ALTAFIM; GIACOMETTI; JANISZEWSKI, 1992) e, apresentaram ótimos resultados, com coeficientes piezoelétricos $d_{33}$ de até $270 \mathrm{pC} / \mathrm{N}$. Essa inovadora perspectiva focando as pequenas cavidades mostrou que é possível criar estruturas com altos índices piezoelétricos e com materiais termicamente mais estáveis, no caso o FEP.

No entanto, as amostras produzidas por essa técnica apresentaram baixa resistência mecânica devido a características antiaderentes do Teflon-FEP.

Em 2005 e 2006, Altafim e seus colaboradores de pesquisa (ALTAFIM et al., 2005) e (ALTAFIM et al., 2006), propuseram uma nova técnica de produção de piezoeletretos. Esse método conciliou um melhor controle na formação das cavidades e, para contornar os problemas vistos com o transdutor de filmes aspergidos por verniz, capaz de desenvolver piezoeletretos mecanicamente mais resistentes. As estruturas oriundas desta técnica eram compostas por dois filmes poliméricos (25 mm de diâmetros e 50 ou $75 \mu \mathrm{m}$ de espessura) não porosos, também de Teflon ${ }^{\circledR}$-FEP, sendo um deles moldado com pequenas bolhas distribuídas e, posteriormente os dois foram colados por uma prensa aquecida.

A prensa apresentava dois discos de metal que pressionavam os filmes, um superior e um inferior, sendo o primeiro móvel, sólido e plano, o outro fixo e perfurado por iguais 20 pequenos orifícios, respectivamente. Ambos tinham um sistema independente do controle da temperatura, limitada à temperatura de fusão dos filmes. No disco inferior havia ainda um mecanismo de conexão com uma bomba de vácuo, em conjunto com uma grade metálica, sendo estas responsáveis pela moldagem das bolhas em um dos filmes, como mostra a Figura 2.9 (ALTAFIM et al., 2006). 


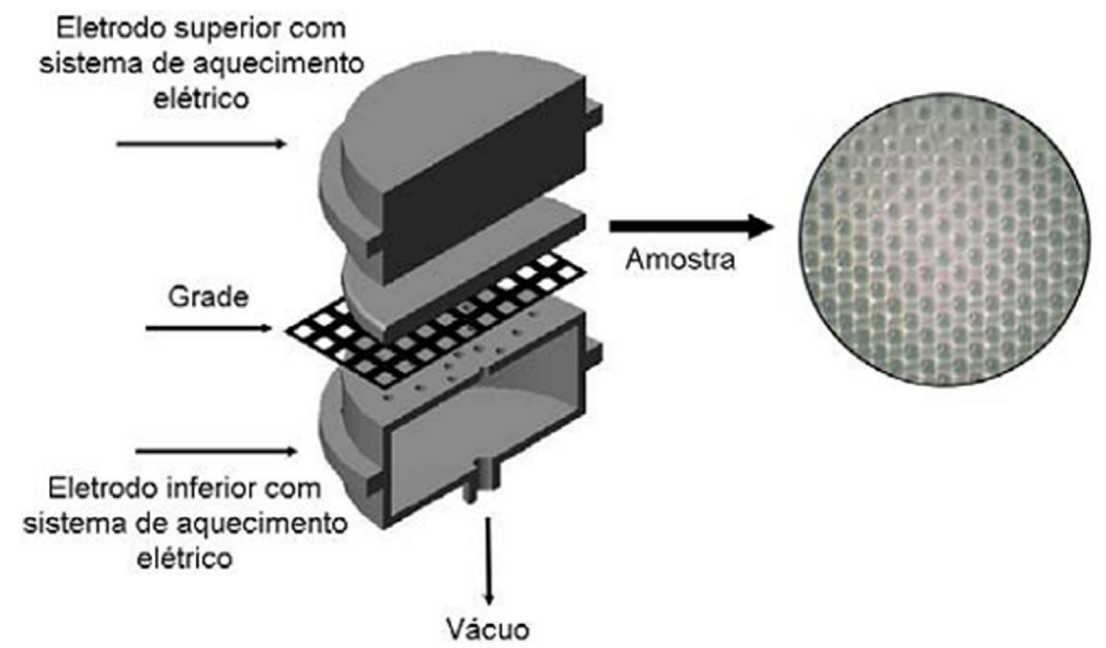

Figura 2.9 - Configuração do dispositivo utilizado para formação de amostra termo-formadas, com distribuição homogênea das bolhas de ar (ALTAFIM et al., 2006).

O procedimento iniciava-se com um pré-aquecimento dos discos, e a posterior disposição da primeira película polimérica sobre a grade também aquecida. Em seguida, a estrutura parcialmente moldada era submetida a um vácuo, responsável pelo estiramento do filme nos locais marcados pela máscara, concebendo formas às bolhas, que tinham aproximadamente $1 \mathrm{~mm}$ de diâmetro. Finalizando a moldagem, uma segunda película foi colocada sobre a primeira, de modo que ambas fossem pressionadas entre as duas placas aquecidas, até os filmes serem fundidos entre si. A Figura 2.10 exibe com detalhes exemplos de amostras formadas utilizando este mecanismo (ALTAFIM et al., 2005).

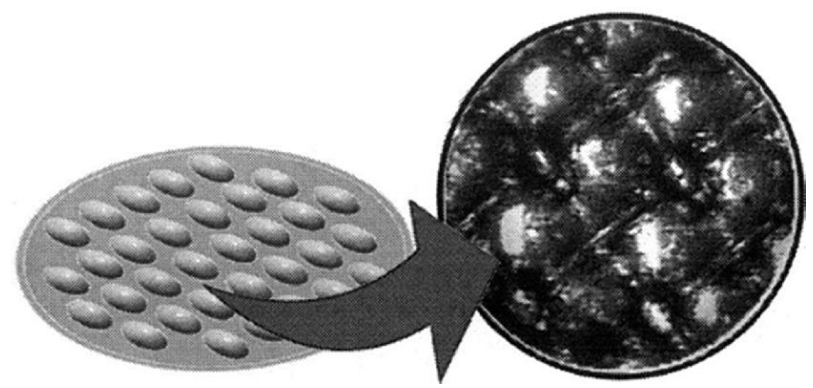

Figura 2.10 - Configuração do dispositivo utilizado para formação de amostra termo-formadas, com distribuição homogênea das bolhas de ar (ALTAFIM et al., 2006).

Esse novo método de fabricação além de permitir uma distribuição regular das bolhas de ar e a melhor adesão dos filmes, evidenciou também a maior estabilidade térmica proporcionada pelo uso do FEP em estruturas poliméricas. As amostras produzidas por esse sistema passaram a receber o nome de piezoeletretos termoformados, pelo fato do processo de produção ser aquecido. A atividade piezoelétrica registrada por esses disposi- 
tivos, depois de submetidas ao carregamento elétrico, registraram coeficientes na ordem de 500 pC/N (ALTAFIM et al., 2006).

Basso et al. (BASSO et al., 2006), em 2006, verificaram também uma maior facilidade nas modelagens matemáticas em estruturas com a distribuição e as dimensões das cavidades controladas, pois estas garantiam um carregamento elétrico mais homogêneo e o desempenho eletromecânico dos filmes poderia ser avaliado de acordo com as propriedades geométricas das cavidades.

No entanto, no método anteriormente descrito desvantagens ainda foram vistas, vindas da termo-modelagem dos filmes o que acarretava defeitos estruturais das bolhas primárias (bolhas definidas exclusivamente pelos espaços "vazados" da grade), prejudicando o controle nos tamanhos das cavidades (ALTAFIM, 2010).

Zhang et al. (ZHANG; HILLENBRAND; SESSLER, 2006) apresentaram um novo ferroeletreto, cujo sistema de produção era similar ao de Altafim e seu grupo. A estrutura do transdutor foi composta por um filme de Teflon ${ }^{\circledR}$-FEP $(12,7 \mu \mathrm{m}$ de espessura; PF $260^{\circ} \mathrm{C}$ ) entreposto por dois filmes de Politetrafluoretileno Teflon ${ }^{\circledR}$-PTFE ( 3 m de espessura; $\mathrm{PF} 327^{\circ} \mathrm{C}$ ), ambos com área de $4,5 \times 4,5 \mathrm{~cm}^{2}$. Uma grade metálica aquecida a $280^{\circ} \mathrm{C}$ foi então pressionada por uma hora, com força de aproximadamente $20 \mathrm{~N}$, sobre esta pilha de fluopolímeros. A Figura 2.11 esquemática ilustra este processo.

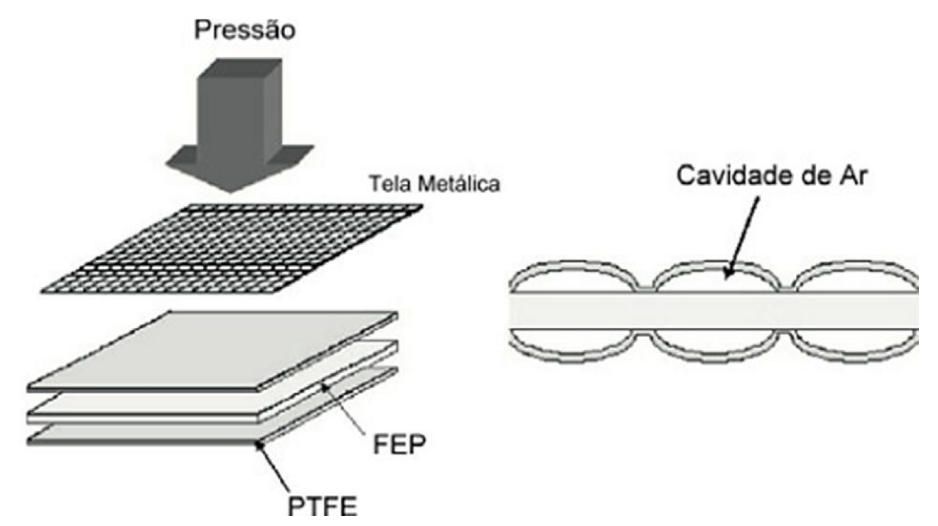

Figura 2.11 - Esquema do procedimento para moldar bolhas de ar de filmes empilhados em 3 camadas (lado esquerdo) e representação gráfica da seção transversal desses filmes (lado direito)(ZHANG; HILLENBRAND; SESSLER, 2006).

Nos pontos de contato entre a grade e a pilha polimérica houve a fusão entre os filmes e a posterior adesão dos mesmos; Nas regiões vazadas da grade formaram-se as cavidades de ar. Passado o período de uma hora, a grade é resfriada e lentamente retirada. Após o carregamento elétrico deste sanduíche de polímeros, foi constatado um coeficiente 
piezoelétrico superior aos $1000 \mathrm{pC} / \mathrm{N}$. Ao submeter este eletreto por 4 dias a um ambiente com $90^{\circ} \mathrm{C}$ de temperatura, foi verificada uma relativa estabilidade térmica já que o coeficiente ficou em torno de 400 pC/N (ZHANG; HILLENBRAND; SESSLER, 2006).

Zhang et al. (ZHANG; HILLENBRAND; SESSLER, 2007) dando sequência aos seus estudos de 2006, aplicaram a mesma técnica na produção de eletretos para um maior número de fluopolímeros empilhados, até um máximo de sete camadas, deixando sempre o PTFE nas extremidades, por seu maior ponto de fusão. Estas estruturas apresentaram uma estabilidade térmica ainda maior, até $90^{\circ} \mathrm{C}$, onde o coeficiente piezoelétrico ficou em torno de $1000 \mathrm{pC} / \mathrm{N}$, apresentando um decaimento de 15\% após cerca de 5 dias. Em temperaturas maiores até $120^{\circ} \mathrm{C}$, a estabilidade pôde ser obtida em níveis menores de aproximadamente $500 \mathrm{pC} / \mathrm{N}$.

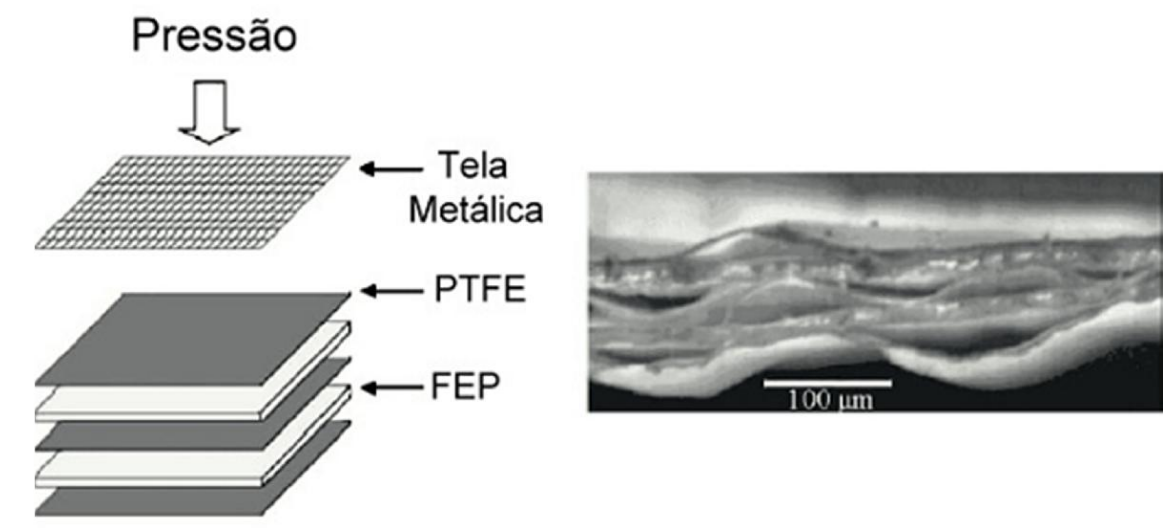

Figura 2.12 - Esquema do procedimento para moldar bolhas de ar de filmes empilhados em 5 camadas (lado esquerdo) e imagem da seção transversal desses filmes (lado direito) (ZHANG; HILLENBRAND; SESSLER, 2007).

Apesar dos elevados coeficientes piezoelétricos e da boa estabilidade térmica, alcançados por essas estruturas, as cavidades intermediárias experimentaram deformações como pode ser visto na Figura 2.12. Portanto, embora o método permita a construção de piezoeletretos com mais filmes empilhados, ele não detém nenhum controle sobre a distribuição e formato das cavidades intermediárias (ZHANG; HILLENBRAND; SESSLER, 2007).

A evolução até o momento dos métodos de termoformação para a produção de piezoeletretos foi de grande valia, já que estruturas bem mais organizadas e cavidades mais bem distribuídas foram configuradas. Os elevados coeficientes piezoelétricos aliados a uma maior estabilidade térmica foi outro avanço considerado. No entanto, alguns inconvenientes pertinentes à configuração das cavidades gasosas, indispensáveis para a po- 
tencialização do efeito piezoelétrico nestes mecanismos, ainda eram vistos como obstáculos. Em (ALTAFIM et al., 2005) atingiu-se uma melhor distribuição das bolhas de ar e uma melhor adesão entre os filmes, mas a bomba de vácuo utilizada não permitiu uma formação homogênea destas bolhas e também houve dificuldade no controle da altura das mesmas. Já em (ZHANG; HILLENBRAND; SESSLER, 2007) apesar dos elevados coeficientes piezoelétricos desempenhados pelos sanduíches de polímeros abordados, o tempo de produção foi considerado alto e o produto final também não apresentou um controle adequado das dimensões das cavidades.

Com base nessas observações novos trabalhos com piezoeletretos foram tomados a fim de aperfeiçoar os pontos negativos verificados e ao mesmo tempo manter as conquistas almejadas com os métodos anteriormente descritos.

RAP Altafim et al. (ALTAFIM et al., 2009) desenvolveram uma estrutura com cavidades padronizadas, pela laminação à quente de dois filmes externos com uma camada intermediária, utilizada como molde, de outro material com temperatura de fusão maior que a dos demais filmes. O molde referido consistia de um filme de Teflon PTFE com 100 $\mu \mathrm{m}$ de espessura e área de 30x40 mm², vazado por retângulos paralelos (área de 1,5x30 $\mathrm{mm}^{2}$ ) que foram cortados por meio de sistema de ablação à laser controlado por computador. Estas aberturas foram espaçadas uma das outra por 1,5 mm. Antes da laminação, o molde foi inserido entre dois filmes de Teflon FEP, cada um com espessura igual a 50 $\mu \mathrm{m}$. O sanduíche formado por estes fluopolímeros foi submetido a uma máquina de laminação, pré-aquecia a $300^{\circ} \mathrm{C}$. Tal temperatura foi escolhida por ser maior que a temperatura de fusão do filme FEP $\left(260^{\circ} \mathrm{C}\right)$ e menor que a temperatura de fusão do filme PTFE $\left(327^{\circ} \mathrm{C}\right)$, conforme o fabricante dos filmes (GOODFELLOW, 2012).

Após a laminação, o sanduíche de polímeros foi resfriado à temperatura ambiente e as duas camadas de FEP mostraram-se fundidas nas regiões de abertura do molde de PTFE. O filme de PTFE devido às suas características antiaderentes, pôde facilmente ser removido do empilhamento, mediante um pequeno corte em uma de suas extremidades. $\mathrm{O}$ resultado concedeu uma estrutura polimérica de filmes Teflon FEP, contendo canais tubulares bem definidos. O procedimento de moldagem e a composição da estrutura polimérica com canais tubulares fundidos podem ser vistos nas Figura 2.13(a) e (b), respectivamente (ALTAFIM et al., 2009). 


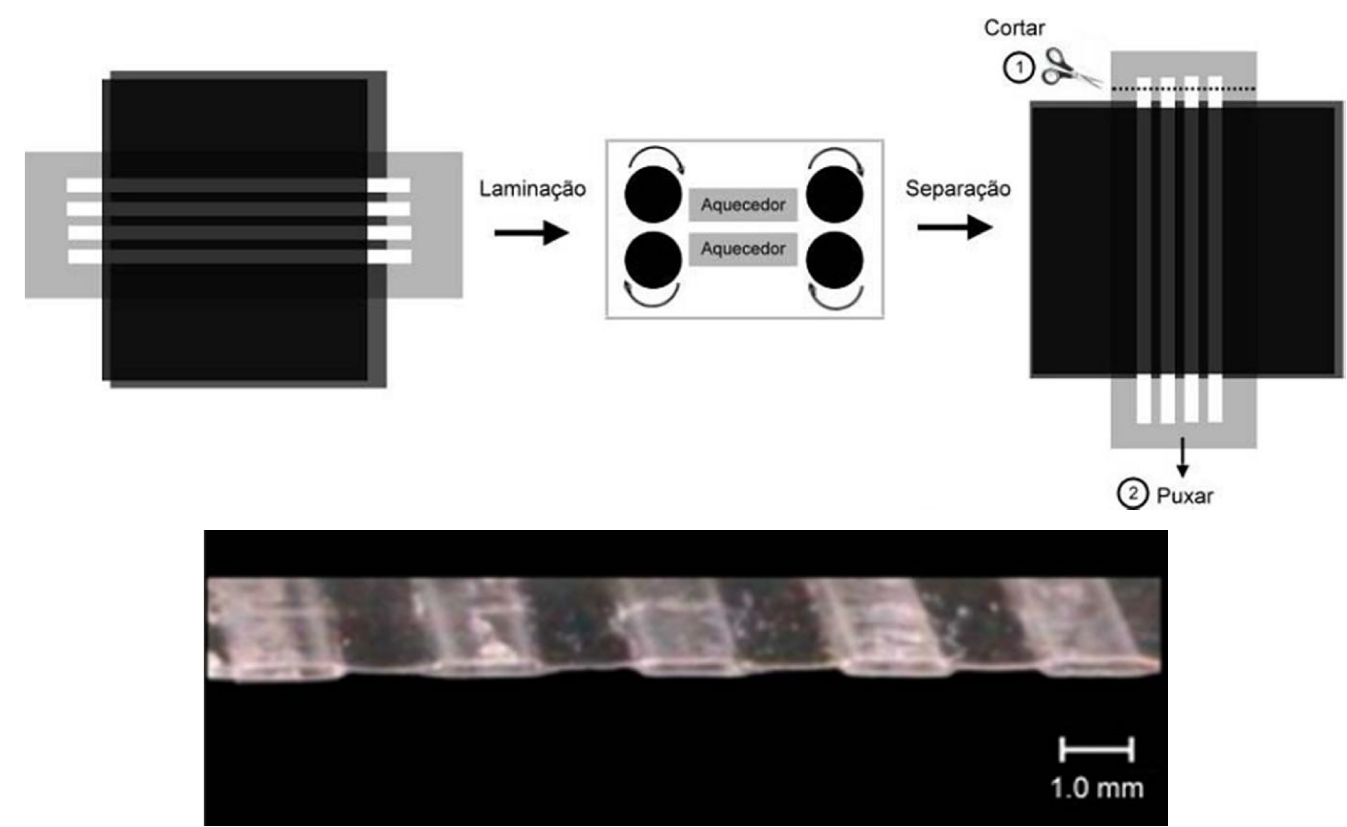

Figura 2.13 - Esquema do procedimento de fabricação em laboratório de piezoeletretos com estruturas padronizadas em canaletas (acima) e micrografia ótica da seção transversal dessa estrutura (abaixo). (ALTAFIM et al., 2009).

Por fim, as amostras foram em ambas as superfícies metalizadas pela vaporização de alumínio, formando eletrodos com $16 \mathrm{~mm}$ de diâmetro e $40 \mathrm{~nm}$ de espessura. Depois de metalizadas, as amostras passaram pelo carregamento elétrico por contato direto, com tensão de $3 \mathrm{kV}$ durante $10 \mathrm{~s}$, em temperatura ambiente, exibindo uma atividade piezoelétrica onde foram obtidos coeficientes $d_{33}$ de até $160 \mathrm{pC} / \mathrm{N}$.

Um espectro de ressonância dielétrica da estrutura celular de filmes FEP, com amostras apresentando quatro diferentes alturas dos canais, é apresentado na Figura 2.14 (ALTAFIM et al., 2009).

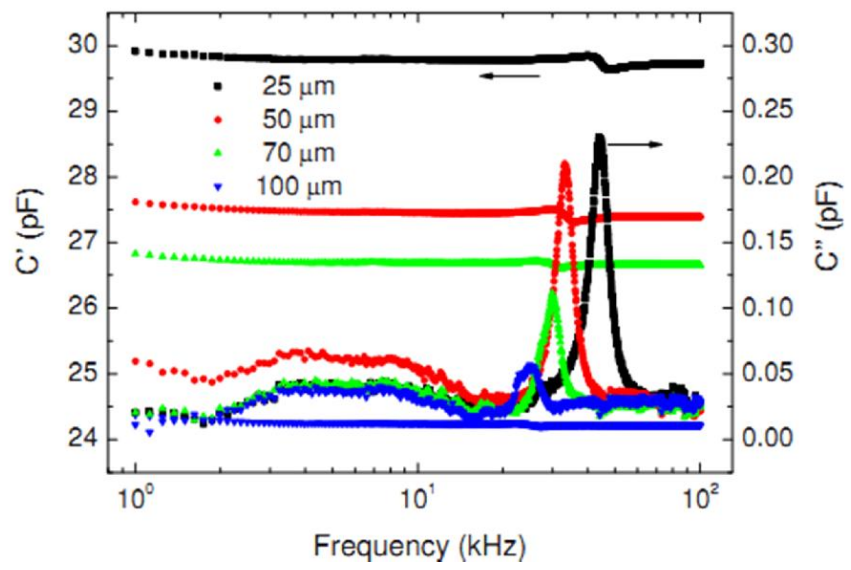

Figura 2.14 - Capacitância real (C') e imaginária (C") da amostra de ferroeletretos produzidos em (ALTAFIM et al., 2009). 
Observa-se no gráfico da Figura 2.14 que as frequências de ressonância encontradas para as amostras metalizadas e carregadas, ficaram na faixa de 20 a $50 \mathrm{kHz}$, em função da dimensão das cavidades, sendo os maiores valores registrados aos ferroeletretos mais finos.

Portanto, verificou-se que a frequência de ressonância neste sistema de produção de ferroeletretos de FEP, pôde ser ajustada pelo controle da altura dos canais tubulares, alterando apenas o molde de PTFE responsável por formar as cavidades durante a laminação. Esse controle da ressonância foi possível, devido à modificação dos níveis de espaço das cargas aprisionadas nas superfícies superior e inferior dos canais.

As amostras carregadas da mesma forma anterior, mas em altas temperaturas, cerca de $140^{\circ} \mathrm{C}$, mostraram-se termicamente estáveis em pelo menos $130^{\circ} \mathrm{C}$, com uma redução de aproximadamente $15 \%$ do coeficiente. Portanto, as vantagens do piezoeletreto descrito são garantidas pela simplicidade de fabricação, a bem controlada geometria que pode ser ajustada para diferentes tamanhos dos canais e padrões, de acordo com as exigências dos dispositivos e aplicações (ALTAFIM et al., 2009).

Em 2010, Falconi e colaboradores elaboraram outro método de produção de piezoeletretos baseado em duas camadas de filmes FEP. O procedimento utilizou basicamente uma prensa hidráulica que serviu pra moldar pequenas bolhas na superfície de uma película, com o auxílio de um gabarito metálico. Depois da moldagem, num processo de laminação semelhante ao desenvolvido em (ALTAFIM et al., 2009), outra película de FEP, não modificada foi fundida à primeira moldada mecanicamente. O processo construtivo ilustrado na Figura 2.15, inicia-se com a prensa exercendo uma pressão sobre uma borracha que pressiona também um filme FEP. Abaixo do filme, encontra-se uma matriz com pequenos orifícios uniformemente distribuídos, responsável por modelar pequenos domos no filme, ao final da moldagem (FALCONI et al., 2010).

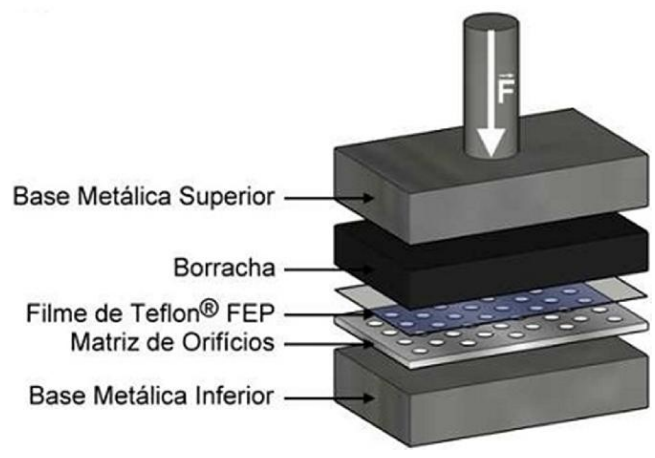

Figura 2.15 - Ilustração do procedimento para produção de domos em filmes FEP. (FALCONI et al., 2010) 
O passo seguinte consistiu em fundir um segundo filme FEP, agora plano e regular, ao filme moldado pela prensa. Ao final da laminação, obtiveram-se amostras com cavidades gasosas de dimensões e distribuição fáceis de serem controladas. Após a moldagem dos filmes, as amostras metalizadas foram carregadas eletricamente e desempenharam coeficientes piezoelétrico na ordem de 215 pC/N. A imagem da Figura 2.16, ilustra o procedimento de laminação a quente utilizado e também uma amostra pronta.

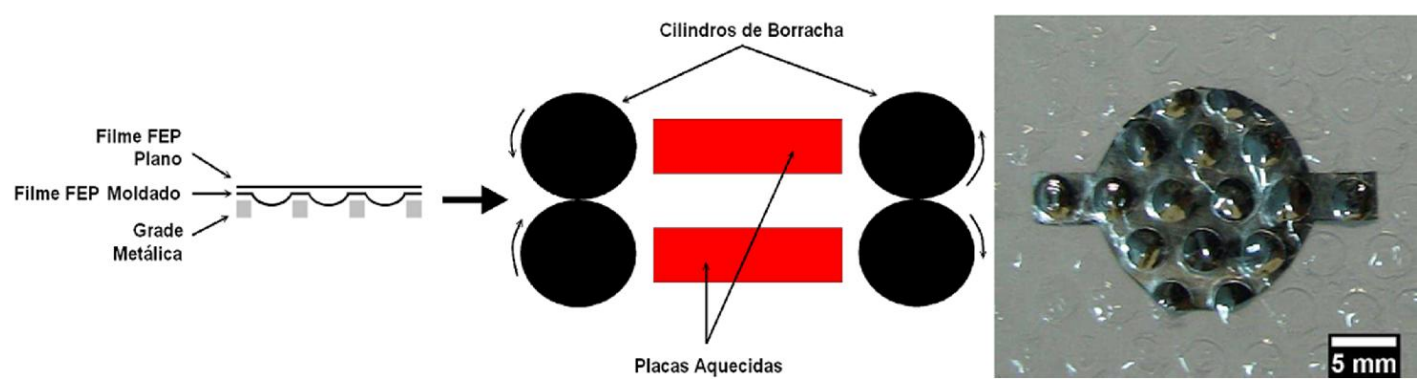

Figura 2.16 - Esquema laminação de filmes FEP, previamente moldado em domos (esquerda) e amostra moldada e metalizada (direita). (FALCONI et al., 2010).

Portanto, este método de moldagem propiciou um adequado controle do diâmetro, altura e distribuição das bolhas sobre a superfície das amostras. No entanto, nada ainda foi publicado sobre a estabilidade térmica dos dispositivos (FALCONI et al., 2010).

Em contrapartida às vantagens desse método é possível verificar na imagem à direita da Figura 2.16, que o procedimento de laminação produziu amostras com leves deformações nas bolhas.

Alternativamente, Falconi e colaboradores em 2011, desenvolveram outro método, no qual a colagem dos filmes com os domos pré-moldados é realizada com o emprego de um filme adesivo. Apesar das características antiaderentes do FEP, os filmes apresentaram ótima aderência, permitindo a produção de piezoeletretos com controle total dos parâmetros das bolhas (FALCONI et al., 2011). 


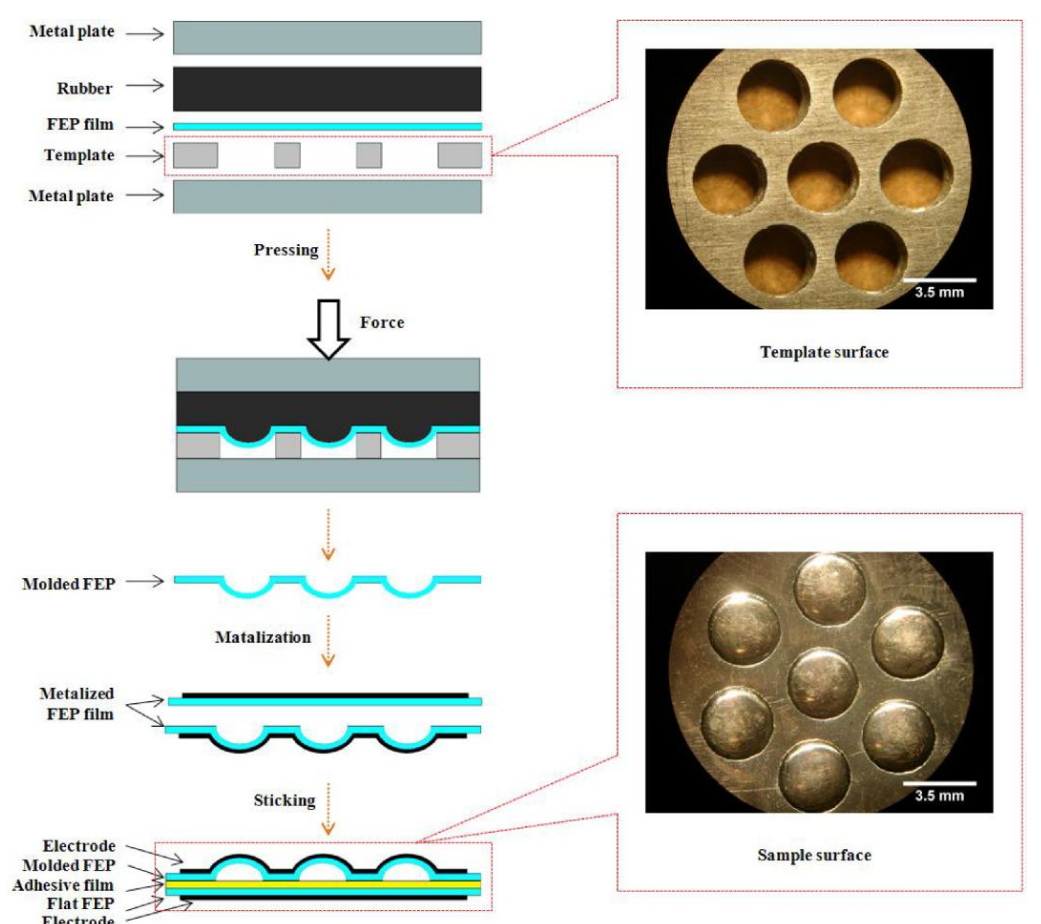

Figura 2.17 - Representação esquemática das camadas do piezoeletreto moldadas a frio (esquerda). À direita, imagens da template e da superfície da amostra. (FALCONI et al., 2011)

Esse novo procedimento de produção de piezoeletretos que não requer aquecimento adicional no empilhamento dos filmes, evidenciou, como pode ser visto nas imagens à direita da Figura 2.17, uma melhoria na uniformidade das cavidades da amostra quando comparadas as amostras do método anterior, (Figura 2.17 imagem à direita).

Essas amostras de piezoeletretos "a frio", após o devido carregamento elétrico, desempenharam um coeficiente $d_{33}$ de aproximadamente $70 \mathrm{pC} / \mathrm{N}$, com um decaimento de $23 \%$ deste valor após 15 horas do carregamento das amostras. A estabilidade térmica deste sensor também foi avaliada com exposição de 1 hora em diferentes temperaturas, onde sua piezoeletricidade se manteve estável em temperaturas até $80^{\circ} \mathrm{C}$ (FALCONI et al., 2011). 


\section{Capítulo 3}

\section{Conceitos Teóricos}

Neste capítulo serão descritos resumidamente os fundamentos teóricos dos temas envolvidos no desenvolvimento dessa pesquisa. A piezoeletricidade que descreve o fenômeno de funcionamento do elemento ativo do hidrofone protótipo e aplicação pretendida, que emprega a geração de imagens por vibroacustografia.

\subsection{Vibroacustografia}

O método de produção de imagens por VA, como já descrito no capítulo de revisão, necessita de uma fonte de US que imprima uma frequência $(\Delta f)$ em $\mathrm{kHz}$ para excitar o alvo de imagem, de maneira que a vibração na frequência desejada seja sensível ao hidrofone que realiza o mapeamento no plano de varredura. A modulação $(\Delta f)$ varia em torno de 30 a $100 \mathrm{kHz}$, conforme referência dos pesquisadores, e pode ser determinada antes mesmo da obtenção dos parâmetros viscoelásticos do material alvo (FATEMI; GREENLEAF, 1998). Outrora se sabe que a escolha pode muitas vezes não proporcionar um contraste adequado, devido a alguns fenômenos acústicos provenientes tanto das propriedades do material quanto do meio em que é feito o mapeamento (BAGGIO, 2011).

O som emitido por um objeto devido a uma excitação pela força de radiação ultrassônica está sujeito a fenômenos tais como, o espalhamento das ondas sonoras. Isso se agrava devido à diferença de impedância acústica e contribui significativamente na qualidade do sinal sonoro propagado entre meios diferentes, nestes casos, o espalhamento tem maior peso no contraste da imagem do que a resposta ressoante. Como melhoria a imagem pode ser adquirida em outras frequências diferentes das de ressonâncias do sistema.

Na prática, é comum a aquisição em várias frequências até que se obtenha a otimização da imagem, monitorando previamente a estabilidade dos sinais elétricos aquisitados. É importante ressaltar que nos experimentos cujo objetivo é destacar estruturas que apresentem diferença de impedância acústica elevada, uma frequência padrão deve ser 
adotada (normalmente na ressonância do hidrofone) para produzir imagens de boa qualidade.

Nos subitens abaixo serão abordadas as peculiaridades inerentes a fonte acústica e como ela trabalha para modular a as ondas de US em $\mathrm{kHz}$.

\subsubsection{A força de radiação dinâmica da VA}

Na propagação de uma onda ultrassônica por um meio qualquer, uma força de radiação é gerada quando se verifica uma alteração (por absorção, espalhamento ou reflexão) da densidade de energia no campo acústico incidente neste meio. Essa força é composta por uma componente oscilatória, resultante da pressão acústica variante no tempo, e outra componente estática, que desloca o meio na direção do gradiente de pressão.

A VA é uma modalidade de imagem que registra a resposta acústica de objetos excitados por uma força de radiação dinâmica e altamente localizada, gerada pela intersecção de ondas ultrassônicas. Esta força é produzida por mudanças na densidade de energia de um campo acústico incidente. A magnitude da força é proporcional à densidade de energia média da onda incidente $\langle E\rangle(\langle\rangle$ representa a média de tempo) e também à $S$ (área projetada do objeto) (FATEMI; GREENLEAF, 1999). Esta força é expressa por

$$
\boldsymbol{F}=\boldsymbol{d}_{\boldsymbol{r}} S\langle E\rangle
$$

$\boldsymbol{d}_{\boldsymbol{r}}$, é dado como o coeficiente de arrasto, que quantifica o arrasto ou a resistência da matéria em um meio fluído, logo influenciando nas propriedades de absorção e espalhamento em um dado objeto. Para uma onda plana, a densidade instantânea de energia é dada pela razão entre a energia acústica total e o volume ocupado pelo fluído, dada por

$$
E=\frac{p^{2}(t)}{\rho c^{2}}
$$

Em que $\boldsymbol{p}(\boldsymbol{t})$ representa pressão acústica total no plano focal, num tempo $\boldsymbol{t}, \boldsymbol{\rho}$ a densidade do meio de propagação e $\boldsymbol{c}$ a velocidade acústica da onda neste meio.

A força de radiação em baixa frequência pode ser produzida pela modulação de um único feixe ou pela combinação não linear de dois feixes de frequências ligeiramente diferentes. No trabalho de (CHEN et al., 2004) avaliou-se a formação de ondas em baixa frequência fazendo uso de transdutores confocal e X-focal, além da Modulação em Amplitude. Nesse trabalho, optou-se por utilizar o transdutor do tipo confocal, pois a imagem de 
VA utilizando esse tipo de transdutor oferece uma maior resolução em relação ao X-focal ou a modo AM, sendo essa resolução limitada à região de intersecção entre as duas ondas convergidas.

A fonte de US confocal é composta por uma cerâmica no formato de disco na parte central (com raio a1) e outra cerâmica anelar na parte externa (com raio interno a21 e raio externo a2). O conjunto é excitado separadamente, gerando dois feixes ultrassônicos coaxiais no mesmo ponto focal. O esquema construtivo desse transdutor é ilustrado na Figura 3.1 .

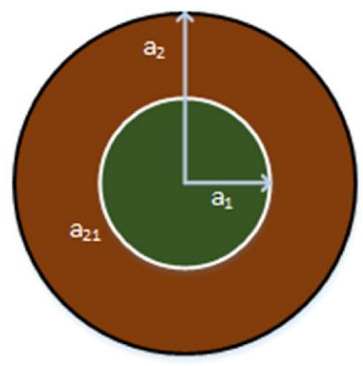

a) Elementos cerâmicos do transdutor confocal

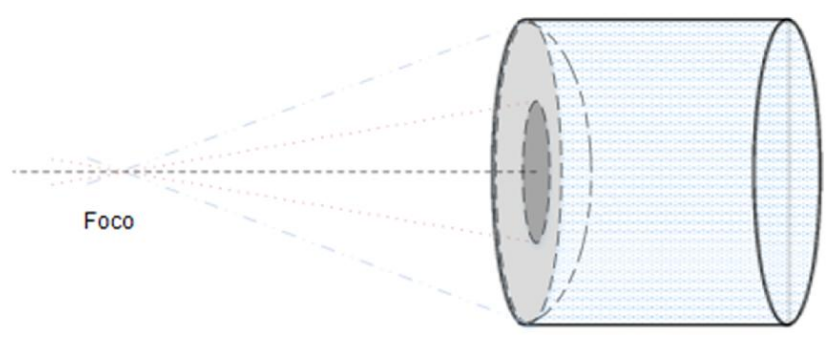

b) Transdutor confocal

Figura 3.1 - Transdutor confocal: a) disposição das cerâmica e b) esquema gráfico do feixe acústico. Adaptado de (BAGGIO, 2011).

O feixe acústico da cerâmica central tem frequência definida pela equação $\left(f_{1}=f_{0}+\Delta\right.$ $f / 2)$, enquanto que a em anel $\left(f_{2}=f_{0}-\Delta f / 2\right)$. Os termos $f_{0}$ e $\Delta f$ representam as frequências de ressonância do PZT e frequência final do feixe. A combinação não linear de frequências, fenômeno observado na VA é descrito pelo cálculo das pressões envolvidas $p_{1}(\boldsymbol{r}$; $\left.f_{1}\right)$ e $p_{2}\left(\boldsymbol{r} ; f_{2}\right)$, no mesmo plano, e uma distância $\boldsymbol{r}$ para as duas fontes de ondas de frequências $f_{1}$ e $f_{2}$ (CHEN et al., 2004). A resposta de baixa frequência ( $\Delta f$ ) é incidida sobre o alvo e a resposta da oscilação deste é captada por um hidrofone acoplado ao sistema, como foi visto na Figura 2.2.

O campo de pressão resultante no plano axial $z=0$ pode ser escrito como:

$$
p(t)=P_{1}(r) \cos \left[f_{1} t+\theta_{1}(r)\right]+P_{2}(r) \cos \left[f_{2} t+\theta_{2}(r)\right]
$$

Sendo $\theta_{1}$ e $\theta_{2}$ as funções de fase das ondas de frequências $f_{1}$ e $f_{2}$, respectivamente. As amplitudes são dadas por 


$$
P_{1}(r)=\rho c u_{01}\left(\frac{\pi a_{1}^{2}}{\lambda_{1} z_{0}}\right) \text { jinc }\left(\frac{r a_{1}}{\lambda_{1} D^{\prime}}\right)
$$

e

$$
P_{2}(r)=\rho c u_{02}\left(\frac{\pi}{\lambda_{2} D}\right)\left[a_{22}^{2} j i n c\left(\frac{r a_{22}}{\lambda_{2} D}\right)-a_{21}^{2} j i n c\left(\frac{r a_{21}}{\lambda_{2} D}\right)\right]
$$

Sendo o comprimento de onda dado por $\lambda_{i}=2 \pi c / \omega_{i} \operatorname{com} i=1,2 ; u_{01}$ e $u_{02}$ são a amplitude da velocidade da partícula na superfície dos elementos 1 e 2 , respectivamente, do transdutor. $j i n c(X)=J_{1}(2 \Pi X / \Pi X)$, com $J_{1}($.) representa a função de Bessel cilíndrica de primeira ordem.

A medida temporal de $p^{2}(t)$ é:

$$
\left\langle p^{2}(t)\right\rangle_{T}=\frac{P_{1}^{2}+P_{2}^{2}}{2}+p_{1} p_{2} \cos \left(\Delta f+\theta_{1}-\theta_{2}\right)
$$

Logo a força resultante no foco é dada por:

$$
F=\frac{d_{r} S}{\rho c^{2}}\left\{\frac{P_{1}^{2}(r)}{2}+\frac{P_{2}^{2}(r)}{2}+P_{1}(r) P_{2}(r) \cos \left[\left(f_{2}-f_{1}\right) t+\left(\theta_{2}(r)-\theta_{1}(r)\right)\right]\right\}
$$

E a componente dinâmica da força no foco representada por

$$
F_{d}=\frac{d_{r} S}{\rho c^{2}}\left\{P_{1}(r) P_{2}(r) \cos \left[\Delta f t+\left[\theta_{2}(r)-\theta_{1}(r)\right]\right]\right\}
$$

Em que $\Delta f$ é a diferença entre as frequências $f_{1}$ e $f_{2}$ (CHEN et al., 2004).

\subsection{Piezoeletricidade}

A piezoeletricidade ou efeito piezoelétrico corresponde à geração de uma polarização elétrica mediante a aplicação de uma tensão mecânica sobre um corpo, sendo que o sinal elétrico é proporcional à deformação material. Esse fenômeno denomina-se efeito piezoelétrico direto. $\mathrm{O}$ efeito inverso também ocorre, e aparece quando uma deformação mecânica é provocada após submeter o material a um campo elétrico.

Durante a atividade piezoelétrica de um material as propriedades elásticas e elétricas estão associadas, assim, os parâmetros elétricos e mecânicos devem estar relacionados nas equações constitutivas. A densidade de fluxo elétrico, ou deslocamento elétrico $(D)$ e campo elétrico $(E)$ representam as grandezas elétricas, enquanto a tensão mecânica 
$(X)$ e a deformação mecânica $(x)$ denotam as grandezas mecânicas (GALLEGO-JUAREZ, 1989).

A relação dos parâmetros elétricos para um material não-piezoelétrico, não submetido a tensões mecânicas e sob a influência de um campo elétrico pode ser expresso por:

$$
D=\varepsilon E \quad\left[C / m^{2}\right]
$$

Sendo $\varepsilon$ compreende a permissividade elétrica do meio.

Se ao mesmo material anterior for aplicada uma tensão mecânica $(X)$ dada em diferente de zero e, submetido a um campo elétrico nulo, ocorre uma deformação $(x)$ dada por:

$$
x=s X
$$

Em que $s$ em $\left(m^{2} / N\right)$ representa a constante de tendência elástica do material avaliado.

Para a avaliação de um meio piezoelétrico, a interação entre as variáveis elétrica e mecânica pode ser descrita por uma relação linear na forma:

$$
\begin{aligned}
& D=d X+\varepsilon^{T} E \\
& x=s^{E} X+d E
\end{aligned}
$$

A primeira equação descreve o efeito piezoelétrico direto e a segunda o efeito inverso. A grandeza simbolizada por d representa a constante de carga piezoelétrica, ou simplesmente, coeficiente piezoelétrico. Na Equação 3.13 a primeira expressão denota o efeito direto para um transdutor (sensor) e a segunda o efeito inverso (atuador) (BERLINCOURT; CURRAN; JAFFE, 1964).

$$
d_{i j}=\left(\frac{\partial D_{i}}{\partial X_{j}}\right)_{T, E}=\left(\frac{\partial x_{j}}{\partial E_{i}}\right)_{X, T}
$$

O coeficiente piezoelétrico $\left(d_{i j}\right)$, representa a polarização elétrica gerada por unidade de tensão mecânica $(X)$ aplicada ao material piezoelétrico e, inversamente, é a deformação mecânica $(x)$ experimentada por um material piezoelétrico, por unidade de campo eléctrico aplicado. As unidades de $d$ são $(\mathrm{C} / \mathrm{N})$ e $(\mathrm{m} / \mathrm{V})$, respectivamente para o efeito piezoelétrico direto e inverso. 
Os subscritos discriminados na constante piezoelétrica $\left(d_{i j}\right)$ servem como orientação da conversão eletromecânica, em que o primeiro subscrito (i) indica a direção da polarização do material quando o campo elétrico externo é igual à zero, e o segundo índice (j) indica o sentido da excitação externa aplicada (APC INTERNATIONAL, 2012). A Figura 3.2(a) mostra as coordenadas dessa orientação e os números que representam essas direções.

a)

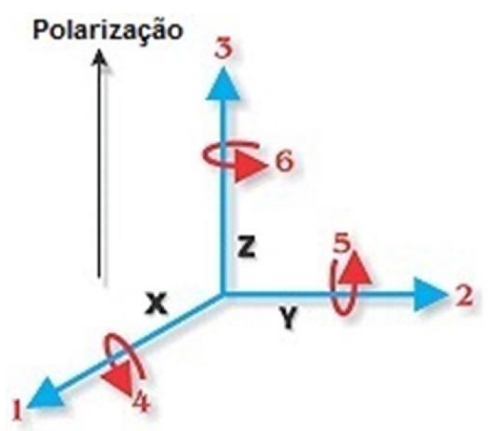

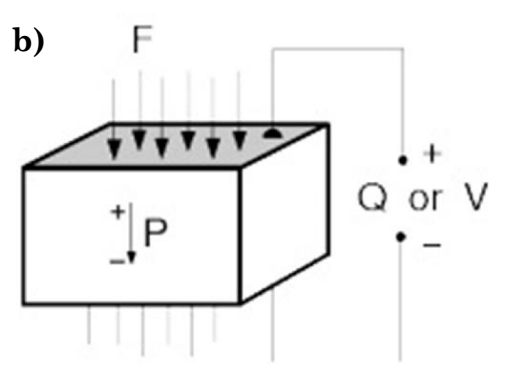

Figura 3.2 - (a) Coordenadas de orientação da aplicação da tensão mecânica e polarização em um material piezoelétrico. (b) Modo espessura.

Em material piezoelétrico a direção de polarização positiva geralmente é feita de modo a coincidir com o eixo $\mathrm{Z}$ do sistema retangular de $\mathrm{X}, \mathrm{Y}$, e Z, conforme Figura 3.2. As direções X, Y e Z cujos subscritos são respectivamente 1, 2 ou 3, correspondem às direções normais ao corpo. Enquanto que as direções de cisalhamento, sobre cada um desses eixos do sistema, são dadas pelos subscritos 4,5 ou 6 , respectivamente.

A polarização dos piezoeletretos ocorre preferencialmente sempre no sentido do campo elétrico aplicado (Figura 3.2b), o que não ocorre nos cristais, nas cerâmicas e nem nos polímeros polares, por possuírem várias geometrias e ângulos de polarização (ALTAFIM, 2006). Com isso, nas aplicações com estes materiais exploram-se aplicações em que a força externa aplicada seja nesta mesma direção, onde as características piezoelétricas são mais fortes. Esse modo de excitação, ou vibração, é conhecido como modo em espessura caracterizado pela simbologia $d_{33}$, do inglês, thickness mode.

\subsubsection{Parâmetros dielétricos e eletromecânicos}

Além da teoria de polarização e indução de cargas elétricas em materiais dielétricos, o estudo de transdutores envolve ainda importantes atributos que influenciam diretamente no desempenho de transdutores piezoelétricos. Esses parâmetros foram contextu- 
alizados no capítulo de revisão bibliográfica e encontram-se resumidamente conceituados na Tabela 3.1.

Tabela 3.1 - Resumo dos principais parâmetros dielétricos e eletromecânicos envolvidos no estudo e desenvolvimento de transdutores piezoelétricos (BASSI, 2012; SHERMAN; BUTLER, 2007; ZHANG; YU, 2011).

\begin{tabular}{c}
\hline Entidade \\
\hline TEMPERATURA \\
OU PONTO DE \\
CURIE \\
\\
PERMISSIVIDADE \\
DIELÉTRICA
\end{tabular}

$$
D=\varepsilon E
$$

Sendo $D$ é o vetor deslocamento elétrico medido em $C / m^{2}, \varepsilon_{i j}$ é a permissividade dielétrica em $F / m$, e $E$ é o vetor campo elétrico em $V / m$.

$$
g=\frac{d}{\varepsilon_{r} \varepsilon_{0}}
$$

PIEZOELÉTRICOS:

CARGa E TENSÃo

O coeficiente de carga $(d)$ é dado em $p C / N$ e o de tensão (g) e $V \cdot m / N$.
Definição

Temperatura, acima da qual, o cristal passa de uma fase não-simétrica (piezoelétrica) para fase de simetria paraelétrica, onde toda a atividade piezoelétrica desaparece. As propriedades piezoelétricas de um material são fortemente influenciadas pela estabilidade térmica dos domínios ferroelétricos. Os dipolos têm uma tendência de voltar para uma orientação aleatória como o aumento de temperatura, deste modo degradando o efeito piezoelétrico em um processo conhecido como "envelhecimento térmico". Geralmente, a máxima temperatura de operação muito abaixo de $\mathrm{T}_{\mathrm{C}}$ é considerada segura, minimizando o efeito de envelhecimento.

A permissividade dielétrica relativa $\varepsilon_{r}$ é a medida da habilidade do material para armazenar cargas elétricas. Em sólidos inorgânicos simples, os dois mecanismos mais importantes que contribuem para a permissividade dielétrica são as polarizações iônica e eletrônica, enquanto que para ferroelétricos dielétricos, o mecanismo de polarização envolve contribuições extrínsecas a partir da rotação dos dipolos e do movimento dos domínios ferroelétricos. Para sensores, uma alta permissividade dielétrica ou capacitância é desejada para superar as perdas associadas com o circuito elétrico. Uma alta permissividade, entretanto, resulta em um reduzido coeficiente de tensão ou sensibilidade piezoelétrica.

O coeficiente piezoelétrico de carga $d$ fornece à carga elétrica induzida na área do eletrodo, em resposta a tensão mecânica aplicada no transdutor. Ou inversamente, a deformação exibida no material piezoelétrico, proporcional ao campo elétrico aplicado nos eletrodos.

$\mathrm{O}$ coeficiente de tensão piezoelétrica $g$ traz a relação do campo elétrico desenvolvido pela pressão aplicada e, inversamente, a relação da deformação elástica pela carga aplicada na área do eletrodo.

A sensibilidade do transdutor precisa ser suficientemente alta de modo que o sinal gerado tenha amplitude maior que o ruído de fundo (background noise). Na prática, o sinal gerado 
FATOR DE ACO-

PLAMENTO ELETROMECÂNICO

FATOR DE DISSIPAÇÃO DIELÉTRI$\mathrm{CA}(\mathrm{FD})$

FATOR DE QUALIDADE MECÂNICO

FATOR DE QUALIDADE MECÂNICO

RESISTIVIDADE E Constante DE TEMPO RC

$$
k^{2}=\frac{U_{m}}{U_{m}+U_{0}}
$$

Sendo $U_{0}$ a energia armazenada não convertida em deslocamento mecânico; $U_{m}$ é a parcela da total energia elétrica de entrada, armazenada na forma mecânica.
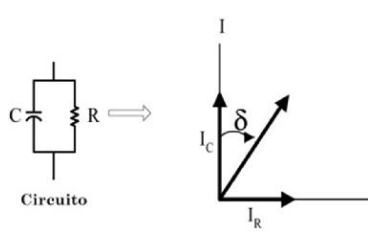

$$
\begin{gathered}
F D=\tan \delta=\frac{I_{R}}{I_{C}} \\
Q_{M}=\frac{f_{r}}{f_{2}-f_{1}}
\end{gathered}
$$

Sendo $f_{r}$ a frequência de ressonância, $f_{1}$ e $f_{2}$ são frequências em -3dB da máxima admitância. Essa diferença pode representar também a largura de banda do transdutor.

$$
Q_{M}=\left(2 \pi f_{r} C_{f} k^{2} Z_{\text {min }}\right)^{-1}
$$
Em que $C_{f}$ é capacitância da amostra livre e $Z_{\min }$ a impedância na frequência de ressonância.

$$
f_{L L}=\frac{\pi R C}{2}
$$

Com $R$ e $C$, representando a resistência de isolação e a capacitância da amostra, respectivamente.
O fator $Q_{M}$ relacionado ao fator de acoplamento eletromecânico $(k)$.

Define-se também pela relação de reatância

é pequeno e tem de ser melhorado por um amplificador de carga ou tensão apropriado. $\mathrm{O}$ coeficiente $g$ é relacionado ao coeficiente $d$ através da permissividade dielétrica.

O fator de acoplamento ( $k$ ) é uma medida do alcance do efeito piezoelétrico (não um fator de eficiência). Ele descreve a capacidade de um material piezoelétrico em converter a energia elétrica em energia mecânica, e vice-versa. $\mathrm{O}$ fator de acoplamento é determinado pela raiz quadrada da relação de energia mecânica armazenada relacionada à energia total absorvida. Em ressonância, $k$ é uma função da forma de oscilação do corpo piezoelétrico.

Um sistema de isolamento ideal, basicamente compreende um dielétrico disposto entre eletrodos, apresentando características puramente capacitivas. Em um material real, por sua vez, existem perdas por condução. Essas perdas podem ser modeladas por resistências elétricas, em série ou paralelo ao capacitor ideal, o que irá alterar o ângulo de fase capacitivo.

O fator de qualidade mecânico $\left(Q_{M}\right)$ caracteriza a "nitidez de ressonância" de um corpo piezoelétrico, ou seja, a capacidade do material de ressoar em determinadas impedâncias. É determinado, principalmente, a partir da largura de banda em - $3 \mathrm{~dB}$ da ressonância série, na qual o sistema é capaz de oscilar.

com a resistência do elemento ativo, no circuito em série equivalente de representação do transdutor.

A alta resistividade em materiais ferroelétricos é muitas vezes desejada na polarização do material, quando um campo elétrico suficientemente alto deve ser aplicado na orientação dos domínios, sem a ocorrência de breakdown ou fuga excessiva de carga. Uma alta resistênoperação do dispositivo, para manter a carga por um tempo suficiente, para o sinal ser detectado por um sistema eletrônico de medição. cia de isolação é também exigida durante a 
MÓDULO DE

ELASTICIDADE

OU YOUNG

RESSONÂNCIA

PIEZOELÉTRICA

Sendo $l$ o comprimento, $\rho$ a densidade e $Y$ o Módulo de elasticidade.

Em que a tensão aplicada sobre uma seção do material é dada em $N / m^{2}$ e, a deformação é admensional. Logo, $Y$ é dado em Pascal ou $\mathrm{N} / \mathrm{m}^{2}$.

$$
f_{r}=\left[2 l\left(\rho \frac{1}{Y}\right)^{1 / 2}\right]^{-1}
$$

O tempo de carga preservada (mantida) é proporcional a constante de tempo $R C$. A mínima frequência útil de um sensor, conhecida como limiar inferior de frequência $\left(f_{L L}\right)$, é inversamente proporcional a constante de tempo.

$$
Y=\frac{\text { tensão }}{\text { deformação }}=\frac{F / A}{\Delta \mathrm{L} / L}
$$

O Módulo de Young (Y) é um indicador da elasticidade de um material isotrópico. É definida como a razão entre a tensão ao longo de um eixo sobre a deformação ao longo desse eixo, na gama de tensão em que a Lei de Hooke detém.

Quando um campo elétrico arbitrário é aplicado, o elemento piezoelétrico pode ser excitado para produzir ressonâncias mecânicas com frequências que estão relacionadas com sua geometria, densidade e constantes elásticas. $\mathrm{Na}$ frequência de ressonância, a impedância do elemento é mínima, então, alta corrente é alcançada em baixa tensão de excitação, enquanto que na frequência de antirressonância, a admitância é mínima, causando uma condição de alta tensão e baixa corrente de excitação.

Na contextualização dos parâmetros piezoelétricos acima, observou-se que suas definições estão intimamente relacionadas com a orientação dos domínios ferroelétricos de um material dielétrico. Assim, a ferroeletricidade será mais bem conceituada no próximo item.

\subsubsection{Ferroeletricidade}

A ferroeletricidade em analogia ao ferromagnetismo evidencia-se durante a orientação dos dipolos elétricos de um cristal polar, no qual a direção destes domínios elétricos pode ser posteriormente modificada pela aplicação de um campo elétrico externo, suficientemente alto. Desta forma, nos materiais ferroelétricos são caraterísticos por apresentar uma polarização espontânea em que o vetor polarização pode ser reorientado, mediante a ação de um campo elétrico externo. Em contrapartida, a polarização elétrica nos materiais dielétricos, isso não acontece, pois a polarização é linearmente dependente do campo elétrico aplicado (GALLEGO-JUAREZ, 1989). O comportamento da curva de histerese ferroelétrica permite traçar a polarização em função do campo elétrico mostrando 
a dependência não linear entre a estes parâmetros, evidenciando um importante critério de análise da ferroeletricidade.

Todos os materiais com ferroeletricidade são também piezo e piroelétricos, embora o contrário não seja sempre verdade. Os materiais piroelétricos compreendem um grupo de materiais cristalinos polares que dispõem de uma polarização espontânea numa determinada faixa de temperatura. Nesse fenômeno os momentos de dipolo tendem a se alinhar mesmo na ausência de um campo elétrico, em resposta a uma excitação térmica. Como descrito anteriormente, o comportamento do efeito piezoelétrico é análogo a este, mas ao invés de térmica, a excitação é mecânica (GALLEGO-JUAREZ, 1989). Em geral, os materiais ferroelétricos possuem alta constante dielétrica e alto ponto de Curie (temperatura sobre a qual deixam de exibir uma polarização espontânea).

Nos polímeros, os coeficientes piezo e piroelétricos podem ser definidos pela Equação 3.14 genérica, expressa como (BERLINCOURT; CURRAN; JAFFE, 1964):

$$
\xi=\frac{1}{A}\left(\frac{\partial Q}{\partial \Xi}\right)
$$

Em que $\zeta$ representa tanto o coeficiente piezoelétrico quanto o piroelétrico, $\mathbb{E}$ é dado como a pressão $p$ ou a temperatura $T$, respectivamente para os efeitos. $A$ e $Q$ simbolizam a área do eletrodo do elemento e a densidades de cargas medidas no eletrodo, respectivamente.

Por muito tempo foi aceito que ferroeletricidade era vista apenas em materiais de natureza polar. Tal pensamento passou a ser desmistificado quando polímeros completamente não polares, quando submetidos a um intenso campo elétrico exibiam certa habilidade de aprisionar cargas em cavidades gasosas existe em sua estrutura. Nesse arranjo as cargas com polaridade diferente ficariam em superfícies opostas, assemelhando-se a macro-dipolos elétricos. Este fenômeno, combinado com as propriedades elásticas de alguns materiais poliméricos, produzia os efeitos piro e piezoelétrico (QIU, 2010).

Estes materiais polarizados foram denominados por ferroeletretos, em razão dessa polarização macroscópica e pelas propriedades fenomenologicamente parecidas com o comportamento observado nos materiais tipicamente ferroelétricos. Os aspectos pouco usuais da polarização dos ferroeletretos têm atraído cada vez mais as atenções científicas e industriais. 


\section{Capítulo 4}

\section{Materiais e Métodos}

Neste capítulo, os sensores piezoelétricos poliméricos, baseados na tecnologia dos piezoeletretos termoformados, são propostos para a construção de transdutores hidroacústicos voltados para aplicações ultrassônicas na faixa de $\mathrm{kHz}$. Seguida à etapa de projeto $\mathrm{e}$ construção do dispositivo, o foco passa a ser a execução de testes comparativos com um hidrofone comercial, mantido como padrão de calibração, para obter a curva de sensibilidade do transdutor em estudo.

Por conveniência, o hidrofone, cujo desenvolvimento é abordado neste trabalho, passa a ser referido pela sigla TRU-1 (transdutor ultrassônico protótipo 1). Em decorrência de resultados promissores, uma primeira aplicação do TRU-1 para diagnósticos médicos, em especial, a de imagens vibroacústicas, também, foi proposta e encontra-se mais bemdescrita nos tópicos subsequentes.

\subsection{Descrição do projeto do protótipo TRU-1}

A etapa inicial deste trabalho concentrou-se no desenvolvimento do primeiro protótipo do transdutor, que compreende resumidamente um invólucro ou encapsulamento metálico, circuito eletrônico de pré-amplificação para o sinal gerado pelo elemento sensor, todo o substrato necessário para acomodar o filme de piezoeletreto e uma conexão de saída para a aquisição dos dados. O desenho integral do primeiro protótipo foi efetuado com auxílio do software Inventor Professional ${ }^{\mathrm{TM}} 2012$ da Autodesk (versão acadêmica) e encontra-se ilustrado na Figura 4.1. Nota-se que o corpo desse protótipo é formado por peças em alumínio (encapsulamento, eletrodos e conector) e náilon (material de retaguarda). Um dos principais focos do projeto foi a vedação e inúmeros testes foram efetuados com a imersão do protótipo em tanques e água. A característica relevante deste protótipo foi ter deixado o elemento sensor diretamente exposto ao meio acústico, neste caso, a água, o que evita, nesta fase, outros materiais para o casamento de impedância acústica. 


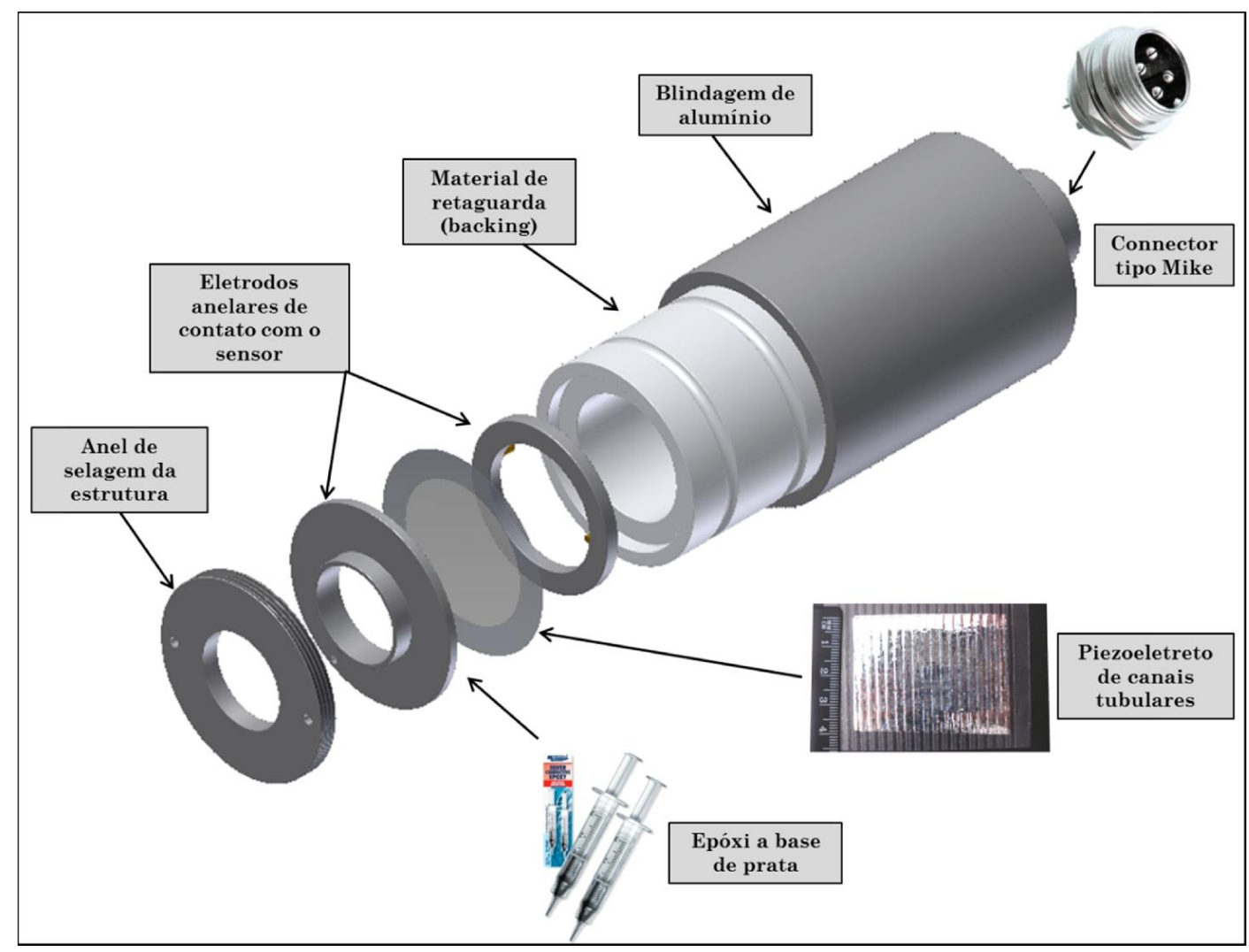

Figura 4.1 - Projeto do hidrofone proposto no trabalho.

O encapsulamento do equipamento, além de acomodar o sensor piezoelétrico, os eletrodos metálicos e a placa do circuito pré-amplificador, ainda, é responsável pela blindagem elétrica do dispositivo. A saída do sinal elétrico, proporcional ao campo acústico, fazse por um conector do tipo Mike de quatro vias, posicionado na extremidade posterior da carcaça. As demais vias do conector também são responsáveis pela alimentação do circuito eletrônico. Complementa o TRU-1 outro compartimento metálico, responsável por alojar a alimentação do pré-amplificador e fazer a interface Mike (conexão utilizada no TRU-1) e BNC (conexão padrão aos equipamentos elétricos de laboratório).

O primeiro protótipo foi construído seguindo o diagrama esquemático da Figura 4.1 e pode ser visto com maiores detalhes na Figura 4.2 . 


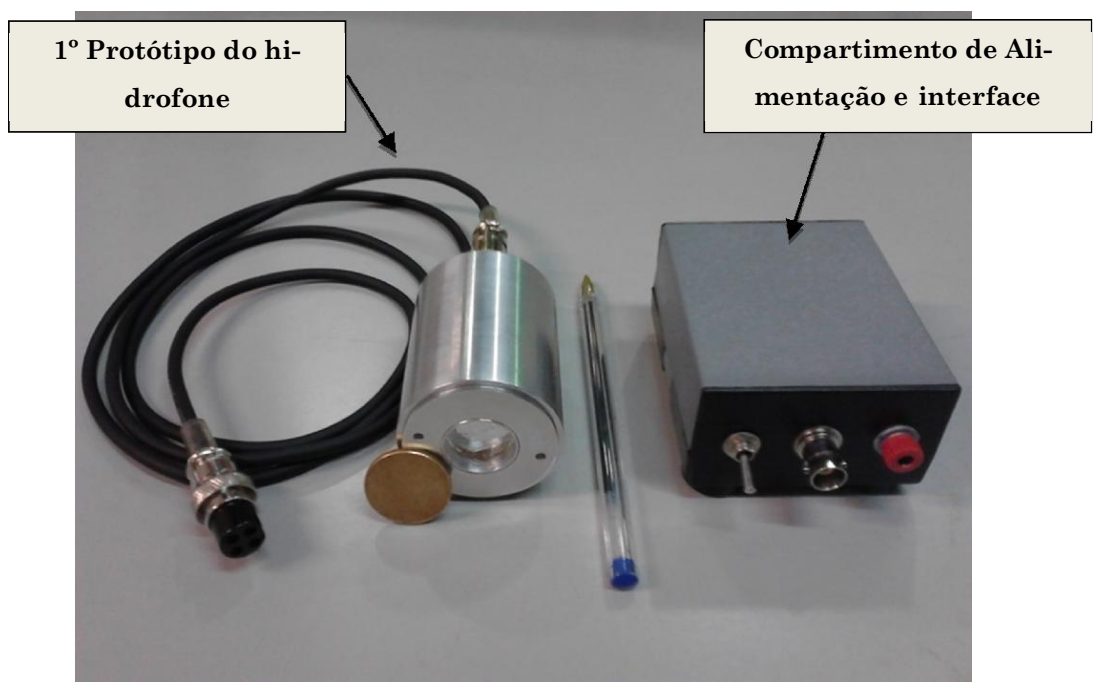

Figura 4.2 - Primeiro protótipo do hidrofone e o compartimento de interface e baterias.

\subsubsection{Elemento sensor}

O elemento piezoelétrico ativo que compõe o TRU-1 é resultante da tecnologia dos piezoeletretos termoformados, conforme proposto (ALTAFIM et al., 2009) e já descrito no Capítulo 2. A escolha por este filme eletroacústico foi motivada principalmente por desempenhar uma atividade piezoelétrica de $160 \mathrm{pC} / \mathrm{N}$, superior a muitos outros piezopolímeros utilizados em transdutores ultrassônicos, dispor de uma estabilidade térmica em torno de $130^{\circ} \mathrm{C}$ e pela grande viabilidade de ser um produto com tecnologia nacional.

Além dessas vantagens, ressaltam-se outros fatores, tais como construção laboratorial ou industrial em larga escala; conformação em diferentes geometrias, inclusive em grandes áreas; e o controle da uniformidade das cavidades internas da estrutura polimérica. Esta característica permite, também, controlar as frequências de ressonância do sensor.

É importante destacar que, na incidência de ondas acústicas, o sensor baseado na tecnologia dos eletretos termoformados apresenta características piezoelétricas mais eficientes em seu modo de vibração longitudinal e, por esta razão, a atividade de caracterização do equipamento explora a incidência de ondas neste modo de vibração, dada por coeficientes piezoelétricos $\left(d_{33}\right)$.

O piezoeletreto empregado como elemento transdutor do TRU-1 exibe uma seção circular de $21 \mathrm{~mm}$ de diâmetro, em que cerca de $346 \mathrm{~mm}^{2}$ da área em cada superfície são metalizados pela vaporização de alumínio, o que constitui uma camada com cerca de 40nm de espessura. Após a metalização, as amostras foram polarizadas utilizando a téc- 
nica de carregamento por contato elétrico direto, com tensão positiva, submetidas a uma tensão DC de 2,7kV por 20 segundos. Exemplos das amostras são apresentados na Figura 4.3.
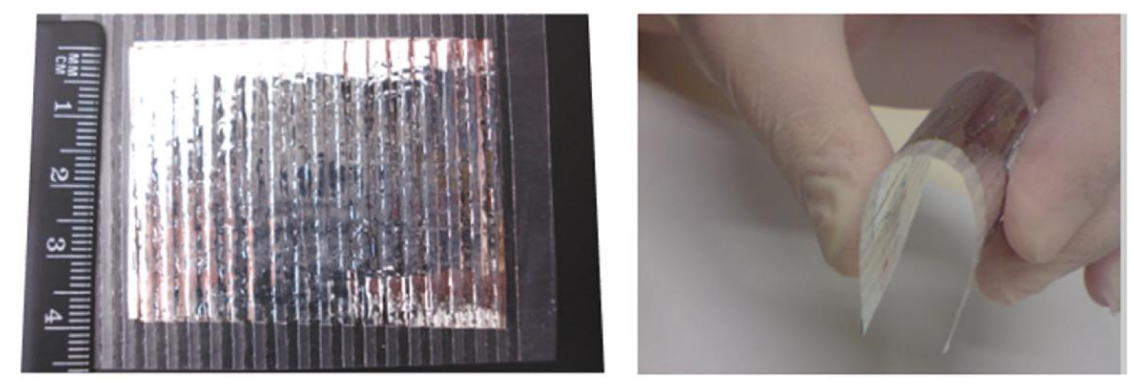

Figura 4.3 - Amostra das medidas e flexibilidade do elemento sensor polimérico do hidrofone.

$\mathrm{Na}$ montagem do equipamento, o filme de eletreto já orientado eletricamente foi depositado diretamente sobre a camada de retaguarda, composta pelo backing e um eletrodo de alumínio, sem a utilização de alguma camada de adesão. A área ativa do sensor, exposta ao meio acústico, com o equipamento montado, compreende uma seção circular com $20 \mathrm{~mm}$ de diâmetro. A fim de prevenir infiltrações no elemento ativo, uma vez que o piezoeletreto se encontra em contato direto com a água, foi adicionada uma camada de vedação, construída com epóxi condutivo de prata (MG Chemicals, modelo 8331) entre o elemento sensitivo e o eletrodo de contato superior, conforme detalhado na Figura 4.1.

\subsubsection{Material de retaguarda}

O material de retaguarda (backing) compreende a camada subjacente ao elemento piezoelétrico e é responsável pelo amortecimento da vibração do filme eletromecânico, o que impede reflexões na parte de trás do elemento ativo, e, consequentemente, evita gerar interferência no sinal de recepção do transdutor. Logo, durante a construção do dispositivo ultrassônico, a seleção de um material de retaguarda adequado para o filme eletromecânico polimérico demanda minuciosas considerações que podem influenciar diretamente em parâmetros tais como faixa de frequências úteis de operação, perdas por inserção e ambiente de operação.

Em geral, os requisitos acústicos para um material de retaguarda do tipo não refletivo, isto é, absorvedor são: a) apresentar uma impedância acústica próxima a do polímero piezoelétrico ativo; e b) a atenuação acústica deve ser suficiente para impedir indeseja- 
das reverberações ${ }^{11}$ acústicas (ou seja, reflexões na superfície da camada de retaguarda). Outros requisitos importantes para esta camada incluem: i) possuir capacidade de aderir adequadamente ao material piezoelétrico; e ii) disponibilidade comercial em substratos de forma suficientemente espessa e apresentar uma alta qualidade de superfície (por exemplo, polido) (BROWN, 2000).

Como camada de retaguarda do TRU-1, utilizou-se uma peça cilíndrica, ilustrada na Figura 4.4. Ela foi confeccionado em nylon $\left(Z_{\text {nailon }}=2.0 \sim 2.3\right.$ MRayl), com geometria cilíndrica e com uma cavidade concêntrica de ar na superfície inferior adjacente ao sensor. A escolha desse formato de backing layer foi favorecida pela equivalência de impedância acústica entre o ar $\left(\mathrm{Z}_{\mathrm{ar}}=0.00042 \mathrm{MRayl}\right)$ e o piezoeletreto $\left(\mathrm{Z}_{\text {eletreto }}=0.0028 \sim 0.00040\right.$ MRayl) (BOVTUN et al., 2007).
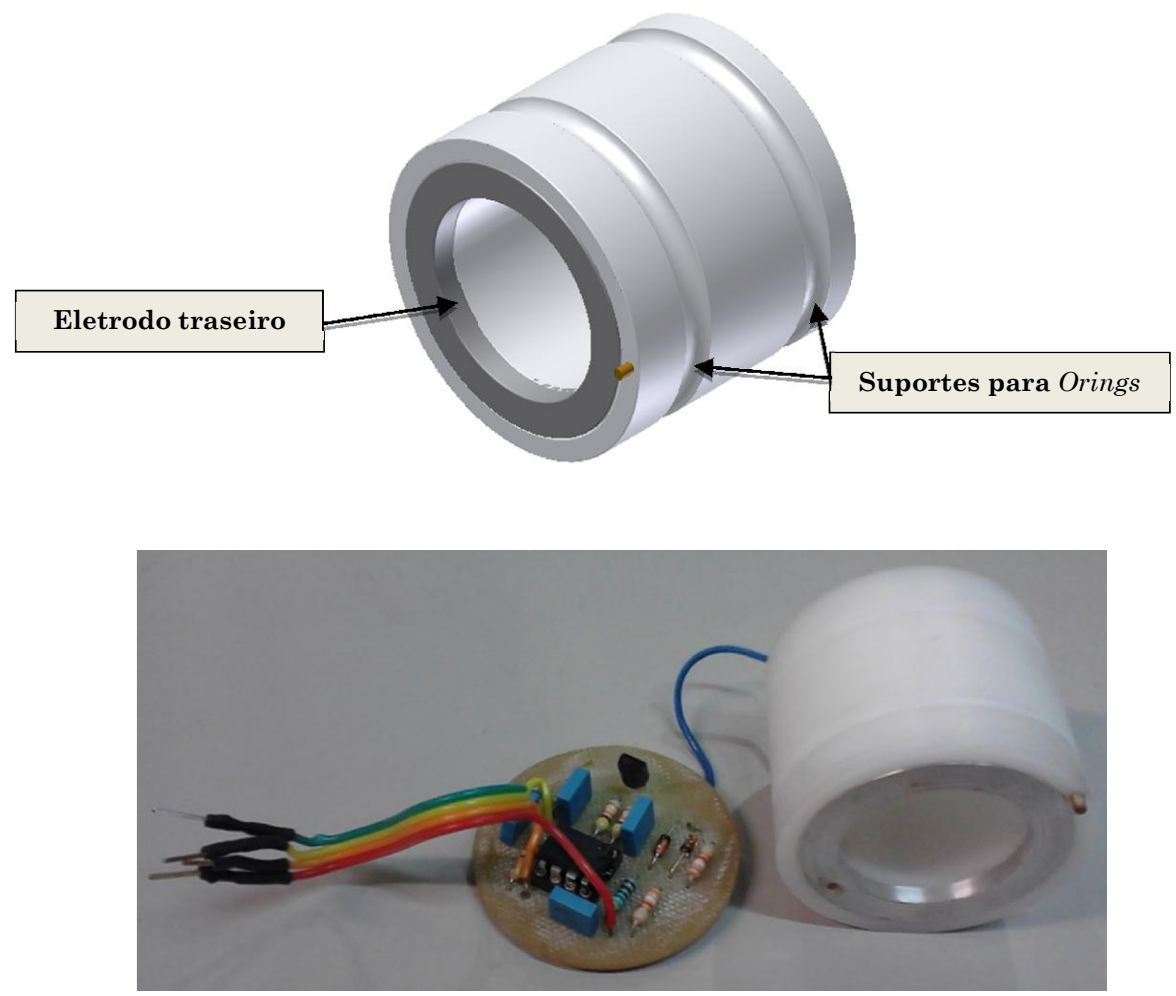

Figura 4.4 - Material de retaguarda. Imagem de projeto (superior) e real com o circuito eletrônico (inferior).

$\mathrm{Na}$ superfície lateral foram fresadas cavidades ao longo da circunferência do corpo cilíndrico para alojar dois anéis de vedação (orings) a fim de evitar uma possível entrada de água que fosse prejudicial ao circuito eletrônico situado abaixo desta peça.

${ }^{11}$ Fenômeno resultante de múltiplas reflexões em um ambiente, provocando um campo acústico remanescente mesmo após a fonte cessar o sinal inicial. 
É possível visualizar, ainda na Figura 4.4, o eletrodo que faz contato com a superfície inferior do filme piezoelétrico. Ele consiste em uma camada de alumínio usinado $\left(Z_{a}=\right.$ 17,3 MRayls) incrustada no corpo de náilon, com diâmetro interno de $26 \mathrm{~mm}$ e espessura de $4 \mathrm{~mm}$.

\subsubsection{Circuito de pré-amplificação}

A construção do circuito pré-amplificador utilizado no TRU-1 foi baseada na operação de um amplificador de instrumentação modelo INA129P. A escolha por esse circuito integrado (CI) se fez principalmente por suas características de baixo ruído $\left(10 \mathrm{nV} /(\mathrm{Hz})^{1 / 2}\right)$ e uma resposta em frequência "plana" (amplificação constante) até 500kHz. Essa informação é válida quando o ganho configurado para o CI é igual a 10x o sinal de entrada (TEXAS INSTRUMENTS INCORPORATED, 2005).

$\mathrm{Na}$ topologia desse circuito eletrônico um primeiro estágio de controle do sinal foi implementado para propiciar um melhor casamento de impedância entre a amostra piezoelétrica e a entrada do INA. Esse estágio consistiu de um arranjo em torno de um transistor de efeito de campo N-FET BF245A, configurado em auto-polarização. O FET permitiu ainda uma amplificação de aproximadamente 1,6 vezes o sinal de entrada, proveniente do sensor eletromecânico. Outra vantagem dessa topologia com o FET, foi a possibilidade de transformar a saída num sinal diferencial necessário ao INA.

O circuito completo, considerando os dois estágios eletrônicos de amplificação, exibiu um ganho final de $24 \mathrm{~dB}$. Um esquema representativo do circuito é exibido Figura 4.5.

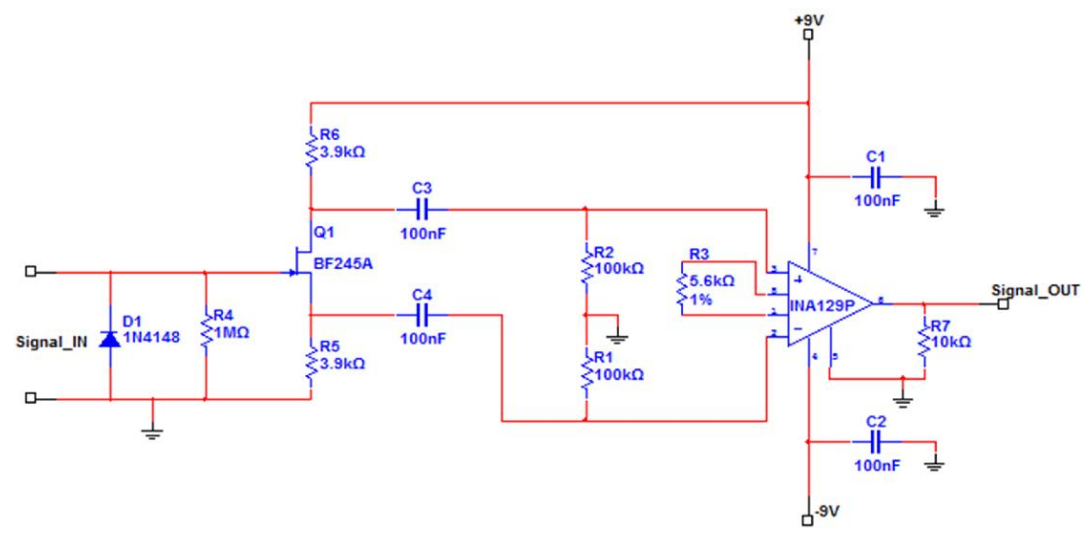

Figura 4.5 - Circuito eletrônico de pré-amplificação. 
A eletrônica embarcada do TRU-1 foi desenvolvida para ser alimentada por duas baterias de $9 \mathrm{~V}$. A bateria, além de ser uma fonte elétrica imune de ruído, também proporciona ao TRU-1 uma mobilidade bastante útil na fase de caracterização do protótipo.

A última etapa no desenvolvimento do circuito de pré-amplificação, consistiu da sua caracterização na resposta em frequências. Esse procedimento foi realizado com a aplicação de um sinal senoidal puro, com o auxílio de um gerador de sinal e, da leitura do sinal amplificado na saída do INA, feita em osciloscópio.

A geração do sinal de entrada foi programada em modo sweep (varredura), de maneira a variar a frequência da onda de 10 a $100 \mathrm{kHz}$. A amplitude foi mantida fixa em $20 \mathrm{mV}$ p.

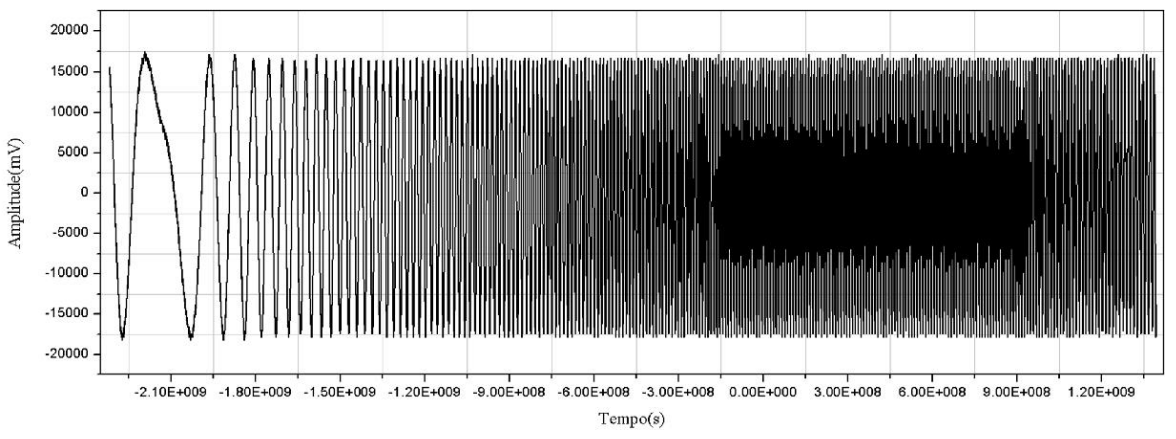

Figura 4.6 - Resposta em frequências do circuito de pré-amplificação do TRU-1. Teste em modo sweep de $10 \mathrm{kHz}$ a $100 \mathrm{kHz}$.

O principal parâmetro avaliado nesse teste se deu a respeito da estabilidade do sinal na saída do circuito, durante a varredura em frequências. A Figura 4.6 exibe o resultado dessa análise, evidenciando que a forma de onda amplificada se manteve constante durante toda a varredura.

\subsection{Calibração}

A calibração de um dispositivo de medida é de fundamental importância para determinar sua confiabilidade. A confiabilidade de um instrumento de medição refere-se ao grau de exatidão entre a medida por ele registrada e o valor real da grandeza. Assim, calibrar um transdutor ultrassônico consiste em determinar seus fatores de conversão direto e indireto, entre duas energias envolvidas (mecânica e elétrica) na operação do elemento piezoelétrico ativo. $\mathrm{O}$ fator de conversão referido é representado pela sensibilidade $(M)$, que é definida pela relação da pressão sobre o elemento transdutor e a tensão 
elétrica correspondente na sua saída, ou vice-versa. A Equação 4.1 denota matematicamente esta relação:

$$
M=\frac{V}{p}
$$

sendo que $V$ representa a amplitude (em volts) do sinal elétrico medido na saída do transdutor e $p$ a pressão (em Pascal) da onda acústica incidente no elemento sensor. Um exemplo de curva de sensibilidade com respostas em frequências para dois hidrofones de membrana monoelemento, semelhante ao desenvolvido neste trabalho, pode ser visto na Figura 4.7.

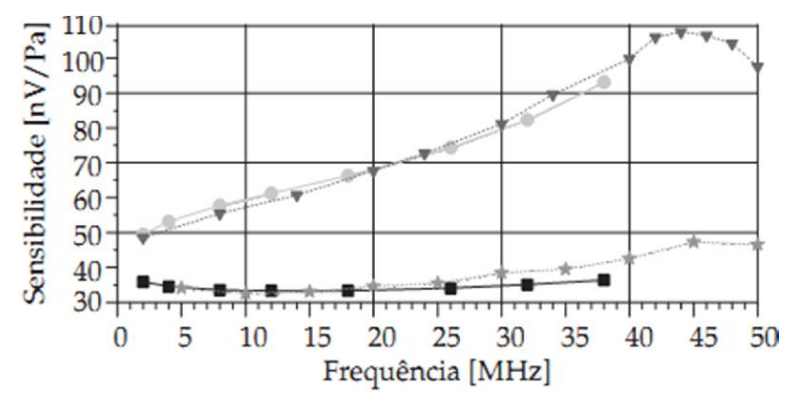

Figura 4.7 - Curvas típicas de hidrofones de membrana (COSTA-FÉLIX; MACHADO, 2007).

Assim, a curva de um instrumento possibilita ao usuário caracterizar as grandezas medidas e estimar a incerteza dos dados adquiridos a partir de uma faixa de erro estabelecida no processo de calibração. No caso de um hidrofone, as medidas do campo acústico são obtidas a partir de um sinal elétrico proporcional à tensão mecânica incidente no seu elemento sensor. Essa proporcionalidade é dada pela curva de sensibilidade e varia para diferentes estruturas piezoelétricas.

Os métodos de calibração de hidrofones na faixa de frequência até $40 \mathrm{MHz}$ encontram-se detalhados na norma (IEC, 2007) e resumidos no trabalho de (COSTA-FÉLIX; MACHADO, 2007). As características de cada método, tais como a incerteza e as faixas (ou limites) de aplicação, são fatores determinantes para quantificar a qualidade da calibração. Em uma visão geral, quanto menor a incerteza e quanto mais ampla forem as faixas úteis de frequência nos experimentos de calibração, melhor e mais genérico será o método. 


\subsubsection{Nível de pressão sonora (SPL)}

Conforme exposto anteriormente, a tensão elétrica gerada nos terminais de um transdutor de US é proporcional à intensidade do campo acústico que incide sobre o elemento sensor do mesmo. Logo, o sinal elétrico obtido por um hidrofone calibrado permite, por intermédio de uma curva de calibração, extrair os valores de pressão acústica correspondentes e, posteriormente, calcular grandezas derivadas, tais como potência e intensidade. A pressão acústica, por sua vez, é comumente expressa em dB por uma relação conhecida como Nível de Pressão Sonora ou, simplesmente, Nível Sonoro (do inglês, Sound Pressure Level) (RAHMAN, 2012).

O SPL é uma medida logarítmica da pressão sonora efetiva $\left(p_{1}\right)$ de uma onda acústica em relação a um valor de referência padronizado $\left(p_{0}\right)$, e que para aplicações subaquáticas se utiliza a pressão de referência equivalente a $1 \mu \mathrm{Pa}$ e aplicações no ar $20 \mu \mathrm{Pa}$ (limiar da audição humana). A Equação 4.2 representa o cálculo do SPL.

$$
S P L(d B)=20 \log \left(\frac{p_{1}}{p_{0}}\right)
$$

A Equação 4.2 pode ser modificada, de forma a manter a mesma lógica, com o intuito de calcular a sensibilidade de um hidrofone em escala logarítmica. Para isso, basta substituir, na fórmula, a pressão $(P)$ pela sensibilidade $(M)$, logo se tem:

$$
\text { Sensibilidade }(d B)=20 \log \left(\frac{M_{1}}{M_{0}}\right)
$$

Com base na equação do SPL, convencionou-se utilizar uma sensibilidade de referência para aplicações subaquáticas equivalente a $1 \mathrm{~V} / \mu \mathrm{Pa}$. A notação adotada para sensibilidade de um hidrofone, relacionada a um valor de referência, tem o formato " $d B$ re $1 V / \mu P a "($ RAHMAN, 2012).

\subsection{Metodologia dos experimentos de Calibração}

A execução de experimentos e medidas se deu em uma parceria com o grupo de pesquisa Grupo de Inovação em Instrumentação Médica e Ultrassom (GIIMUS) da Faculdade de Física, Ciências e Letras de Ribeirão Preto (FFCLRP) da USP. A instrumentação e o sistema de aquisição de dados existentes no laboratório, bem como a qualificação dos grupos, foram os fatores determinantes para definir uma rotina de experimentos, inicialmente, focados na determinação da sensibilidade do novo hidrofone em estudo e, poste- 
riormente, em outros testes de caracterização, tais como relação sinal-ruído e a curva de diretividade.

Os testes experimentais para calibrar o TRU-1 foram executados com o método comparativo entre dois hidrofones; e, como padrão, usou-se o ITC-6050C, calibrado e caracterizado de acordo com normas internacionais. Esse método é descrito no item 12 da norma (IEC, 2007) e intitula-se Método da Substituição ou Comparação.

No Método da Substituição, a pressão acústica irradiada de uma fonte de US é mapeada, primeiramente, com o hidrofone de referência e, depois, com protótipo, dessa maneira, procurando manter exatamente as mesmas condições espaciais dos instrumentos, bem como a intensidade e a forma de propagação das ondas.

Como a pressão acústica é proporcional ao sinal elétrico medido na saída do hidrofone calibrado, ela pode ser determinada pela curva de sensibilidade do equipamento fornecida pelo fabricante. Com a pressão acústica conhecida, a partir do sinal elétrico gerado pelo hidrofone sob teste, pode-se definir sua sensibilidade.

A incerteza desta técnica de calibração advém da incerteza da calibração do hidrofone de referência, somadas às incertezas dos equipamentos constituintes do sistema de medidas.

Todos os experimentos foram desenvolvidos em dois tanques com água desgaseificada, equipados com sistema de rastreio controlável nos três eixos; um, denominado Tanque 1 , com dimensões $1,60 \times 0,80 \times 0,70 \mathrm{~m}^{3}$; e, outro, Tanque 2, construído pela Figlabs, modelo TA-125u nas dimensões de $1,10 \times 0,6 \times 0,6 \mathrm{~m}^{3}$, semelhante ao exibido na Figura 4.8 abaixo.

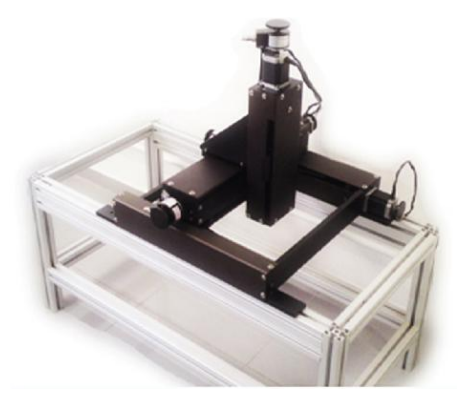

Figura 4.8 - Tanque de experimentos com sistemas de rastreio (FIGLABS PESQUISA E DESENVOLVIMENTO LTDA, 2014).

Os demais equipamentos usados nos testes encontram-se mais bem descritos nos itens subsequentes. 


\subsubsection{Padrão de Calibração}

O equipamento utilizado como padrão da calibração foi um hidrofone comercial (ITC6050C, Santa Barbara, CA, EUA). As especificações nominais principais deste padrão são:

- Frequência de ressonância em $50 \mathrm{kHz}$.

- Alimentação DC de 24 volts.

- Banda de operação na faixa de $300 \mathrm{~Hz}$ a $100 \mathrm{kHz}$.

- Sensibilidade média de $-157 \mathrm{~dB}$ re $1 \mathrm{~V} / \mu \mathrm{Pa}$.

- Pressão acústica de saturação $181 \mathrm{~dB}$ re $1 \mu \mathrm{Pa}$.

- Pré-amplificação interna de 20dB.

- Temperatura de operação -2 a $25^{\circ} \mathrm{C}$.

- Profundidade máxima de operação $=900$ metros

As dimensões do hidrofone ITC são de aproximadamente $30 \mathrm{~cm}$ de comprimento por $5 \mathrm{~cm}$ de largura. A Figura 4.9, a seguir, ilustra o perfil geométrico do equipamento.

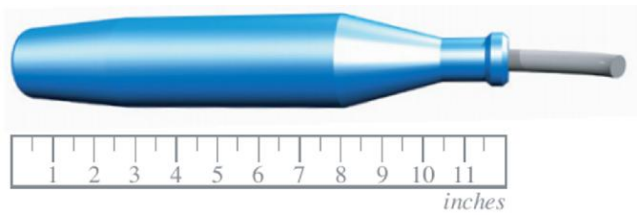

Figura 4.9 - Morfologia do Hidrofone ITC-6050C, utilizado no projeto como padrão de calibração (INTERNATIONAL TRANSDUCER CORPORATION, 2014).

Esse hidrofone, que opera também como emissor e/ou receptor de ondas, tem sido comumente empregado em operações militares, como um sonar, devido às suas características de funcionar em ambientes profundos, pela robustez e alta sensibilidade. Contudo o fabricante o configura e assegura-o, ainda, como um padrão de calibração para aplicações subaquáticas (INTERNATIONAL TRANSDUCER CORPORATION, 2014). A curva da sensibilidade desse equipamento é ilustrada na Figura 4.10. 


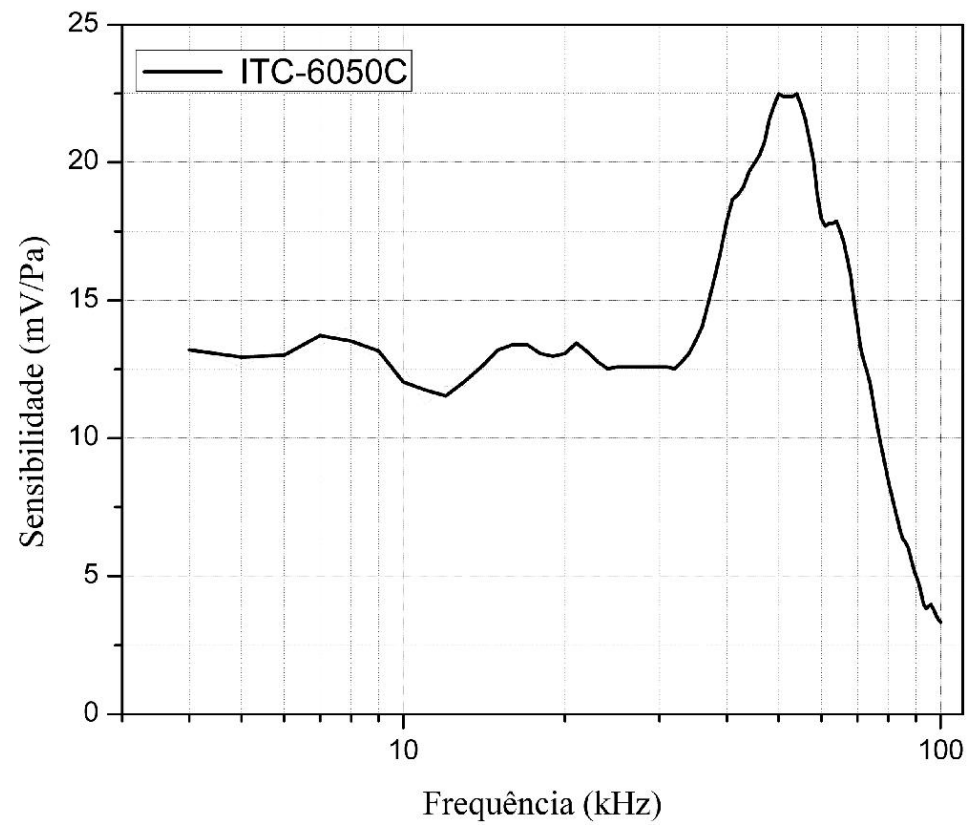

Figura 4.10 - Curva de calibração do hidrofone comercial utilizado nos experimentos de caracterização do protótipo TRU-1.

Uma vez que se tenha o sinal elétrico nos terminais de saída do TRU-1, obtido em uma resposta em frequência, e, também, a pressão exercida pelo mesmo campo acústico, na mesma resposta em frequência, conclui-se obter a sensibilidade do TRU-1 na relação Volts por Pascal.

\subsubsection{Fonte de Geração das ondas de US}

A fonte para geração do campo ultrassônico foi mantida em todos os experimentos de calibração, inclusive nas etapas de geração de imagens por vibroacustografia. A morfologia desse transdutor compreende as características do transdutor confocal de dois elementos piezocerâmicos, descritas no item 2.4.1 do Capítulo 2.

Essa cerâmica confocal foi construída no laboratório GIIMUS, com dois elementos cerâmicos de PZT-4. Sua região focal está localizada a cerca de $7 \mathrm{~cm}$ da superfície e o feixe tem um comprimento aproximado de $0,7 \mathrm{~cm}$. A frequência de ressonância do transdutor, operando com ambas as piezocerâmicas é, aproximadamente, 3,2MHz. Ao analisar individualmente os elementos interno e externo, a faixa de ressonância varia, como se pode verificar nas curvas da Figura 4.11. 


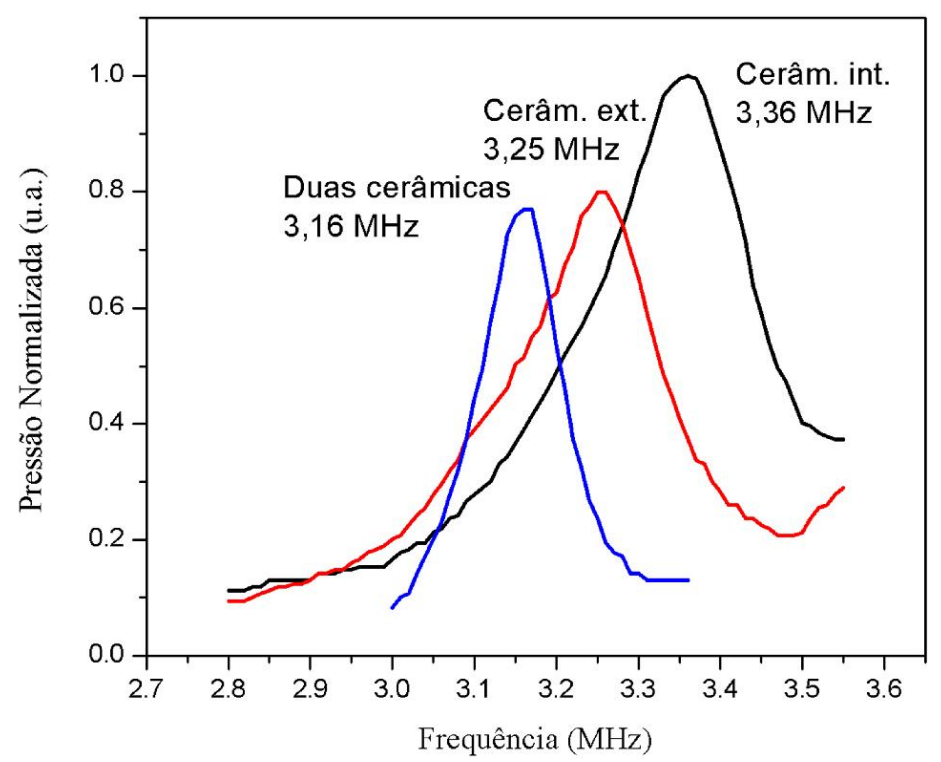

Figura 4.11 - Curva com a frequência de ressonância do transdutor PZT confocal.

Quando excitados por geradores de função convencionais, a potência de entrada deve ser amplificada para um melhor desempenho desse transdutor, o que compreende tensões de no máximo 40Vpp (volts pico a pico) em cada cerâmica.

\subsubsection{Teste comparativo 1: Modulação em Amplitude (AM)}

O primeiro ensaio comparativo entre TRU-1 e ITC6050C teve como propósito verificar a sensibilidade do protótipo nas frequências de 40 e $50 \mathrm{kHz}$, bem como analisar os níveis de excitação elétrica adequados para se operar o atuador cerâmico nos testes seguintes. A escolha dessas frequências justificou-se por ser uma região de ressonância do TRU-1, obtida em testes qualitativos e do hidrofone padrão, respectivamente para 40 e $50 \mathrm{kHz}$.

A condução em modo AM foi implementada com o intuito de reduzir o efeito de reverberação dentro do tanque. Nessas análises, apenas o elemento interno (em formato de disco) do transdutor confocal foi ligado ao gerador de sinal. O campo foi mapeado por ambos os hidrofones. As características quanto à geração, recepção e aquisição dos sinais são dadas a seguir.

\section{GERAÇÃo DO SINAL}

O sinal modulado aplicado à fonte de PZT foi gerado por dois geradores de função, um em frequência de $\mathrm{MHz}$ e outro, que modula o primeiro externamente em baixa fre- 
quência, em kHz. O primeiro, modelo Hewlett-Packard HP8656B, foi configurado em modo AM, na frequência de $3.23 \mathrm{MHz}$ e profundidade de modulação em $99 \%$. O segundo, (modelo Agilent 33220A) atuou como modulador em modo senoidal, com amplitude de 1 Vpp e com frequências $40 \mathrm{kHz}$ e $50 \mathrm{kHz}$.

\section{RECEPÇÃO}

Para sensoriamento do campo, os dois hidrofones em avaliação foram dispostos separadamente e equidistantes da região do foco do transdutor de PZT. Desse modo, verificou-se a resposta dos hidrofones desde um valor mínimo de sinal até um ponto de saturação.

\section{AQUISIÇÃO}

A pressão acústica da fonte de US, agora convertida em um sinal elétrico após a recepção pelos hidrofones, foi filtrada e amplificada pelo lock-in (Signal Recovery, modelo DSP 7265), cujos parâmetros ganho, sensibilidade e constante de tempo do filtro foram $0 \mathrm{~dB}, 100 \mathrm{mV}$ e $500 \mathrm{~ms}$ e $60 \mathrm{~dB}, 200 \mu \mathrm{V}$ e $500 \mathrm{~ms}$, respectivamente, para o ITC-6050C e TRU-1, e, depois, analisados em um osciloscópio (Tektronix, modelo TDS-2024).

A Figura 4.12 ilustra um diagrama esquemático da organização dos equipamentos e instrumentos de medição no experimento.

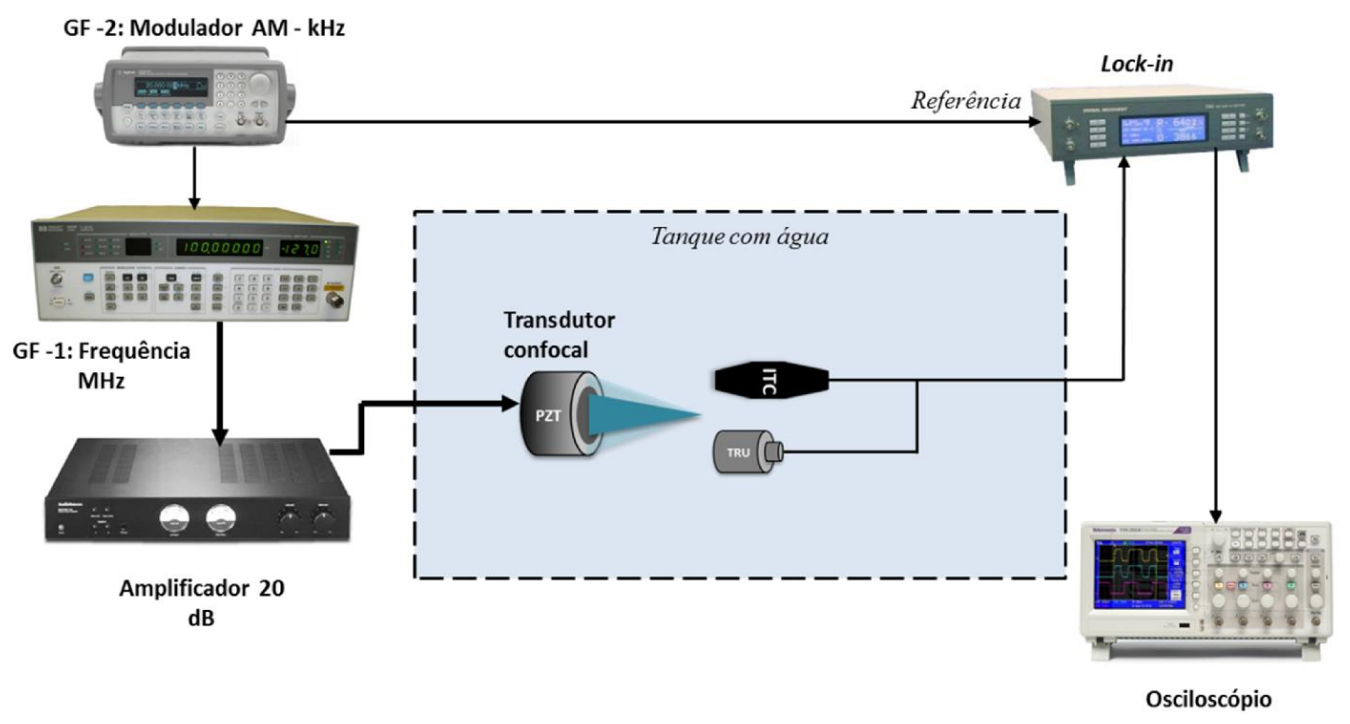

Figura 4.12 - Arranjo experimental em modo AM.

As medidas foram obtidas aplicando-se tensões de 2,5Vpp até $35 \mathrm{Vpp}$ em passos de $0,5 \mathrm{Vpp}$ e realizadas, em três sequências, para obterem-se as médias e desvios padrão 
correlatos. A escolha dessa faixa de tensão foi embasada em testes qualitativos que antecederam o teste quantitativo e indicaram esses valores como limiares de mínimo e máximo na identificação do sinal, por parte do hidrofone padrão. Na tabulação dos resultados, foi avaliada a pressão acústica emitida em função da excitação da fonte, bem como os valores lidos de tensão lidos por cada hidrofone.

\subsubsection{Teste comparativo 2 - Onda contínua (CW)}

A configuração experimental inicial do modo AM foi alterada devido à elevada intensidade das ondas de US, que poderia causar danos ao elemento ativo dos hidrofones quando localizado muito próximo ao transdutor confocal ou mesmo acentuar o efeito de reverberação no material de backing, o que causaria inconsistência nas medidas. Nessa nova configuração, um alvo vibrante foi posicionado na região focal onde anteriormente se encontravam os sensores acústicos. Como alvo, foi usada uma pequena esfera metálica de $3 \mathrm{~mm}$ de diâmetro, colada a fios de cabelo e centralizada a um aro de PVC. Durante os experimentos, essa esfera foi irradiada por um feixe ultrassônico com frequência de batimento adequada. Este alvo pode ser visto na imagem da Figura 4.13.

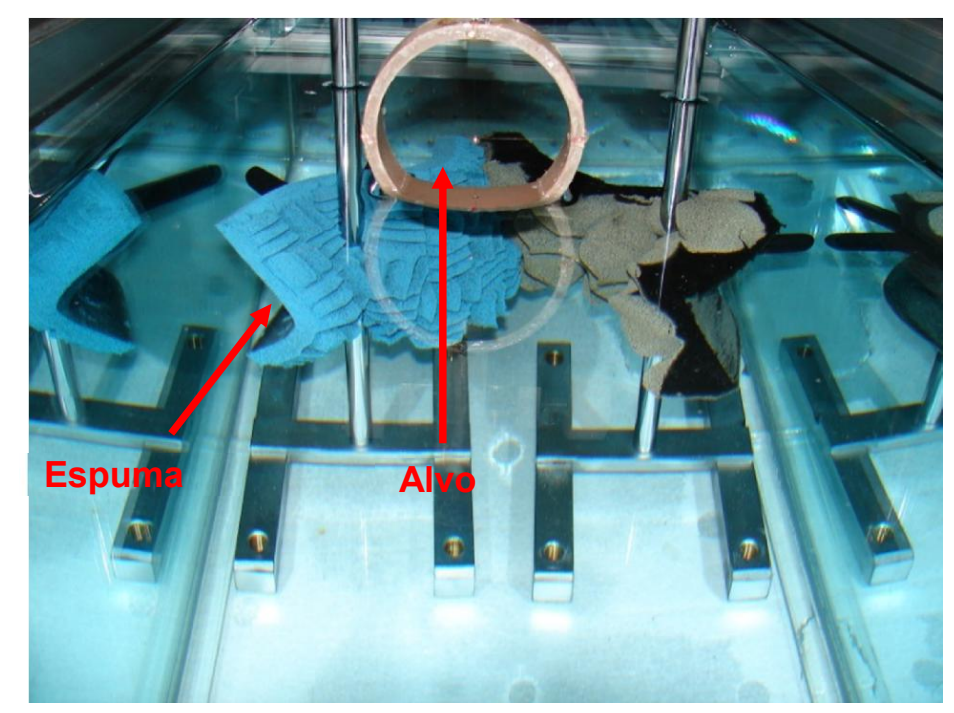

Figura 4.13 - Espumas acústicas atrás do alvo esférico e metálico.

O correto posicionamento do alvo na região focal do atuador cerâmico foi verificado com o auxílio de um pulser-receiver (Olympus-Panametrics-NDT, modelo 5800). Deslocando-se a pequena esfera, com o sistema de rastreio, em uma região próxima a da fonte 
confocal, foi possível observar o posicionamento exato do alvo. Essa posição coincide com a maior amplitude do eco recebido.

No experimento, no modo de propagação em onda contínua (CW) em si, como o próprio nome sugere, as piezocerâmicas do atuador foram excitadas em modo senoidal contínuo, ou seja, sem intermitência do sinal elétrico aplicado. A ideia de executar o experimento comparativo em CW, mesmo com ciência da existência do problema com as ondas estacionárias, foi proposta a fim de conhecer o quanto esses padrões estacionários poderiam afetar em um mapeamento futuro. Também, completando os experimentos, foram tomados alguns cuidados para atenuar o efeito das reflexões dentro do tanque, como a utilização de espuma acústica para absorver a energia atrás do alvo vibrante, como pode ser visto na fotografia da Figura 4.13.

Observa-se, ainda, que outra vantagem desse tipo de geração de sinal reside no uso do lock-in, que filtra e amplifica o sinal em uma banda muito estreita da frequência com eficiência. Não é o caso, por exemplo, de utilizar esse equipamento, em burst, cuja dificuldade reside em fixar uma referência, para uma oscilação de interesse em kHz.

O diagrama esquemático na Figura 4.14 ilustra a disposição dos equipamentos e, posteriormente, são descritos maiores detalhes do teste.

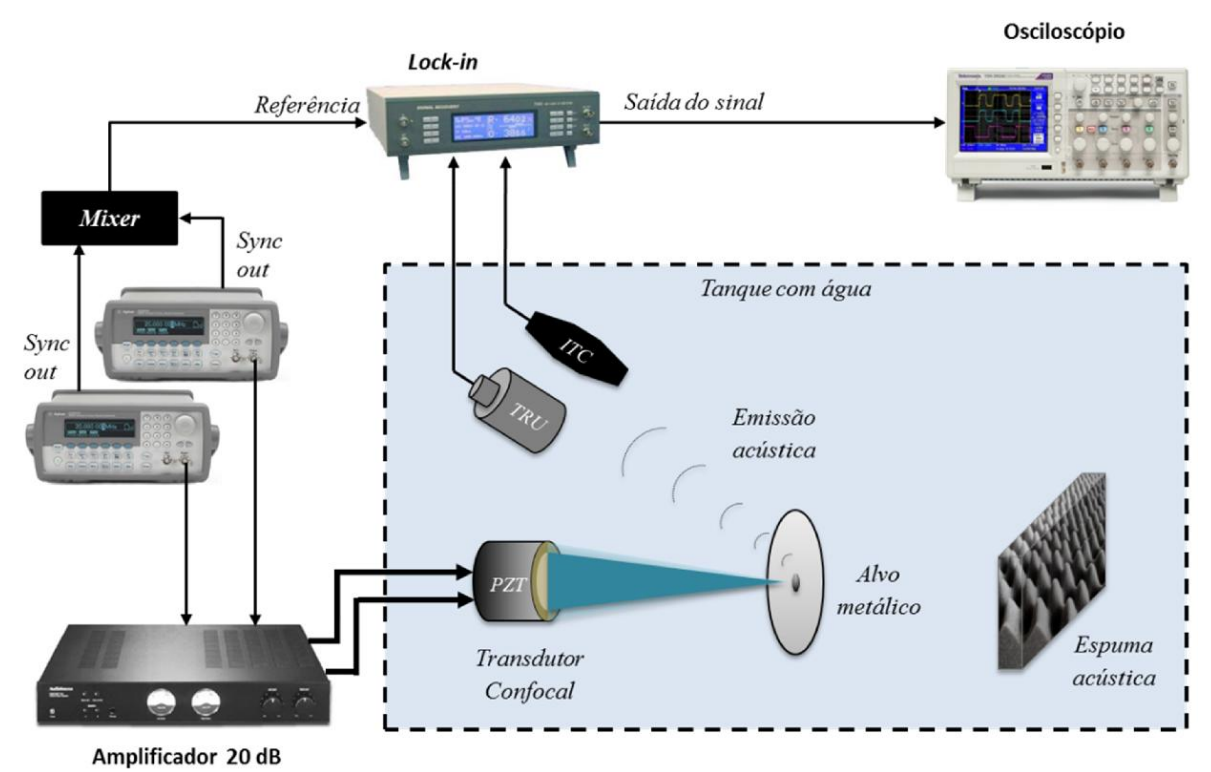

Figura 4.14-Setup do experimento em CW. 


\section{GERAÇÃo}

Nesse experimento, diferentemente do modo AM, foram aplicados aos dois elementos da fonte PZT sinais independentes em $\mathrm{MHz}$, com produção de um sinal de baixa frequência modulado no ponto focal desejado. Esse procedimento consiste em excitar as cerâmicas interna e externa, respectivamente, com ondas de frequências $\left(f_{r}+\Delta f / 2\right)$ e $\left(f_{r}\right.$ $\Delta f / 2$ ). Como as cerâmicas têm o mesmo ponto focal, nesse ponto resulta um campo acústico controlado de frequência $\Delta f$. Para este experimento, foi fixado o sinal referência em $f_{r}$ de $3,2 \mathrm{MHz}$, com $\Delta f$ variando em passos de $1 \mathrm{kHz}$, na faixa de $4 \mathrm{kHz}$ a $80 \mathrm{kHz}$. Para a excitação de cada elemento cerâmico, foram empregados dois geradores de função (GF) (Agilent, modelo 33220A) associados a um amplificador. A tensão elétrica na saída de cada GF foi de 2 Vpp, amplificada em $20 \mathrm{~dB}$.

\section{RECEPÇÃO}

A rotina de sensoriamento foi inicialmente executada com o hidrofone padrão de calibração e, posteriormente, com o protótipo. Os sensores foram posicionados sobre o atuador de PZT e os três dispositivos suportados no mesmo eixo. Espumas acústicas foram dispostas atrás do objeto irradiado pelo feixe para amenizar reflexões nas paredes internas do tanque. Essas disposições dos hidrofones e do transdutor confocal encontram-se ilustradas nas imagens da Figura 4.15.
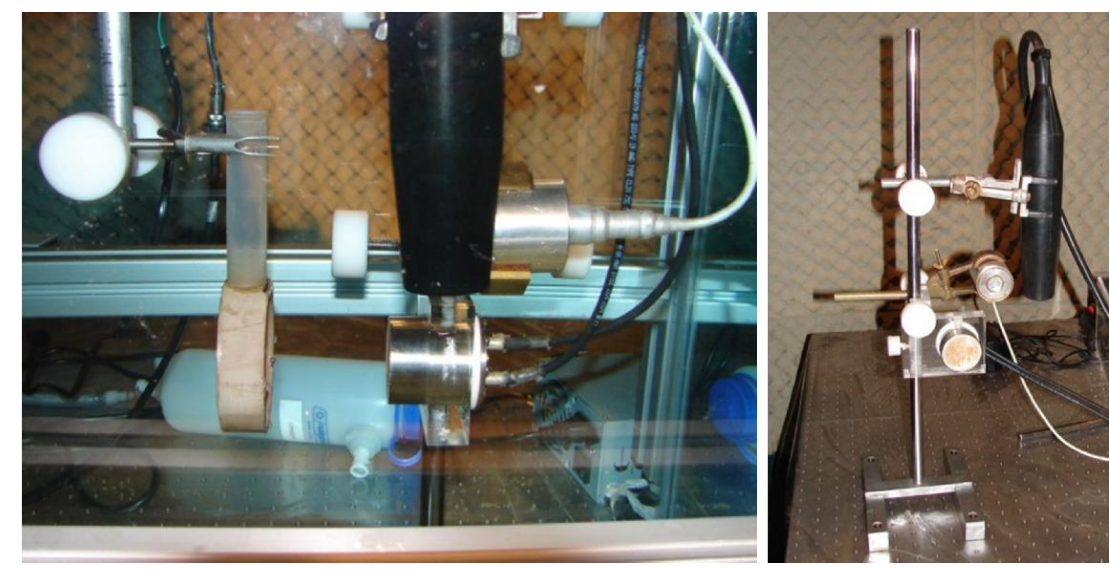

Figura 4.15 - Posicionamento do atuador e dos sensores, no mesmo eixo. O alvo fixado em outra base em frente aos transdutores.

\section{AQUISIÇÃO}

A pressão acústica, produzida pela fonte de US e convertida em um sinal elétrico pelos hidrofones, foi captada por equipamentos de aquisição. O primeiro deles, um amplificador do tipo lock-in (Signal Recovery, modelo DSP 7265), cujos parâmetros ganho, sen- 
sibilidade e constante de tempo do filtro foram $10 \mathrm{~dB}, 200 \mathrm{mV}$ e $500 \mathrm{~ms}$ e $20 \mathrm{~dB}, 10 \mathrm{mV}$ e $500 \mathrm{~ms}$, respectivamente, para o ITC-6050C e TRU-1. Para o funcionamento do lock-in em modo $\mathrm{CW}$, ele necessitava de uma referência da frequência de batimento $(\Delta f)$. Para isso, foi utilizado um equipamento denominado mixer, conectado aos canais "sync out" dos GF, e que basicamente realizava uma subtração de $f_{1}$ e $f_{2}$ e enviava o valor de $\Delta f$ para sincronizar o lock-in. Essa operação pode ser também executada por filtros com mais de uma entrada, na opção de subtração entre dois canais.

Por fim, a resposta DC produzida pelo lock-in, equivalente à amplitude do sinal de batimento sensoriado, já filtrado e com ganho, foi amostrada em um osciloscópio (Tektronix, modelo TDS-2024). A leitura destes dados foi realizada visualmente, em uma sequência de três medidas, para posterior análise estatística dos dados e confecção dos gráficos comparativos.

\subsubsection{Teste comparativo 3: Modo Burst}

Com o intuito de aprimorar a reprodutibilidade dos resultados em relação à formação de ondas estacionárias dentro do tanque os experimentos foram executados em modo Burst. Esse modo de propagação das ondas consiste no disparo de pacotes (pulsos contendo uma quantidade desejável de ciclos de ondas senoidais) em intervalos de tempo constantes. Nesse modo é possível parametrizar, nos geradores de funções, o tempo de disparo entre um pacote e outro, e a quantidade de ciclos por pulso, além das características da frequência e amplitude da onda.

A parametrização dos geradores de função para que a fonte operasse em modo burst foi definida, a princípio, em função do número de ciclos em $\mathrm{kHz}$ suficientes para um adequado mapeamento dos hidrofones. A metodologia descrita a seguir relata os testes preliminares para a execução deste ensaio:

I. Definir o batimento: frequência de interesse, resultante da subtração de $f_{1}$ e $f_{2}$, nessa ordem.

II. Definir o número de ciclos, em baixa frequência: número de ciclos a serem gerados pela fonte, na frequência de interesse.

III. Calcular o período (em segundos) do burst: multiplica a quantidade de ciclos definidos em II pelo período da frequência de interesse. 
IV. Definir as frequências $\left(f_{1}\right.$ e $\left.f_{2}\right)$ referentes a cada cerâmica: nesse caso, optou-se por dimensionar $f_{1}$ e $f_{2}$, a partir da ressonância $f_{r}$, dada como referência, de modo a aproveitar ao máximo essa região.

V. Calcular o número de ciclos de alta frequência:

$$
n \underline{\operatorname{o}} \operatorname{ciclos}_{M H z}=n^{\circ} \operatorname{ciclos}_{k H z} \times \frac{\frac{1}{\Delta f}}{\frac{1}{f_{2}}}
$$

Os digramas da Figura 4.16 ilustram o esquema da geração de ondas senoidais em $\mathrm{kHz}$, vindo da interação de outras duas ondas em $\mathrm{MHz}$. O batimento resultante é propagado em modo burst, dessa maneira, mantendo a mesma dimensão dos dois sinais que o geraram.

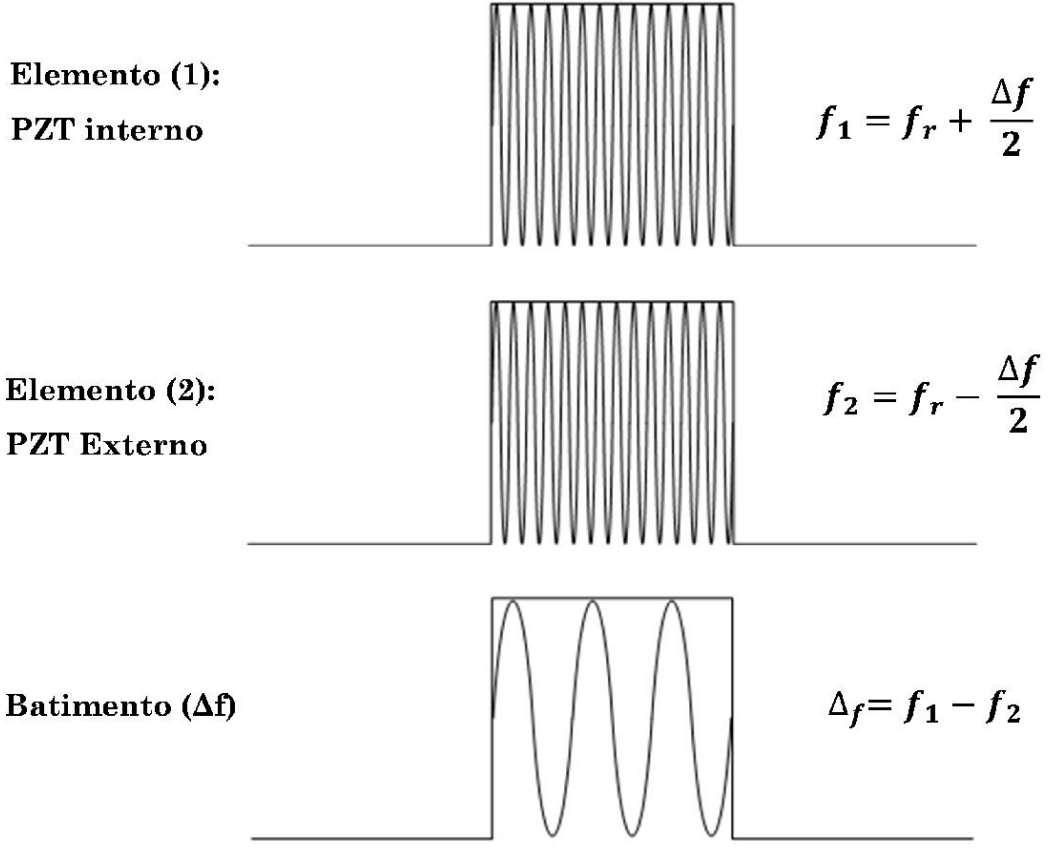

Figura 4.16 - Configuração das formas de onda com sinais em modo burst. A frequência desejada é resultante do batimento entre as ondas 1 e 2 . Os três "pacotes" apresentam as mesmas dimensões. 


\section{GERAÇÃo}

Nessas aquisições, a frequência de ressonância da cerâmica interna, equivalente a $3.25 \mathrm{MHz}$, foi dada como frequência de referência $\left(f_{r}\right)$, a partir da qual se orientavam as frequências de batimento $(\Delta f)$, que foram programadas na faixa de $30 \mathrm{kHz}$ a $100 \mathrm{kHz}$, em uma varredura com passos de $1 \mathrm{kHz}$. Para a excitação elétrica do transdutor confocal, empregaram-se dois geradores de função, mesmo modelo anterior, sincronizados entre si, assim, um gerador controlava o disparo do outro. O burst foi configurado com período de $120 \mathrm{~ms}$ e 3000 ciclos por "pacote" e amplitude da onda de $2 \mathrm{Vpp}$, a qual foi ainda amplificada em 20dB (amplificador montado em laboratório, para operação em alta frequência, $\mathrm{MHz}$ ) antes de atingir o transdutor.

\section{RECEPÇÃo}

A sequência das aquisições com os hidrofones foi a mesma do CW, mas a disposição destes sensores dentro do tanque foi modificada, como mostra a Figura 4.17. A distância entre o PZT e a posição dos sensores foi fixada em aproximadamente $20 \mathrm{~cm}$, a qual pode ser calculada com base no tempo de voo da onda, desde o disparo do pacote até o primeiro registro feito pelos hidrofones.

\section{AQUISIÇÃO}

Os sinais captados pelos hidrofones foram adquiridos por um osciloscópio (Agilent, modelo MSO7104B) e armazenados em disco via USB para posterior tratamento do sinal no software MatLab®, na região de interesse. A aquisição no osciloscópio foi amostrada em 128 médias (sobreposição de 128 formas de onda, a fim de eliminar sinais aleatórios) para reduzir ao máximo o ruído envolvido na medida e poder avaliar o sinal líquido de acordo com a frequência $\Delta f$. Durante as aquisições, foi mantido um intervalo de 30 segundos entre as medidas para estabilização da leitura do sinal com médias. 


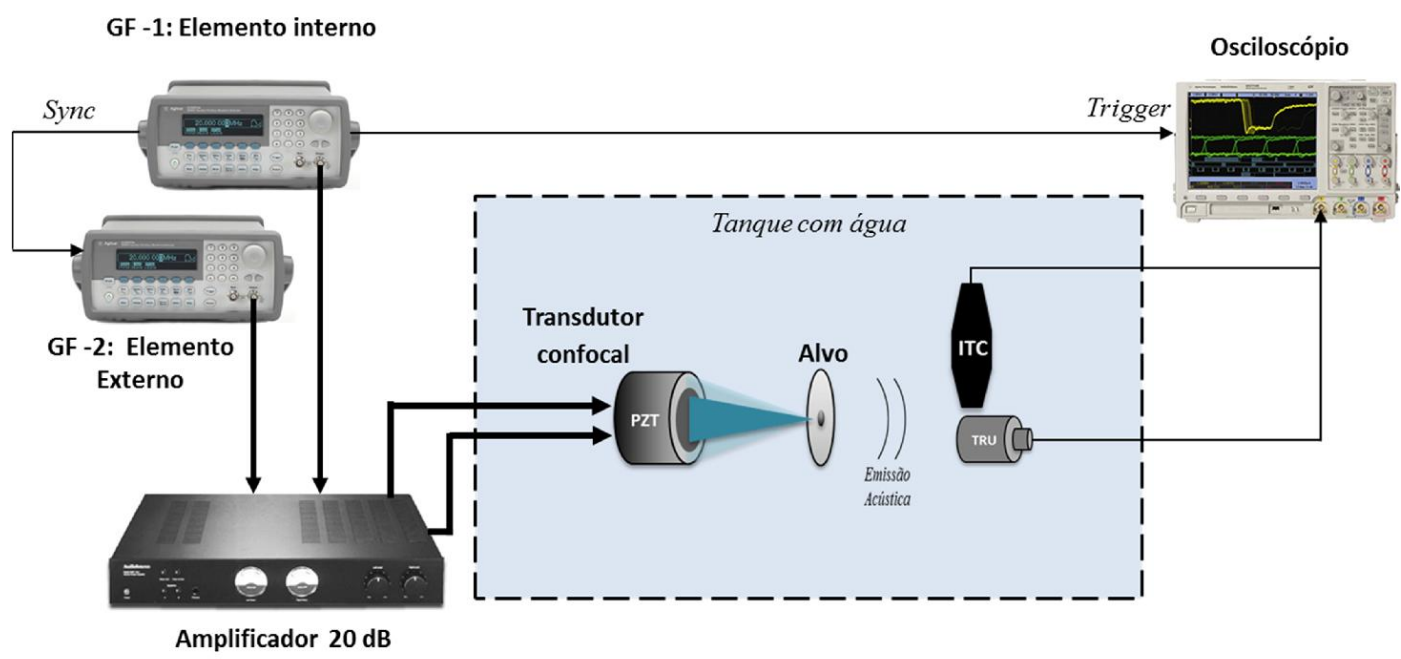

Figura 4.17 - Setup do experimento em burst.

$\mathrm{Na}$ análise dos resultados, foi verificada a sensibilidade líquida do elemento ativo do hidrofone, ou seja, sem considerar o ganho de $24 \mathrm{~dB}$ associado ao circuito eletrônico interno.

\subsection{Curva do padrão de diretividade}

A característica de diretividade ou padrão polar consiste em uma curva que fornece a resposta de um sensor em função da direção das ondas sonoras incidentes sobre seu elemento ativo e utiliza como referência um determinado plano e uma determinada frequência predefinidos. Essa curva está intimamente relacionada ao projeto do equipamento, no que diz respeito ao formato do elemento eletroacústico, da localização da região sensível e da distribuição das células sensíveis para o caso de um dispositivo matricial.

A curva de sensibilidade é mais bem-traçada em um diagrama polar, onde o comprimento do raio é proporcional à resposta elétrica do transdutor, com seu valor relacionado à alguma referência ( $\mathrm{dB}$, normalização, etc.).

No levantamento do padrão de diretividade do TRU-1, foi utilizado o goniômetro da Figura 4.18. Algumas adaptações foram feitas no instrumento, de forma a fixar o protótipo no seu eixo de rotação. 


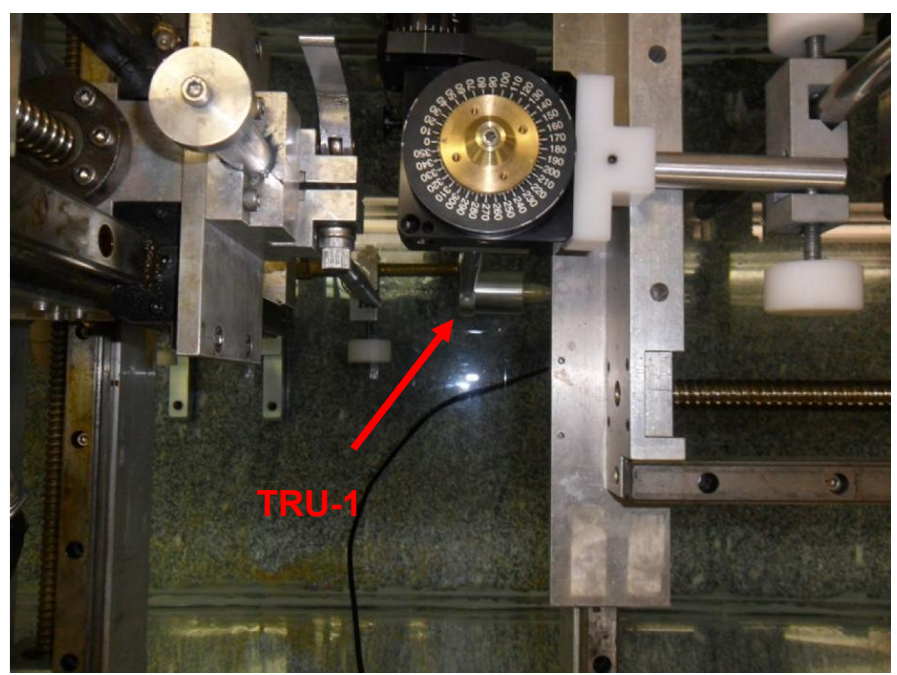

Figura 4.18 - TRU-1 acoplado no eixo de rotação do goniômetro e instalado no arranjo experimental.

As medidas realizadas nessa etapa apresentaram um arranjo experimental e, também, a forma de geração do sinal idêntico ao teste comparativo em modo Burst. A única diferença se deu no posicionamento do TRU-1 durante o sensoriamento. Nos testes anteriores, cujo objetivo se limitava à verificação da sensibilidade do transdutor, tanto o protótipo quanto a fonte de US permaneceram em coordenadas fixas, de modo a orientar a região sensível do hidrofone direta e centralizada nas emissões acústicas.

Nessa caracterização, tomando-se como referência a Figura 4.19, definiu-se como origem (ângulo $0^{\circ}$ no goniômetro) a posição frontal às ondas emitidas pelo alvo metálico irradiado pelo feixe transdutor de PZT, alinhando-o ao centro do filme piezoelétrico do TRU-1. A partir da origem, o hidrofone preso ao goniômetro foi "rotacionado" no plano $\mathrm{XY}$, nos sentidos: $0^{\circ}$ a $120^{\circ}$ e $0^{\circ}$ a $-120^{\circ}$, em passos de $1^{\circ}$.

Optou-se por delimitar esses ângulos durante a rotação, pela morfologia do TRU-1 que apresenta uma região sensível unidirecional e plana. Não havendo, portanto, a necessidade de ultrapassar essa região de varredura, já que as ondas de US não seriam mais capazes de incidir diretamente sobre o filme transdutor.

As medidas foram estabelecidas nas frequências de $40 \mathrm{kHz}$ e $50 \mathrm{kHz}$, e o setup do experimento transcorreu conforme o diagrama da Figura 4.19. 


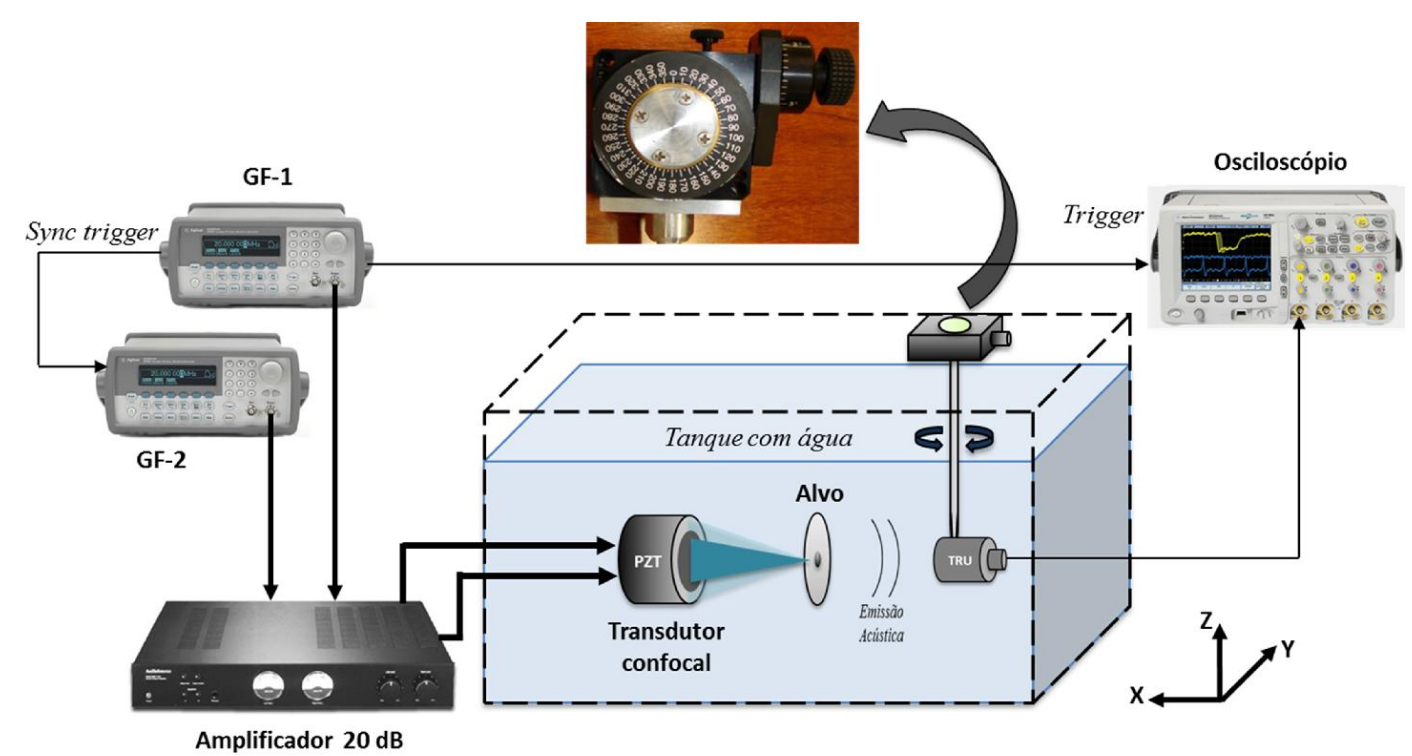

Figura 4.19 - Arranjo do experimento em modo burst para obter o padrão de diretividade do TRU-1.

As demais características do experimento foram as seguintes:

- Modo de excitação da fonte acústica: Burst com 1500 ciclos e período de 300ms.

- Alvo: esfera metálica com $1 \mathrm{~mm}$ de diâmetro, presa e centralizada por fios de cabelo em um aro de PVC, com $10 \mathrm{~cm}$ de diâmetro. A distância entre o alvo e o hidrofone foi de $20 \mathrm{~cm}$.

- Frequência de referência $\left(f_{r}\right)$ para definir o batimento $(\Delta f)$ foi de $3,2 \mathrm{MHz}$. O cálculo de $f_{1}$ e $f_{2}$ também se manteve constante em relação ao procedimento anterior. Assim como a excitação elétrica de $2 \mathrm{Vpp}$.

- Aquisição em 8 médias, osciloscópio (Agilent, modelo MSO6012A).

\subsection{Relação Sinal-Ruído}

Em medições reais, a informação principal normalmente contém ruídos que podem ser oriundos dos próprios instrumentos de medição, do ambiente externo, como, por exemplo, o funcionamento de equipamentos elétricos, conversação humana, vibrações, etc., ou, ainda, blindagem eletrostática não adequada. Todos esses sinais espúrios e indesejáveis podem afetar com maior ou menor intensidade o mapeamento de um campo.

Em alguns casos é possível atenuar o nível de ruído, com o controle do meio ambiente, para tanto, fazendo experimentos em uma câmara anecoica, por exemplo. Quando 
essa distorção é inerente ao equipamento e passível de ser discernida, diferenciando-a do sinal principal, a solução mais hábil se torna o emprego de filtros eletrônicos ou digitais, implementados com o auxílio de ferramentas computacionais.

Uma medida da qualidade do sinal recebido degenerado pelo ruído é a relação entre a potência do sinal e a potência do ruído, comumente denominada relação sinal-ruído e, muitas vezes, abreviada para SNR (do inglês, signal-to-noise-ratio). Sua definição se dá conforme a Equação 4.5, consiste na razão entre a potência do sinal e a potência do ruído.

$$
S N R=\frac{W_{\text {sinal }}}{W_{\text {ruído }}}
$$

Em que $W$ é a potência média.

Para esse cálculo é imprescindível que ambas as grandezas sejam medidas no mesmo sistema e condições vetoriais equivalentes. Seguidas essas condições, a SNR pode ser obtida por meio do cálculo do quadrado da relação de amplitude, como na Equação 4.6.

$$
S N R=\frac{W_{\text {sinal }}}{W_{\text {ruído }}}=\left(\frac{A_{\text {sinal }}}{A_{\text {ruído }}}\right)^{2}
$$

Sendo $A$ é a amplitude em valor RMS (do inglês, root mean square).

Como os sinais, neste estudo, apresentam uma vasta banda dinâmica, tornou-se útil utilizar a escala em $d B$ para facilitar o gerenciamento de grandes intervalos em números. Assim como na sensibilidade com o SPL, em decibéis, a SNR é definida como:

$$
S N R_{d B}=10 \log _{1}\left(\frac{A_{\text {sinal }}}{A_{\text {ruído }}}\right)^{2}=20 \log _{1} 0\left(\frac{A_{\text {sinal }}}{A_{\text {ruído }}}\right)
$$

É importante entender que a SNR é geralmente utilizada para indicar valores médios, uma vez que é possível obter valores instantâneos desta medida que venham ser consideravelmente diferentes.

Os ensaios para obter a sensibilidade do dispositivo concentraram-se apenas na onda fundamental referente à excitação do atuador confocal. Este procedimento possibilitou 
utilizar o amplificador lockin para filtrar o sinal detectado e eliminar a maior parte do ruído de banda larga. Quando o sinal é periódico e o ruído é aleatório é possível aumentar a SNR com a aplicação da funcionalidade de média nas medições, disponível em osciloscópios e pela repetitividade das aquisições. Neste caso, o ruído se reduz como a raiz quadrada do número de amostras médias (ROBERTS, 2009).

No intuito de obter a relação sinal-ruído do TRU-1, realizaram-se novas aquisições em modo burst, também na faixa de $30 \mathrm{kHz}$ a $100 \mathrm{kHz}$, com intervalos de $1 \mathrm{kHz}$. Neste caso, os dados adquiridos via osciloscópio mantiveram, desde o início, a mesma taxa de aquisição referente ao sinal amostrado na tela. Nas medidas anteriores, o sinal foi constantemente ajustado no osciloscópio para uma melhor visualização da forma de onda, de acordo com a alteração das escalas de tempo e amplitude.

Nessa primeira etapa, o registro dos dados no osciloscópio foi feito em 32 médias e, após processamento, calculou-se a potência RMS da frequência $(\Delta f)$ de interesse. A segunda parte consistiu na coleta do ruído de fundo (do inglês, background noise) e também do cálculo da potência. Importante ressaltar que as propriedades de amostragem da primeira aquisição (comprimento e intervalo de tempo entre os pontos) e o ambiente de medidas não foram alterados de modo a comparar sinais equivalentes em dimensões.

Os demais parâmetros do experimento foram os seguintes:

- Modo de propagação do campo acústico: burst com 1000 ciclos e período de 100ms.

- Alvo: o mesmo do teste do padrão de diretividade.

- Frequência de referência $\left(f_{r}\right)$ igual a $3,2 \mathrm{MHz}$.

- O cálculo de $f_{1}$ e $f_{2}$, a partir de $f_{r}$, seguiu a lógica adotada desde o primeiro teste em burst.

- Aquisição em 32 médias, osciloscópio (Agilent, modelo MSO7104B).

\subsection{Imagens por vibroacustografia}

As imagens feitas aplicando a técnica de vibroacustografia, descrita nos Capítulos 2 e 3 , foram todas em modo CW. As justificativas para utilização desse modo de propagação foram a viabilidade do uso do lock-in, facilidade no processamento de sinal, bem como o algoritmo já implementado em Labview ${ }^{\circledR}$ para esse modo de aquisição. 


\subsubsection{Imagem 1: esfera metálica}

Um primeiro estudo de desempenho dos hidrofones para a aplicação na VA foi realizado no tanque acústico 2, cujas dimensões foram citadas no início do capítulo. Ele foi preenchido com água desgaseificada, posicionado sobre uma mesa antivibratória e localizado em uma sala semi-anecóica com temperatura controlada $\left(23^{\circ} \mathrm{C}\right)$. Como objeto gerador das imagens, optou-se por uma esfera metálica de $0,97 \pm 0,01 \mathrm{~mm}$ de diâmetro, fixada sobre um plástico filme plano o qual estava uniformemente colado em um aro de PVC com $10 \mathrm{~cm}$ de diâmetro. A Figura 4.20 ilustra esse aparato com mais detalhes.

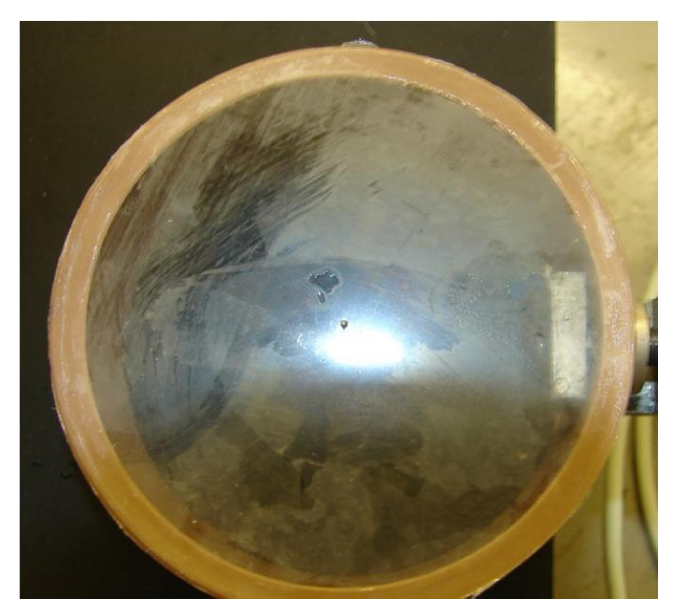

Figura 4.20 - Esfera com 1mm de diâmetro, dada como objeto de imagem.

O transdutor ultrassônico confocal foi o mesmo empregado até o momento como atuador acústico, com região focal em aproximadamente $7 \mathrm{~cm}$ e frequência central em aproximadamente $3,2 \mathrm{MHz}$.

$\mathrm{O}$ aro de PVC foi posicionado frontalmente ao transdutor confocal e fixado ao sistema de rastreio. Ao movimentar o aparato com o pequeno alvo, ao longo do plano YZ e a uma distância fixa de $7 \mathrm{~cm}$, foi possível monitorar a resposta acústica da esfera, tanto com o TRU-1 quanto pelo hidrofone comercial ITC-6050C, posicionados lateralmente ao transdutor, conforme se observa na Figura 4.21. 


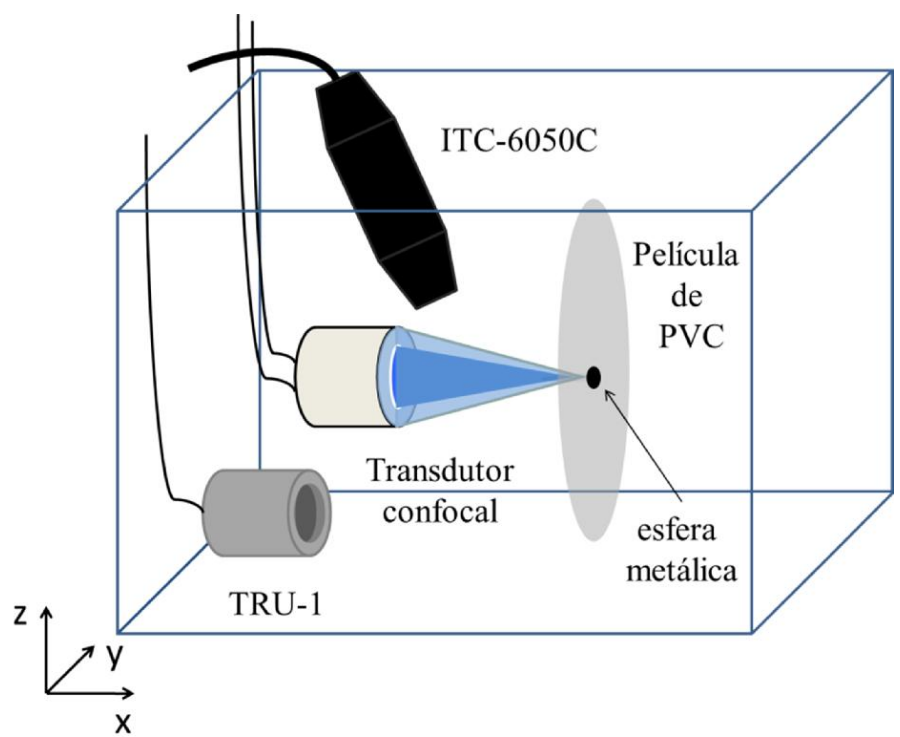

Figura 4.21 - Diagrama experimental do ensaio de vibroacustografia com o uso de um hidrofone comercial (ITC-6050C) e do hidrofone de piezoeletreto (TRU-1).

A alimentação elétrica dos elementos do transdutor confocal seguiu a mesma lógica de cálculo de frequência para garantir o batimento, onde $f=f_{0} \pm \Delta f / 2$ e amplitude pico a pico de $25 \mathrm{~V}$, sendo $f_{0}=3,2 \mathrm{MHz}$ e $\Delta f=37 \mathrm{kHz}$. Os sinais foram aplicados por dois geradores de função (Agilent, modelo 33220A) e amplificados em $20 \mathrm{~dB}$ por um instrumento dedicado a frequências em $\mathrm{MHz}$ (construído no laboratório). Os dois hidrofones foram conectados a um amplificador lock-in (Signal Recovery, modelo DSP 7265) responsável por aplicar um ganho externo e, ao mesmo tempo, filtrar o sinal lido pelos sensores submersos na água.

Os parâmetros do lock-in estabelecidos nos testes foram de $10 \mathrm{~dB}$ e $50 \mathrm{~dB}$ de ganho externo, com sensibilidade de $100 \mathrm{mV}$ e $500 \mu \mathrm{V}$, para o ITC-6050C e TRU-1, respectivamente. Uma constante de tempo (TC) igual a $50 \mathrm{~ms}$ foi atribuída ao filtro em ambos os casos.

Posteriormente, a resposta acústica dos hidrofones foi processada em função das coordenadas de deslocamento, formando imagens com resolução de $0,25 \mathrm{~mm}$, com profundidade de pixel representada pela amplitude do sinal.

A resolução citada no parágrafo anterior, refere-se a resolução espacial do sistema de rastreio que determina a distância de cada pixel formador da imagem. Essa resolução é controlada pelo motor de passo do sistema de aquisição. Já a resolução da imagem propriamente dita, com referência a nitidez do corpo retratado, está diretamente relacionada as características do foco do transdutor confocal, entre elas o diâmetro e pontos de espalhamento. 


\subsubsection{Imagem 2: pequena esfera presa em fios de cabelo}

Um novo experimento para formação de imagens foi proposto com arranjo similar na geração e orientação dos equipamentos. $\mathrm{O}$ objeto de imagem permaneceu com a pequena esfera metálica, no entanto substituiu-se o plástico filme por fios de cabelo no formato de "+" para fixar e centralizar a esfera no aro de PVC. A vantagem seria, inicialmente, reduzir os artefatos de movimento na imagem e, também, verificar o poder de resolução dos hidrofones ao identificar, também na imagem, os fios de cabelo que têm espessura na ordem de micrometros.

Na Figura 4.22 é possível identificar o transdutor confocal, objeto de imagem e, adiante, o TRU-1 fazendo o mapeamento.

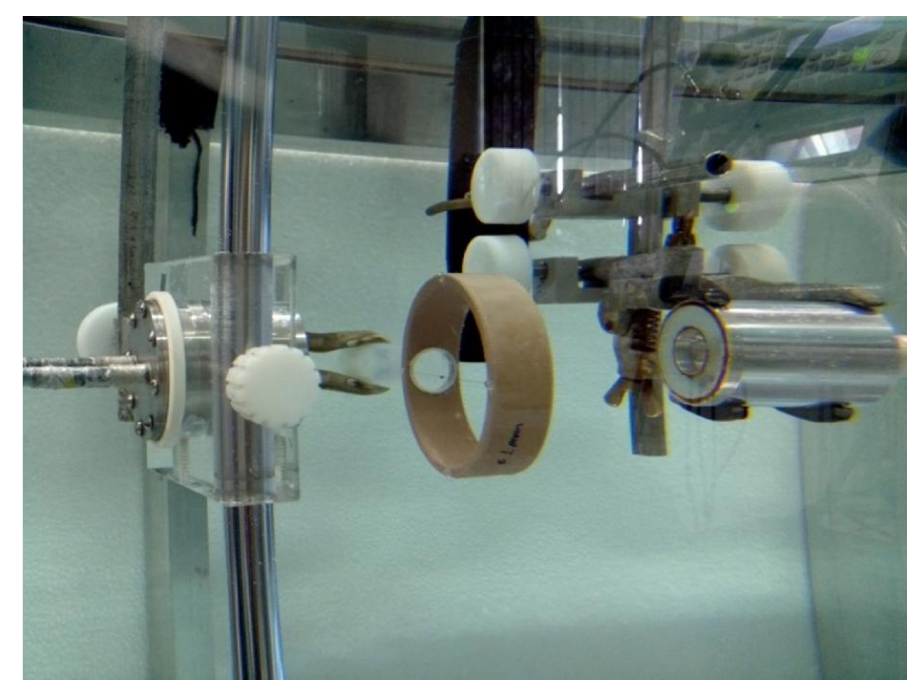

Figura 4.22 - Aquisição de imagem por VA de uma esfera com 1mm de diâmetro com o TRU-1, fixadada por fios de cabelo e centralizada em um aro de PVC.

A amplitude do sinal de excitação do transdutor de PZT foi reduzida para 1,5Vpp, em relação ao rastreamento anterior, no intuito de solicitar menos potência do amplificador RF. A frequência de batimento $(\Delta f)$ escolhida foi de $50 \mathrm{kHz}$ por ser a ressonância do ITC6050, e assim permitir uma comparação com TRU-1 na região em que o hidrofone comercial é mais sensível. É importante frisar que o protótipo também "responde" bem nessa frequência.

A distância entre o atuador e o hidrofone foi de aproximadamente de $17 \mathrm{~cm}$, o que deixa a região sensível centralizada e na frente do objeto de imagem. 
O algoritmo implementado em LabView ${ }^{\circledR}$ foi configurado para adquirir imagens com $0,125 \mathrm{~mm}$ de resolução, equivalente a 10 passos no sistema de rastreio ( 1 passo equivale a $12,5 \mu \mathrm{m}$ ), varrendo uma região quadrada de $4 \mathrm{x} 4 \mathrm{~cm}$ no plano $\mathrm{YZ}$ (orientação da Figura 4.20).

Nessa varredura, o lock-in foi programado com 0dB e $20 \mathrm{~dB}$ de ganho externo com sensibilidade de $1000 \mathrm{mV}$ e $10 \mathrm{mV}$, para o ITC-6050C e TRU-1, respectivamente. E a constante de tempo (TC) do filtro, setada em $640 \mu \mathrm{s}$.

Para a composição da imagem, manteve-se a metodologia anterior, onde a profundidade de pixel foi representada pela amplitude do sinal em função das coordenadas de deslocamento do rastreio. A interface entre o sistema de aquisição e o microcomputador foi realizado por uma placa de aquisição NI (National Instruments, NI PCIe-6320) e tratamento do sinal no MatLab®.

\subsubsection{Imagem 2: estrutura óssea}

Em razão da possibilidade de se gerar imagens de pequenos objetos oscilantes, optouse por aplicar a técnica de VA e verificar o nível de resolução do TRU-1, no mapeamento de uma estrutura ósseo animal. O transcorrer da experiência em laboratório seguiu exatamente o mesmo arranjo de equipamentos anterior. A resolução espacial nesse mapeamento foi aumentada no intuito de agilizar a varredura com sistema de rastreio.

A Figura 4.23 na próxima página ilustra a disposição dos equipamentos na aquisição da imagem do osso. O mesmo foi executado com o TRU-1.

Depois de discutidas as metodologias de caracterização e ensaios pertinentes ao TRU-1, o próximo capítulo deste trabalho compreende as considerações e comentários analíticos em relação aos resultados obtidos. 


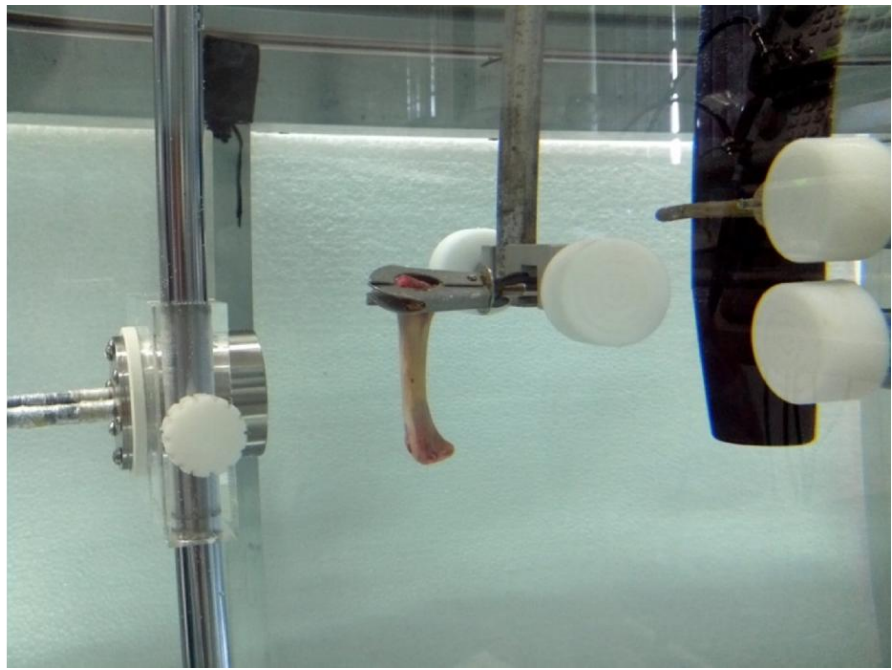

Figura 4.23 - Vibroacustografia de uma estrutura óssea. Na fotografia é exibido o posicionamento da região sensível do ITC-6050C, frente ao objeto de imagem excitado pelo transdutor confocal. O mesmo rastreio foi realizado com o TRU-1, com a região sensível em igual posicionamento. 


\section{Capítulo 5}

\section{Resultados e Discussão}

Neste capítulo serão expostos e comentados os resultados obtidos nos experimentos detalhados no Capítulo 4. Visto que os testes tiveram como propósito principal a caracterização de um hidrofone protótipo, o produto das medições para determinar a sensibilidade, sempre, foi comparado com os produzidos por outro hidrofone comercial, calibrado e caracterizado. Os demais testes, padrão de diretividade e SNR agregam informações cruciais para a evolução de um instrumento de medidas.

\subsection{Testes comparativos}

Nos testes comparativos, conforme teoria anterior, buscou-se inicialmente determinar, com o hidrofone ITC-6050C, a pressão acústica emitida por fonte genérica excitada eletricamente em três modos distintos: AM, CW e Burst. Realizado o mapeamento por sensor tido como padrão e, baseado nas suas informações de calibração, foi possível determinar a sensibilidade do TRU-1. É importante ressaltar que, nos cálculos de pressão do campo envolvido nos testes, considerou-se que o ITC-6050C apresenta sensibilidade constante quando dado em função da pressão emitida por uma fonte acústica, se não saturado. Conforme curva de calibração do fabricante, a sensibilidade deste equipamento varia em função da frequência de operação na faixa de $300 \mathrm{~Hz}$ a $70 \mathrm{kHz}$ (INTERNATIONAL TRANSDUCER CORPORATION, 2014).

Outra informação importante nesta investigação envolve o ganho externo aplicado pelos filtros aos mapeamentos com os hidrofones. Essa amplificação não foi considerada na orientação dos dados de maneira a avaliar somente a resposta do dispositivo sensor em particular. Apenas foi considerada a amplificação interna de $25 \mathrm{~dB}$ e $20 \mathrm{~dB}$, respectivamente, para o TRU-1 e ITC-6050C. 


\subsubsection{AM}

A primeira bateria de testes realizada foi promovida em apenas duas frequências de operação, escolhidas por serem faixas de ressonância do ITC-6050C e onde o TRU-1 melhor respondeu em testes preliminares de caráter qualitativo.

Os gráficos da Figura 5.1 reproduzem a resposta elétrica de ambos os sensores (padrão e protótipo), proporcional à pressão acústica gerada pelo elemento interno do transdutor confocal, quando excitado eletricamente numa faixa de $2,6 \mathrm{Vpp}$ até $35 \mathrm{Vpp}$.

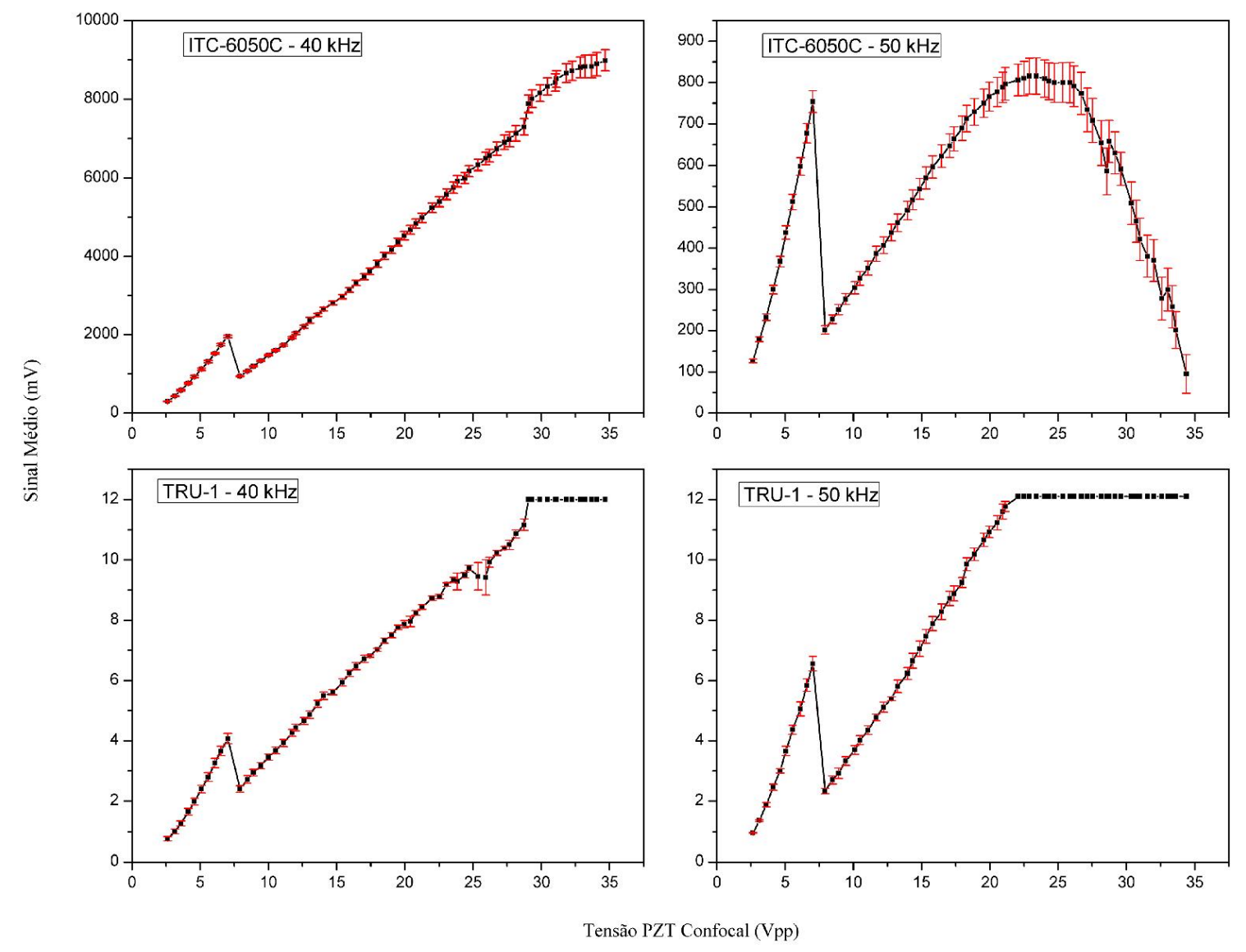

Figura 5.1 - Gráficos da resposta elétrica dos hidrofones, nas aquisições em modo AM.

Em todas as medidas no modo AM, foi possível verificar uma descontinuidade na resposta dos sensores, quando a fonte foi excitada acima de aproximados 7,8Vpp. Isso ocorreu por uma mudança de fase do sinal na saída do gerador de função (HP-8656B), para valores superiores ao mencionado. Como ocorre a mudança de fase, ocorre também uma mudança no padrão das ondas estacionárias dentro do tanque, consequentemente, 
no campo captado pelos hidrofones, assim, ocorrendo uma alteração brusca dos valores lidos.

Nas medidas em $40 \mathrm{kHz}$, o TRU-1 respondeu de maneira linear até cerca de $23 \mathrm{Vpp}$, quando as incertezas nas medidas começaram a aumentar e oscilaram até os $29 \mathrm{Vpp}$, ao entrar em saturação. O ITC-6050C manteve resposta constante até $25 \mathrm{Vpp}$, a partir daí, as incertezas também aumentaram, mas ele não chegou a saturar.

Em $50 \mathrm{kHz}$, o TRU-1 respondeu bem até $15 \mathrm{Vpp}$, quando as incertezas têm aumento gradativo até $20 \mathrm{Vpp}$, ao entrar em saturação novamente. No ITC-6050C, ocorreu algo semelhante, onde as precisões das medidas passam a cair a partir de $15 \mathrm{Vpp}$, alcançando uma região de saturação em $23 \mathrm{Vpp}$ e, posteriormente, as medidas ficam desordenadas e bastante imprecisas.

Nessa etapa foi possível concluir que o transdutor confocal para geração de ondas de US opera com confiabilidade e linearidade na faixa de 10 a 20Vpp. Vale ressaltar que esses valores se verificaram quando os hidrofones foram posicionados no foco do atuador.
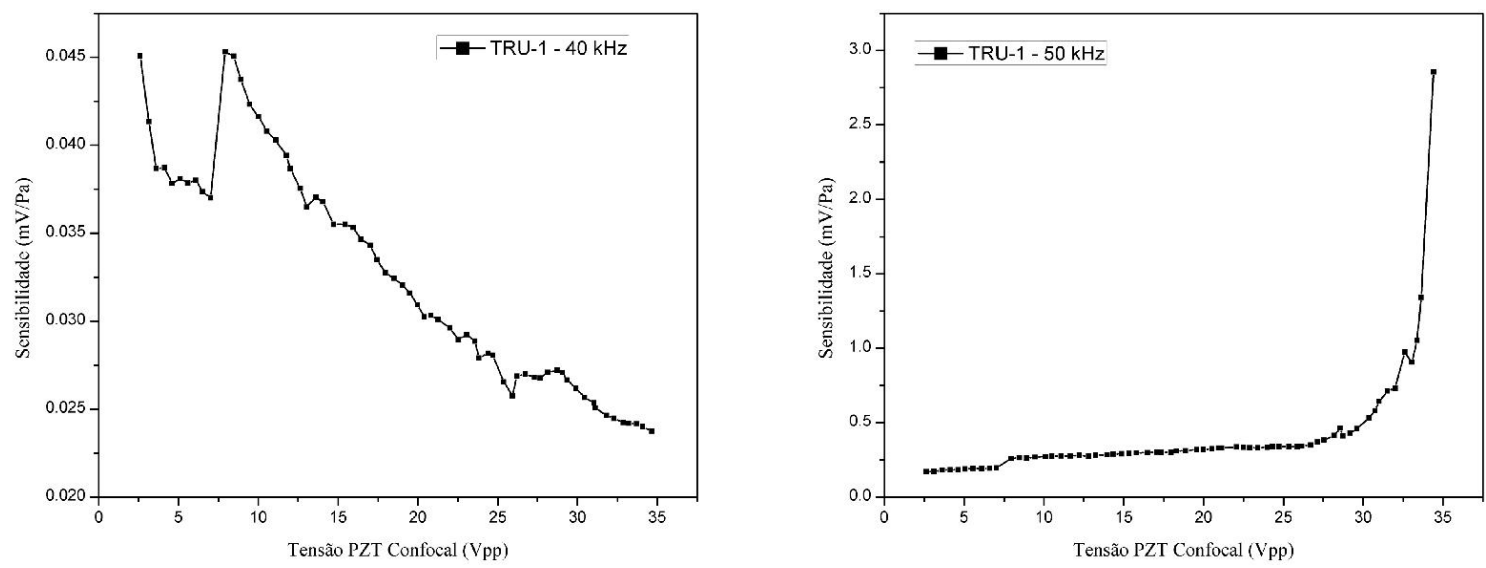

Figura 5.2 - Sensibilidade do TRU-1 em modo AM, em 40kHz e 50kHz.

Ao analisar os dados das curvas de sensibilidade da Figura 5.2, em ambas as frequências, percebe-se que sinal elétrico do TRU-1 aumentava com o aumento da potência da fonte. No entanto, na frequência de $40 \mathrm{kHz}$ esse aumento não foi proporcional ao da excitação elétrica do confocal, fazendo com que a sensibilidade caísse gradualmente, como se o sensor de piezoeletreto estivesse saturado, e provocasse alterações nas medidas. No teste em $50 \mathrm{kHz}$, e a sensibilidade do TRU-1 manteve-se constante, com saturação apenas a partir dos 30Vpp, que é uma magnitude não recomendada para excitar o confocal. 
O fato de realizar experimentos posicionando os hidrofones no alvo da fonte de US não é recomendável com altos valores Vpp devido à alta energia localizada, que pode ter provocado alteração na sensibilidade de ambos os sensores e o processo de saturação prematuro. Ressalta-se ainda que este procedimento poderia ter danificado os sensores piezoelétrcios dos hidrofones. No entanto percebeu-se que as medidas, quando aferidas em uma baixa excitação, que compreende valores até $15 \mathrm{Vpp}$, os dados mostraram-se relativamente coerentes.

\subsubsection{Onda contínua (CW)}

Os gráficos da Figura 5.3 mostram a resposta elétrica do TRU-1 em uma faixa de $4 \mathrm{kHz}$ a $80 \mathrm{kHz}$ e sua sensibilidade também nesse espectro, respectivamente, para os gráficos 1 e 2 .
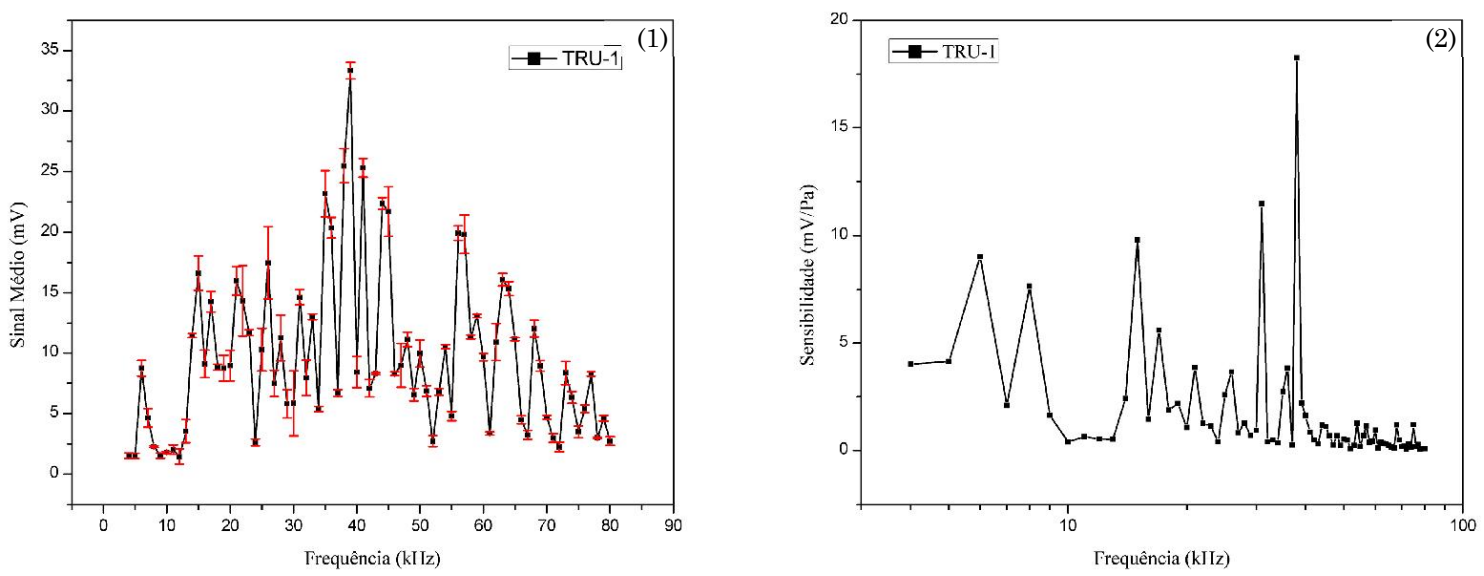

Figura 5.3 - Resposta em frequências do sinal elétrico gerado pelo TRU-1 (1) e, a sensibilidade do protótipo também em frequências (2).

Ao verificar os dados, principalmente, no gráfico de sensibilidade, é possível perceber a existência de picos de ressonância em 38,31, 15, 6 e 8kHz, em ordem decrescente de sensibilidade. A maior delas, em $38 \mathrm{kHz}$, foi em torno de $18,3 \mathrm{mV} / \mathrm{Pa}$, com erro de $2 \%$. A incerteza média de todas as medidas foi de $0,74 \mathrm{mV}$.

Nos gráficos da Figura 5.4, os resultados anteriormente comentados são comparados com os do hidrofone da ITC. No primeiro deles, os sinais elétricos de ambos estão normalizados de acordo com a maior tensão exibida nas aquisições em frequência, sendo $33,33 \mathrm{mV}(\mathrm{em} 39 \mathrm{kHz})$ e $895,98 \mathrm{mV}(\mathrm{em} 64 \mathrm{kHz})$ as referências de normalização para TRU1 e ITC-6050C, respectivamente. 

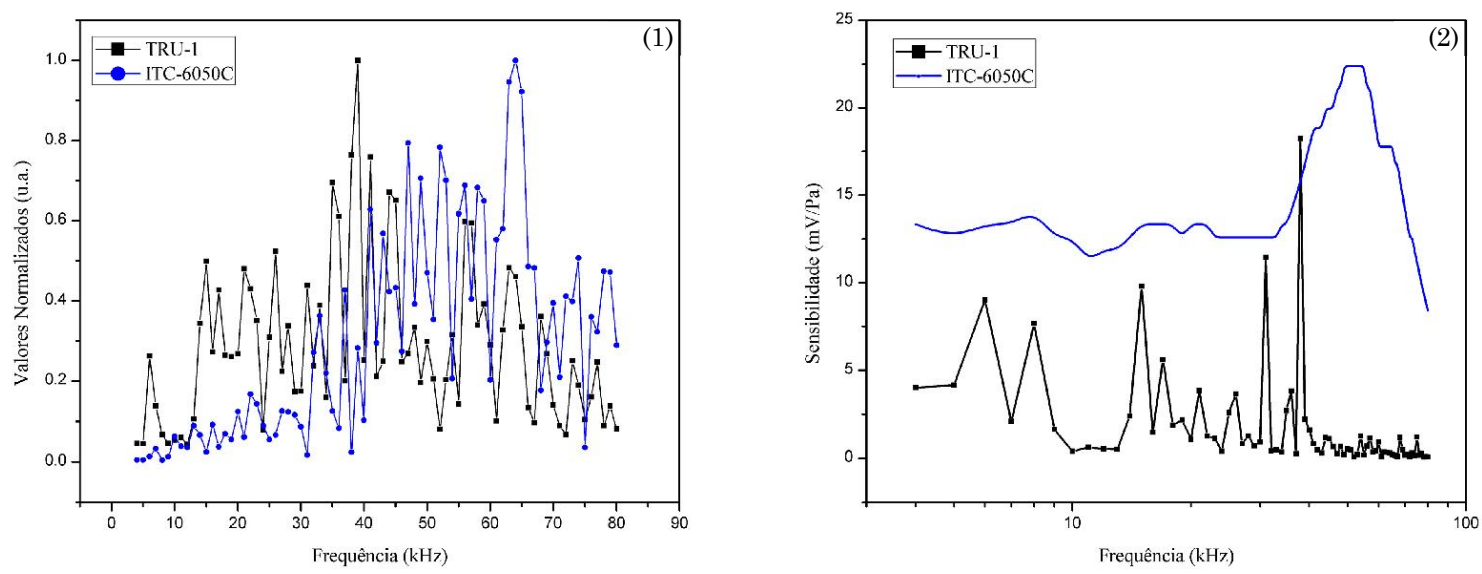

Figura 5.4 - Gráficos comparativos entre o TRU-1 e o ITC-6050C no modo CW: (1) Valores normalizados da resposta elétrica (u.a.) e (2) sensibilidade em $\mathrm{mV} / \mathrm{Pa}$.

Examinado os dados do gráfico 1 é possível distinguir regiões das aquisições que representam variações na resposta eletromecânica dos sensores. Na curva do ITC, pode-se observar que ele teve uma melhor resposta na faixa de 40 a $65 \mathrm{kHz}$. O protótipo, por sua vez, apontou de 35 a $45 \mathrm{kHz}$. Avaliando a sensibilidade nota-se que no maior pico de ressonância do TRU-1 ele se mostrou mais sensível à pressão acústica que o hidrofone comercial.

A sensibilidade média obtida para o TRU-1 foi de 1,712mV/Pa, o que equivale a $182,73 \mathrm{~dB}$ re $1 \mathrm{~V} / \mu \mathrm{Pa}$ em SPL. O valores mínimo e máximo nessa avaliação foram de $0,066 \mathrm{mV} / \mathrm{Pa}(-203,55 \mathrm{~dB}$ re $1 \mathrm{~V} / \mu \mathrm{Pa})$ em $78 \mathrm{kHz}$ e $18,25 \mathrm{mV} / \mathrm{Pa}(-154,78 \mathrm{~dB}$ re $1 \mathrm{~V} / \mu \mathrm{Pa})$ em $38 \mathrm{kHz}$, respectivamente. No ITC-6050C, a sensibilidade média dada pelo fabricante é de $-157 \mathrm{~dB}$ re $1 \mathrm{~V} / \mu \mathrm{Pa}$, equivalente a $14,13 \mathrm{mV} / \mathrm{Pa}$. Na sua ressonância, esse valor sobe para $153 \mathrm{~dB}$ re $1 \mathrm{~V} / \mu \mathrm{Pa}(22,4 \mathrm{mV} / \mathrm{Pa})$.

\subsubsection{Burst}

O sensoriamento em modo burst diferenciou-se das outras duas, pois os dados aqui foram primeiramente salvos em mídia USB, para tanto, utilizou-se as saídas do osciloscópio e, em seguida, os dados foram manipulados para extrair a resposta em volts.

A Tabela 5.1 exibe os parâmetros da configuração empregados em relação à frequência de excitação de cada elemento cerâmico $\left(f_{1}\right.$ e $\left.f_{2}\right)$, à frequência de batimento $(\Delta f)$, à quantidade de ciclos em $\mathrm{MHz}$, ao período total do "pacote" de senoides $\left(t_{b}\right)$, à quantidade de ciclos em $\mathrm{kHz}$ e ao comprimento total do burst $\left(\lambda_{b}\right)$. As informações foram calculadas conforme as diretrizes indicadas no capítulo de materiais e métodos. 
Tabela 5.1 - Parâmetros do estudo em modo burst na resposta em frequências de 30 a $100 \mathrm{kHz}$.

\begin{tabular}{|c|c|c|c|c|c|c|}
\hline$f 1(\mathrm{MHz})$ & $f 2(M H z)$ & $\Delta f(k H z)$ & Ciclos em MHz & Tb (s) & Ciclos em kHz & $\lambda$ do burst (m) \\
\hline 3.265 & 3.235 & 30 & 3000 & $9.274 \mathrm{E}-04$ & 27.82 & 1.372 \\
\hline 3.2655 & 3.2345 & 31 & 3000 & $9.275 \mathrm{E}-04$ & 28.75 & 1.373 \\
\hline 3.266 & 3.234 & 32 & 3000 & $9.276 \mathrm{E}-04$ & 29.68 & 1.373 \\
\hline 3.2665 & 3.2335 & 33 & 3000 & $9.278 \mathrm{E}-04$ & 30.62 & 1.373 \\
\hline 3.267 & 3.233 & 34 & 3000 & $9.279 \mathrm{E}-04$ & 31.55 & 1.373 \\
\hline 3.2675 & 3.2325 & 35 & 3000 & $9.281 \mathrm{E}-04$ & 32.48 & 1.374 \\
\hline 3.268 & 3.232 & 36 & 3000 & $9.282 \mathrm{E}-04$ & 33.42 & 1.374 \\
\hline 3.2685 & 3.2315 & 37 & 3000 & $9.284 \mathrm{E}-04$ & 34.35 & 1.374 \\
\hline 3.269 & 3.231 & 38 & 3000 & $9.285 \mathrm{E}-04$ & 35.28 & 1.374 \\
\hline 3.2695 & 3.2305 & 39 & 3000 & $9.286 \mathrm{E}-04$ & 36.22 & 1.374 \\
\hline 3.27 & 3.23 & 40 & 3000 & $9.288 \mathrm{E}-04$ & 37.15 & 1.375 \\
\hline 3.2705 & 3.2295 & 41 & 3000 & $9.289 \mathrm{E}-04$ & 38.09 & 1.375 \\
\hline 3.271 & 3.229 & 42 & 3000 & $9.291 \mathrm{E}-04$ & 39.02 & 1.375 \\
\hline 3.2715 & 3.2285 & 43 & 3000 & $9.292 \mathrm{E}-04$ & 39.96 & 1.375 \\
\hline 3.272 & 3.228 & 44 & 3000 & $9.294 \mathrm{E}-04$ & 40.89 & 1.375 \\
\hline 3.2725 & 3.2275 & 45 & 3000 & $9.295 \mathrm{E}-04$ & 41.83 & 1.376 \\
\hline 3.273 & 3.227 & 46 & 3000 & $9.297 \mathrm{E}-04$ & 42.76 & 1.376 \\
\hline 3.2735 & 3.2265 & 47 & 3000 & $9.298 \mathrm{E}-04$ & 43.70 & 1.376 \\
\hline 3.274 & 3.226 & 48 & 3000 & $9.299 \mathrm{E}-04$ & 44.64 & 1.376 \\
\hline 3.2745 & 3.2255 & 49 & 3000 & 9.301E-04 & 45.57 & 1.377 \\
\hline 3.275 & 3.225 & 50 & 3000 & $9.302 \mathrm{E}-04$ & 46.51 & 1.377 \\
\hline 3.2755 & 3.2245 & 51 & 3000 & $9.304 \mathrm{E}-04$ & 47.45 & 1.377 \\
\hline 3.276 & 3.224 & 52 & 3000 & $9.305 \mathrm{E}-04$ & 48.39 & 1.377 \\
\hline 3.2765 & 3.2235 & 53 & 3000 & 9.307E-04 & 49.33 & 1.377 \\
\hline 3.277 & 3.223 & 54 & 3000 & $9.308 \mathrm{E}-04$ & 50.26 & 1.378 \\
\hline 3.2775 & 3.2225 & 55 & 3000 & $9.310 \mathrm{E}-04$ & 51.20 & 1.378 \\
\hline 3.278 & 3.222 & 56 & 3000 & $9.311 \mathrm{E}-04$ & 52.14 & 1.378 \\
\hline 3.2785 & 3.2215 & 57 & 3000 & $9.312 \mathrm{E}-04$ & 53.08 & 1.378 \\
\hline 3.279 & 3.221 & 58 & 3000 & $9.314 \mathrm{E}-04$ & 54.02 & 1.378 \\
\hline 3.2795 & 3.2205 & 59 & 3000 & $9.315 \mathrm{E}-04$ & 54.96 & 1.379 \\
\hline 3.28 & 3.22 & 60 & 3000 & 9.317E-04 & 55.90 & 1.379 \\
\hline 3.2805 & 3.2195 & 61 & 3000 & $9.318 \mathrm{E}-04$ & 56.84 & 1.379 \\
\hline 3.281 & 3.219 & 62 & 3000 & $9.320 \mathrm{E}-04$ & 57.78 & 1.379 \\
\hline 3.2815 & 3.2185 & 63 & 3000 & $9.321 \mathrm{E}-04$ & 58.72 & 1.380 \\
\hline 3.282 & 3.218 & 64 & 3000 & $9.323 \mathrm{E}-04$ & 59.66 & 1.380 \\
\hline 3.2825 & 3.2175 & 65 & 3000 & $9.324 \mathrm{E}-04$ & 60.61 & 1.380 \\
\hline 3.283 & 3.217 & 66 & 3000 & $9.325 \mathrm{E}-04$ & 61.55 & 1.380 \\
\hline 3.2835 & 3.2165 & 67 & 3000 & $9.327 \mathrm{E}-04$ & 62.49 & 1.380 \\
\hline 3.284 & 3.216 & 68 & 3000 & $9.328 \mathrm{E}-04$ & 63.43 & 1.381 \\
\hline 3.2845 & 3.2155 & 69 & 3000 & $9.330 \mathrm{E}-04$ & 64.38 & 1.381 \\
\hline 3.285 & 3.215 & 70 & 3000 & $9.331 \mathrm{E}-04$ & 65.32 & 1.381 \\
\hline 3.2855 & 3.2145 & 71 & 3000 & $9.333 \mathrm{E}-04$ & 66.26 & 1.381 \\
\hline 3.286 & 3.214 & 72 & 3000 & $9.334 \mathrm{E}-04$ & 67.21 & 1.381 \\
\hline 3.2865 & 3.2135 & 73 & 3000 & $9.336 \mathrm{E}-04$ & 68.15 & 1.382 \\
\hline 3.287 & 3.213 & 74 & 3000 & $9.337 \mathrm{E}-04$ & 69.09 & 1.382 \\
\hline 3.2875 & 3.2125 & 75 & 3000 & $9.339 \mathrm{E}-04$ & 70.04 & 1.382 \\
\hline 3.288 & 3.212 & 76 & 3000 & $9.340 \mathrm{E}-04$ & 70.98 & 1.382 \\
\hline 3.2885 & 3.2115 & 77 & 3000 & $9.341 \mathrm{E}-04$ & 71.93 & 1.383 \\
\hline 3.289 & 3.211 & 78 & 3000 & $9.343 \mathrm{E}-04$ & 72.87 & 1.383 \\
\hline 3.2895 & 3.2105 & 79 & 3000 & $9.344 \mathrm{E}-04$ & 73.82 & 1.383 \\
\hline 3.29 & 3.21 & 80 & 3000 & $9.346 \mathrm{E}-04$ & 74.77 & 1.383 \\
\hline 3.2905 & 3.2095 & 81 & 3000 & $9.347 \mathrm{E}-04$ & 75.71 & 1.383 \\
\hline 3.291 & 3.209 & 82 & 3000 & 9.349E-04 & 76.66 & 1.384 \\
\hline 3.2915 & 3.2085 & 83 & 3000 & $9.350 \mathrm{E}-04$ & 77.61 & 1.384 \\
\hline 3.292 & 3.208 & 84 & 3000 & $9.352 \mathrm{E}-04$ & 78.55 & 1.384 \\
\hline 3.2925 & 3.2075 & 85 & 3000 & $9.353 \mathrm{E}-04$ & 79.50 & 1.384 \\
\hline 3.293 & 3.207 & 86 & 3000 & $9.355 \mathrm{E}-04$ & 80.45 & 1.384 \\
\hline 3.2935 & 3.2065 & 87 & 3000 & $9.356 \mathrm{E}-04$ & 81.40 & 1.385 \\
\hline 3.294 & 3.206 & 88 & 3000 & $9.357 \mathrm{E}-04$ & 82.35 & 1.385 \\
\hline 3.2945 & 3.2055 & 89 & 3000 & $9.359 \mathrm{E}-04$ & 83.29 & 1.385 \\
\hline 3.295 & 3.205 & 90 & 3000 & $9.360 \mathrm{E}-04$ & 84.24 & 1.385 \\
\hline 3.2955 & 3.2045 & 91 & 3000 & $9.362 \mathrm{E}-04$ & 85.19 & 1.386 \\
\hline 3.296 & 3.204 & 92 & 3000 & $9.363 \mathrm{E}-04$ & 86.14 & 1.386 \\
\hline 3.2965 & 3.2035 & 93 & 3000 & 9.365E-04 & 87.09 & 1.386 \\
\hline 3.297 & 3.203 & 94 & 3000 & $9.366 \mathrm{E}-04$ & 88.04 & 1.386 \\
\hline 3.2975 & 3.2025 & 95 & 3000 & $9.368 \mathrm{E}-04$ & 88.99 & 1.386 \\
\hline 3.298 & 3.202 & 96 & 3000 & 9.369E-04 & 89.94 & 1.387 \\
\hline 3.2985 & 3.2015 & 97 & 3000 & $9.371 \mathrm{E}-04$ & 90.89 & 1.387 \\
\hline 3.299 & 3.201 & 98 & 3000 & $9.372 \mathrm{E}-04$ & 91.85 & 1.387 \\
\hline 3.2995 & 3.2005 & 99 & 3000 & $9.374 \mathrm{E}-04$ & 92.80 & 1.387 \\
\hline 3.30 & 3.20 & 100 & 3000 & $9.375 \mathrm{E}-04$ & 93.75 & 1.387 \\
\hline
\end{tabular}




\section{ANÁLISE DO SINAL}

Após a aquisição dos dados em modo burst, conforme metodologia anteriormente descrita, efetuou-se a análise do sinal, cuja forma de onda típica encontra-se na Figura 5.5(1). Este sinal completo pode ser analisado em 4 regiões: A - transitório inicial (transdutor liga); B - região de interesse com os ciclos em (kHz) resultantes do batimento; C transitório final (transdutor desliga) e D - oscilação residual dos elementos cerâmicos. Na outra imagem (2) é retratado o sinal de interesse para o estudo comparativo entre os hidrofones, uma região onde o sinal é relativamente periódico, não apresentando oscilações bruscas de amplitude e frequência.
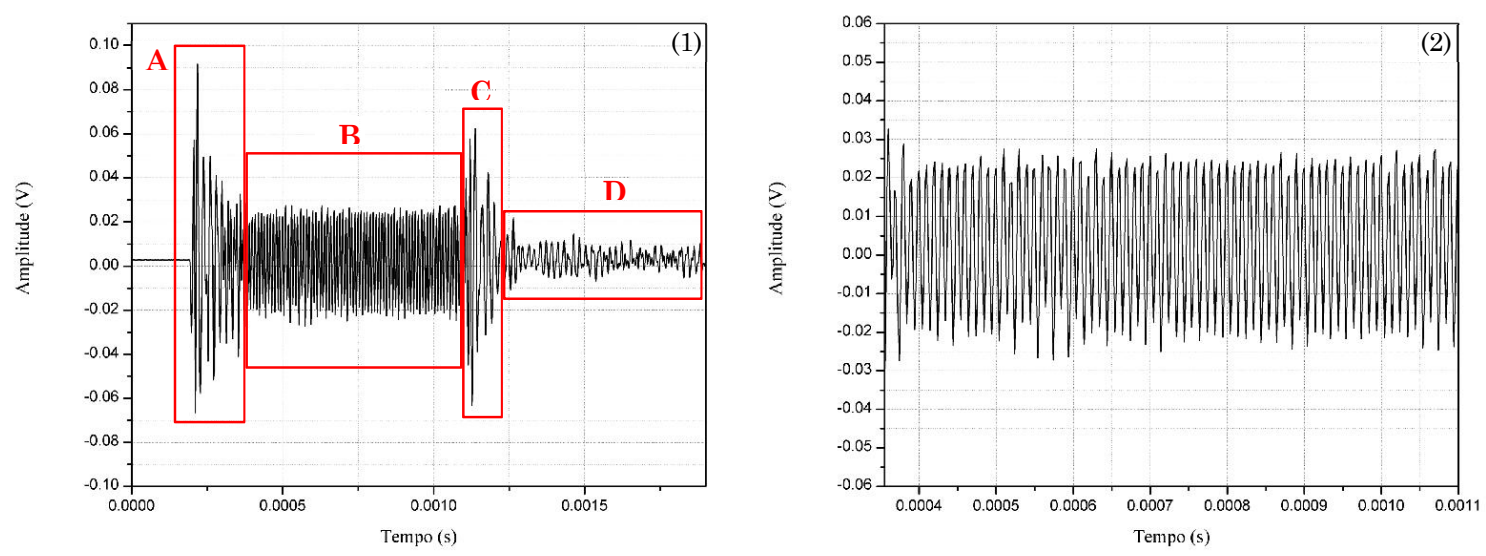

Figura 5.5 - Sinal Burst completo (1). Seleção da região de interesse para análise da sensibilidade (2). Exemplo correspondente à aquisição feita pelo ITC-6050C em $100 \mathrm{kHz}$.

\section{PROCESSAMENTO DO SINAL}

$\mathrm{Na}$ sequência da primeira análise que tratou da interpretação dos dados da aquisição, executou-se o processamento digital na região de interesse do sinal de modo a discretizá-lo no domínio da frequência. Para isso foi utilizada a Transformada de Fourier (FFT, do inglês Fast Fourier Transform) do MatLab.

Na Figura 5.6 é exibido, no domínio da frequência, o sinal da região de interesse plotado na Figura 5.5(2). Esse procedimento foi realizado também em cada aquisição, de 30 a $100 \mathrm{kHz}$ e, a partir da FFT, foi extraída a amplitude do sinal na frequência fundamental (aquela aplicada excitação da fonte) para, com essa informação, criar as curvas comparativas entre os dois hidrofones. 


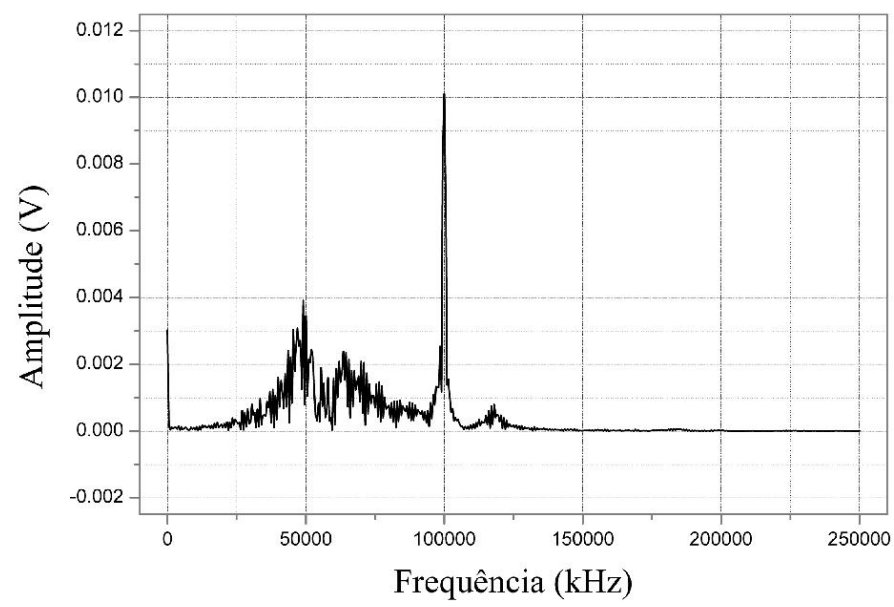

Figura 5.6 - FFT da região de interesse, que apresenta frequência de batimento $(\Delta f)$.

Observa-se ainda na Figura 5.6 que a maior amplitude foi em $100 \mathrm{kHz}$, o que concorda com a frequência fundamental do sinal aquisitado. Em algumas medidas foi constatado que a amplitude de sinais diferentes do aplicado no PZT, provenientes de ruído e, principalmente no nível DC, foi maior que o fundamental, mas em todos os casos foi perceptível o sinal desejado, efetuando-se uma sequência de medidas a fim de comprovar a identidade com a fonte.

\section{RESUlTADOS}

Os resultados obtidos com o TRU-1 na varredura em frequências de 30 a $100 \mathrm{kHz}$ são ilustrados na Figura 5.7. O gráfico (1) ilustra a resposta elétrica média; e o gráfico (2), a sensibilidade obtida a partir da divisão do sinal elétrico pela pressão acústica da fonte de US.
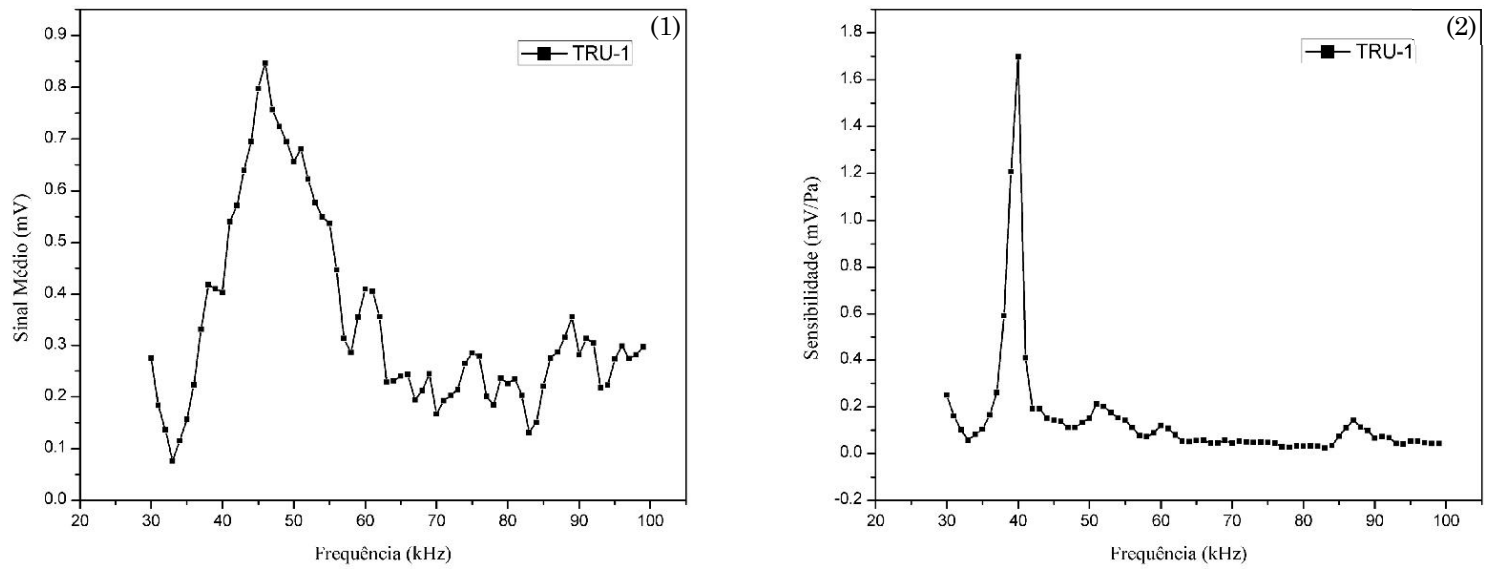

Figura 5.7 - Resposta em frequências do TRU-1 no modo burst: sinal elétrico (1); sensibilidade (2). 
Na leitura do gráfico (1) acima é perceptível que o hidrofone respondeu de maneira mais uniforme que no modo CW. O sinal elétrico máximo obtido foi de aproximadamente $0,846 \mathrm{mV}$ em $46 \mathrm{kHz}$ e a média das medidas ficou em torno de $0,346 \mathrm{mV}$. A leitura dos dados foi programada no osciloscópio para amostragem em 128 médias, o que deixa a incerteza de que as medidas correspondam aos valores dados pelo fabricante do instrumento.

No outro gráfico, o (2), não existem mais os sucessivos picos de ressonância vistos em CW, o que deixa a região de ressonância delimitada entre 39 e $40 \mathrm{kHz}$, onde a sensibilidade alcançada foi de 1,698mV/Pa. Na Figura 5.8, as curvas anteriores são comparadas às obtidas previamente com o ITC-6050C.
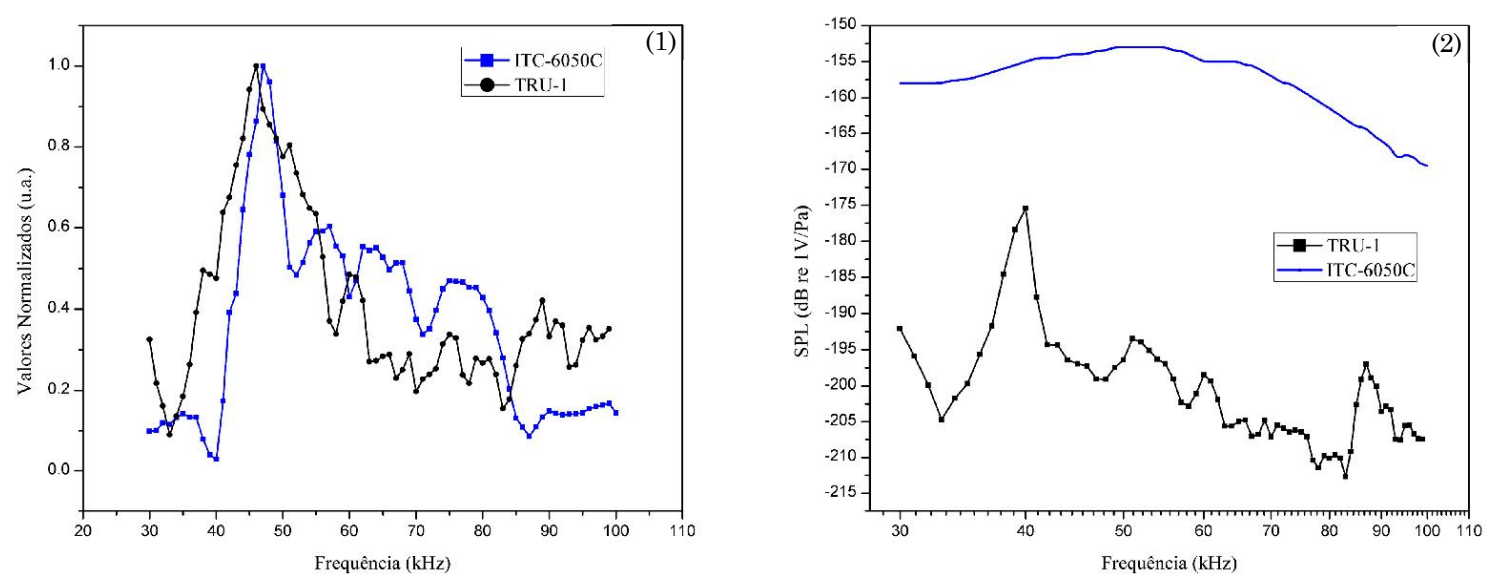

Figura 5.8 - Gráficos comparativos entre o TRU-1 e o ITC-6050C no modo burst: (1) Valores normalizados da resposta elétrica (u.a.) e (2) sensibilidade em $\mathrm{SPL}(\mathrm{dB}$ re $1 \mathrm{~V} / \mu \mathrm{Pa})$.

O comportamento do TRU-1 nesses testes mostrou ser mais condizente com o mapeamento feito pelo ITC-6050C, como pode ser visto no gráfico 1, cujas curvas dos valores normalizados (pela amplitude máxima) dos hidrofones estão relativamente alinhadas. $\mathrm{O}$ maior registro feito pelo hidrofone padrão foi de $142,8 \mathrm{mV}$ e médias das suas medidas ficou em torno de $52,17 \mathrm{mV}$.

Na curva do ITC, pode-se observar que ele teve uma melhor resposta na faixa de 45 a $50 \mathrm{kHz}$. O protótipo, por sua vez, foi de 40 a $55 \mathrm{kHz}$. Essas informações retratam que o TRU-1 atingiu uma largura de banda pouco maior em relação ao modo CW, onde a resposta elétrica foi avaliada.

No estudo da sensibilidade, a média calculada para o TRU-1 foi de $0,142 \mathrm{mV} / \mathrm{Pa}$, o que equivale a $-196,95 \mathrm{~dB}$ re $1 \mathrm{~V} / \mu \mathrm{Pa}$ em $\mathrm{SPL}$. O valores mínimo e máximo nessa avaliação foram de $0,023 \mathrm{mV} / \mathrm{Pa}(-212,67 \mathrm{~dB}$ re $1 \mathrm{~V} / \mu \mathrm{Pa})$ em $83 \mathrm{kHz}$ e $1,698 \mathrm{mV} / \mathrm{Pa}(-175,4 \mathrm{~dB}$ re $1 \mathrm{~V} / \mu \mathrm{Pa}$ ) em $40 \mathrm{kHz}$, respectivamente. No ITC-6050C, a sensibilidade média dada pelo 
fabricante é de $-157 \mathrm{~dB}$ re $1 \mathrm{~V} / \mu \mathrm{Pa}$, equivalente a $14,13 \mathrm{mV} / \mathrm{Pa}$. Na sua ressonância, esse valor sobe para $-153 \mathrm{~dB}$ re $1 \mathrm{~V} / \mu \mathrm{Pa}(22,4 \mathrm{mV} / \mathrm{Pa})$.

\section{ESTUDO DO TRANSITÓRIO}

$\mathrm{Na}$ análise das respostas em burst notou-se uma oscilação padrão nas extremidades do sinal de interesse, diferente da frequência de batimento. Essa oscilação corresponde a um transitório no instante de acionamento (início da excitação) do transdutor confocal e no seu desligamento (retirada da excitação). Essa peculiaridade foi atribuída ao atuador, pois foi notada em ambos os hidrofones. O estudo foi executado em 4 frequências diferentes, 30, 40, 60 e 70kHz, com utilização dos dois sensores.
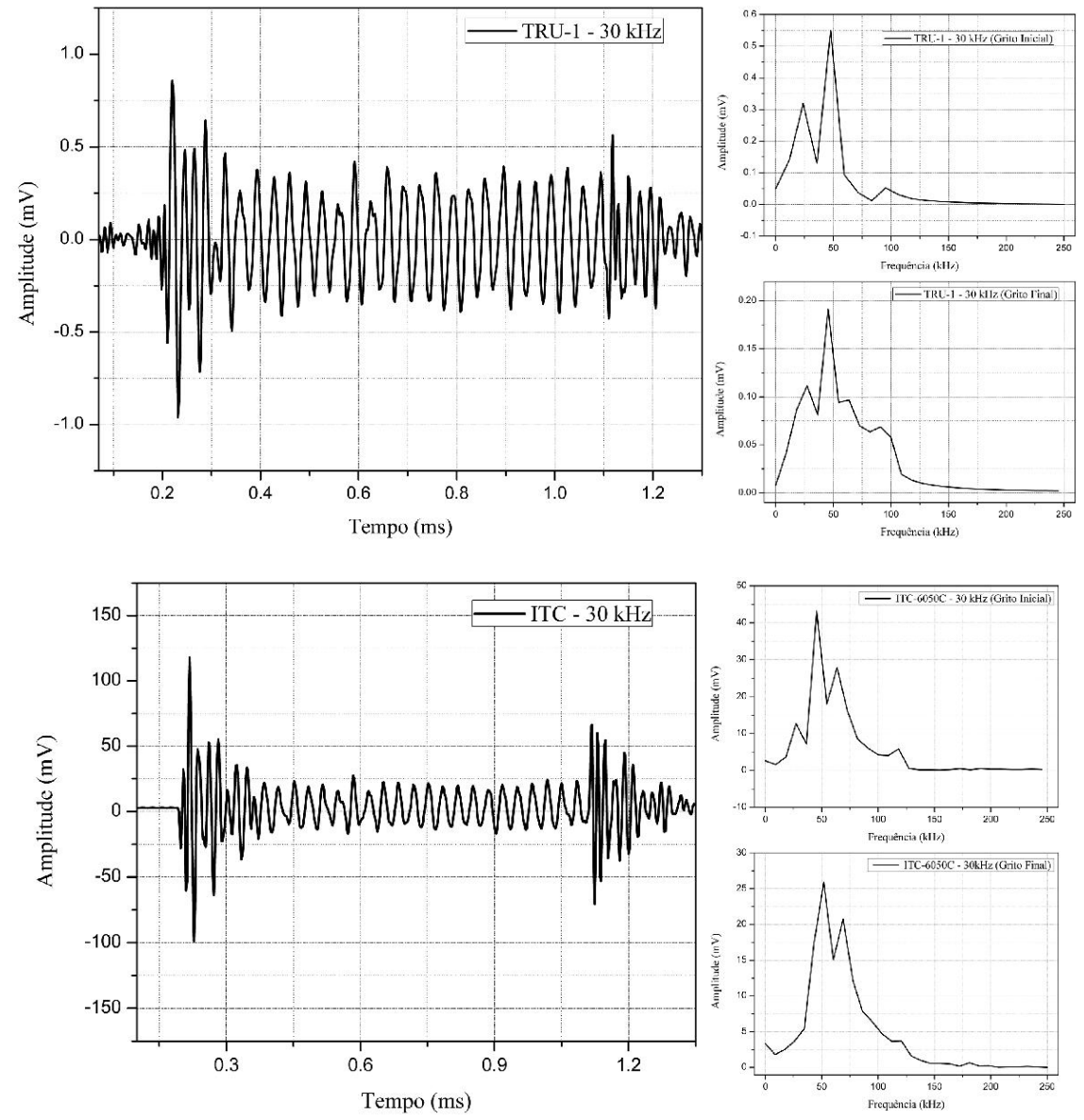

Figura 5.9 - Análises do transitório na excitação e desligamento do transdutor confocal de PZT, em $\Delta f=$ $30 \mathrm{kHz}$, mapeados com o TRU-1 e o ITC-6050C.

No primeiro teste desse estudo, cujos resultados são exibidos na Figura 5.9, a excitação do PZT foi feita em $30 \mathrm{kHz}$ e sua resposta mapeada com os sensores TRU-1 e ITC. 
Nas regiões A e B do sinal, vistas no domínio da frequência, verificou-se uma frequência predominante em $50 \mathrm{kHz}$, comum aos dois mapeamentos.

Fato idêntico foi verificado na segunda avaliação, onde o sinal de interesse era de $40 \mathrm{kHz}$. Conforme a Figura 5.10, os gráficos menores exibem uma maior amplitude na frequência de $50 \mathrm{kHz}$, para o sinal de "grito".
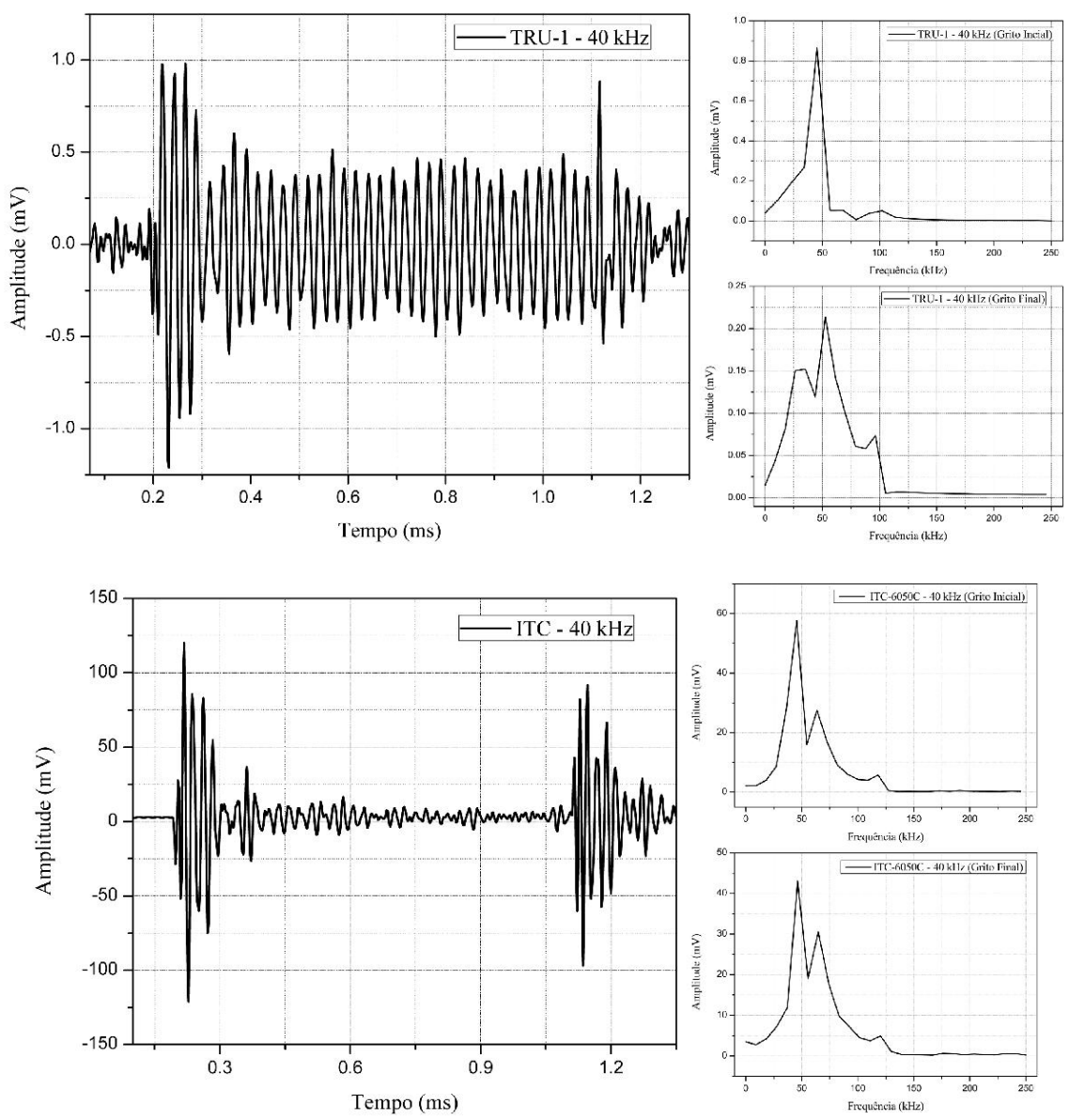

Figura 5.10 - Análises do transitório na excitação e desligamento do transdutor confocal de PZT, em $\Delta f=$ $40 \mathrm{kHz}$, mapeados com o TRU-1 e o ITC-6050C.

No burst de $60 \mathrm{kHz}$, a predominância de um sinal em $50 \mathrm{kHz}$ durante os transitórios também ficou evidente, principalmente nas medidas feitas pelo TRU-1, conforme gráficos de respostas em frequências, vistas na Figura 5.11. Nas medidas com o ITC, esse pico ficou em uma faixa de $50 \mathrm{kHz}$ a $60 \mathrm{kHz}$. 

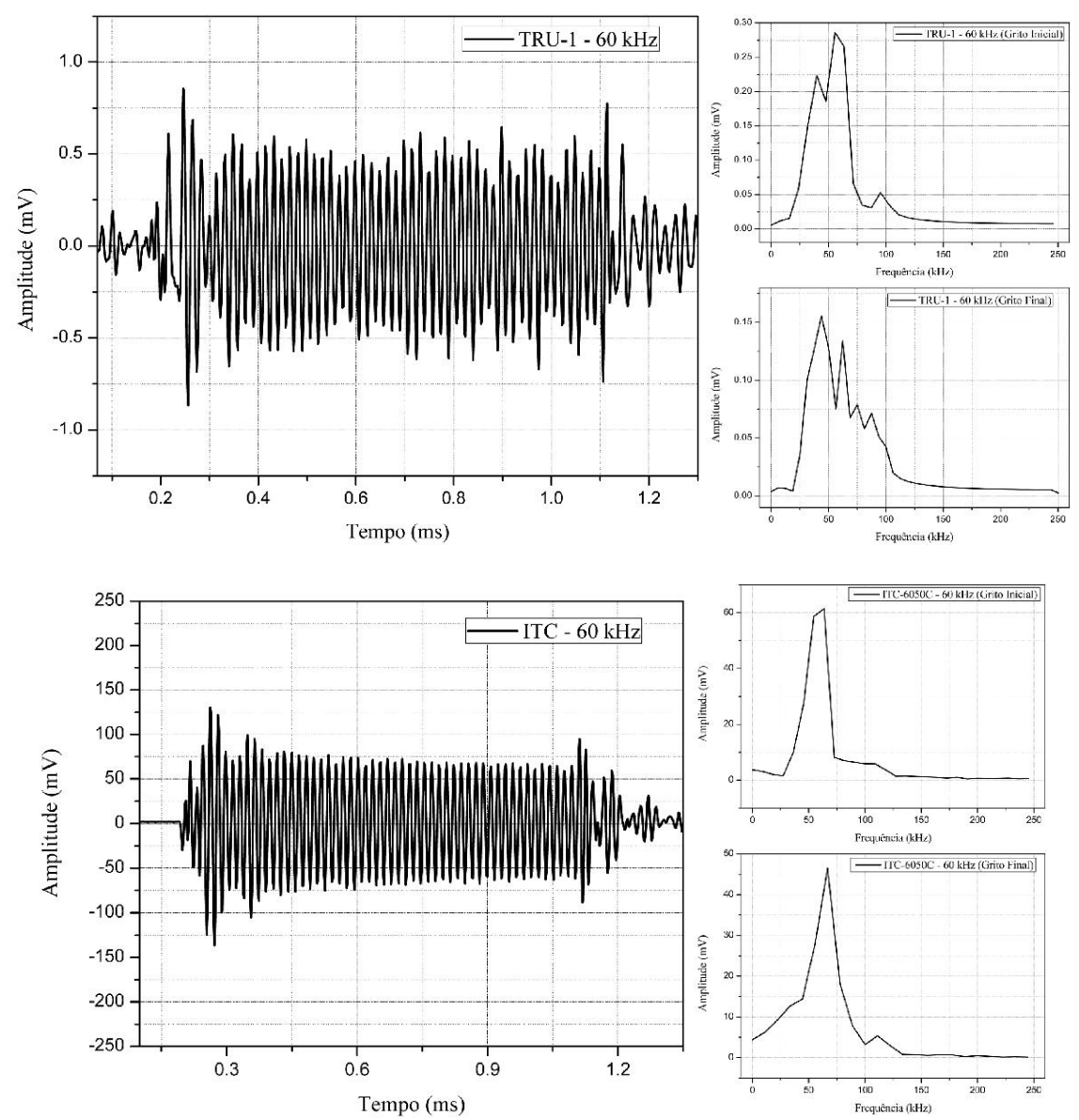

Figura 5.11 - Análises do transitório na excitação e desligamento do transdutor confocal de PZT, em $\Delta f=$ $60 \mathrm{kHz}$, mapeados com o TRU-1 e o ITC-6050C.

$\mathrm{Na}$ última avaliação, a frequência de interesse dada pela excitação do atuador cerâmico foi de 70kHz. No mapeamento feito pelo TRU-1, a FFT realizada nos sinais de "grito" mostrou ainda a presença de uma maior amplitude em $50 \mathrm{kHz}$. Na resposta exibida pelo ITC observou-se um desvio, que colocou a frequência predominante dos transitórios numa região de aproximadamente $60 \mathrm{kHz}$. 

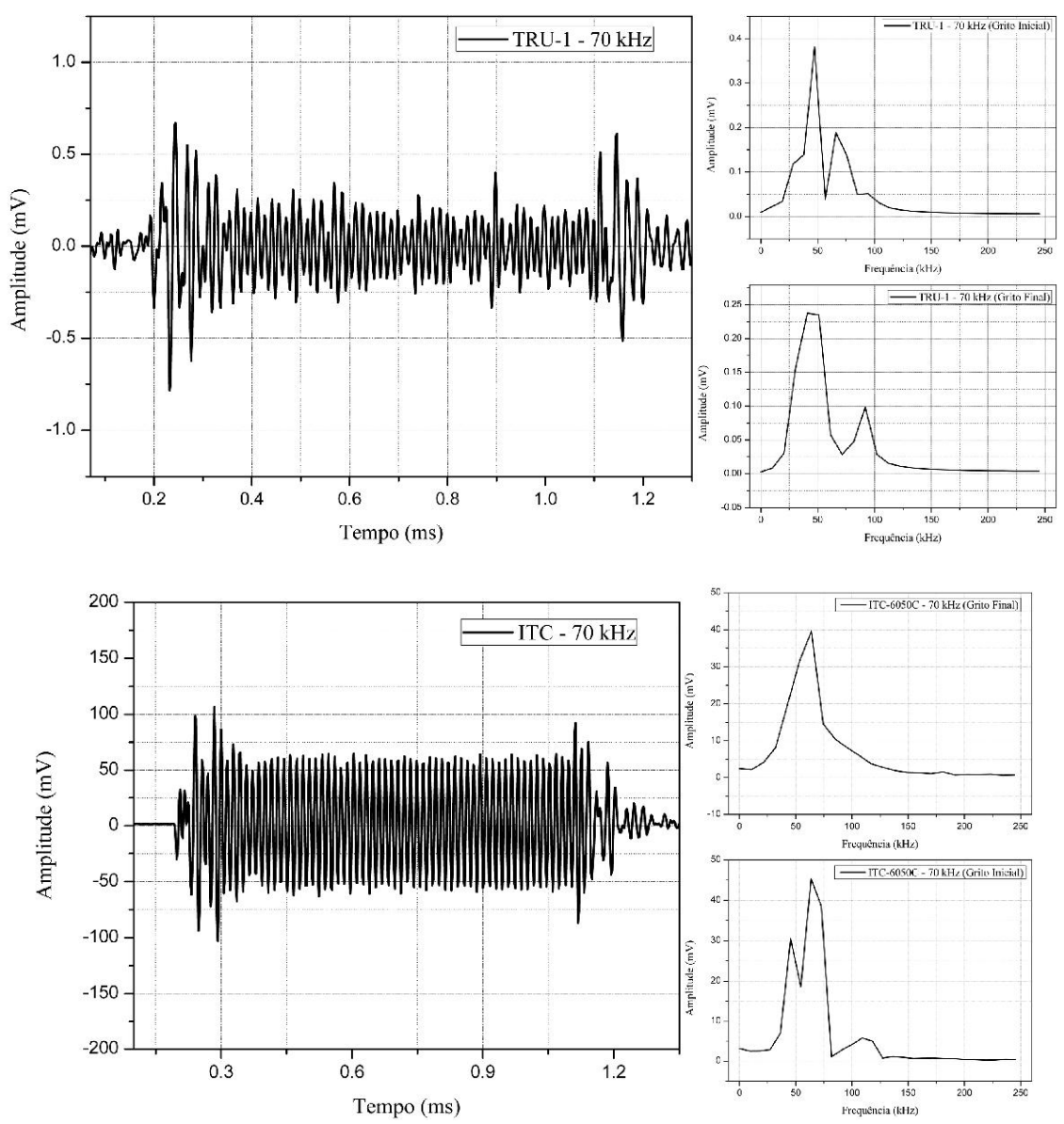

Figura 5.12 - Análises do transitório na excitação e desligamento do transdutor confocal de PZT, em $\Delta f=$ $70 \mathrm{kHz}$, mapeados com o TRU-1 e o ITC-6050C.

O estudo da resposta transitória do atuador cerâmico confocal limitou-se a uma região compreendida nos três ciclos iniciais e finais do sinal completo mapeado, ou seja, nos instantes de ativação e desligamento do burst. Concluiu-se que esse sinal apresentara um frequência fundamental que variava em uma faixa de 50 e $60 \mathrm{kHz}$. Essa situação pode ser atribuída a uma forma de onda quadrada que incide sobre o transdutor de PZT, quando o gerador de sinal era ligado e desligado. Esse tipo de sinal é inerente a emissão em burst, que modula no sinal "quadrado" um pacote de sinais senoidais.

Tal fator passou a ser considerado, principalmente, na definição do número de ciclos a ser avaliado, para que as informações de frequência entre o "grito" e o sinal de interesse não fossem conflitantes. 


\section{DISTÂNCIA ENTRE ATUADOR E RECEPTOR}

Os gráficos da Figura 5.13 retratam os sinais em modo burst e seus respectivos "pacotes", dados por um sinal de trigger. Os exemplos referem-se às medidas em $50 \mathrm{kHz}$ para os dois hidrofones sob teste.
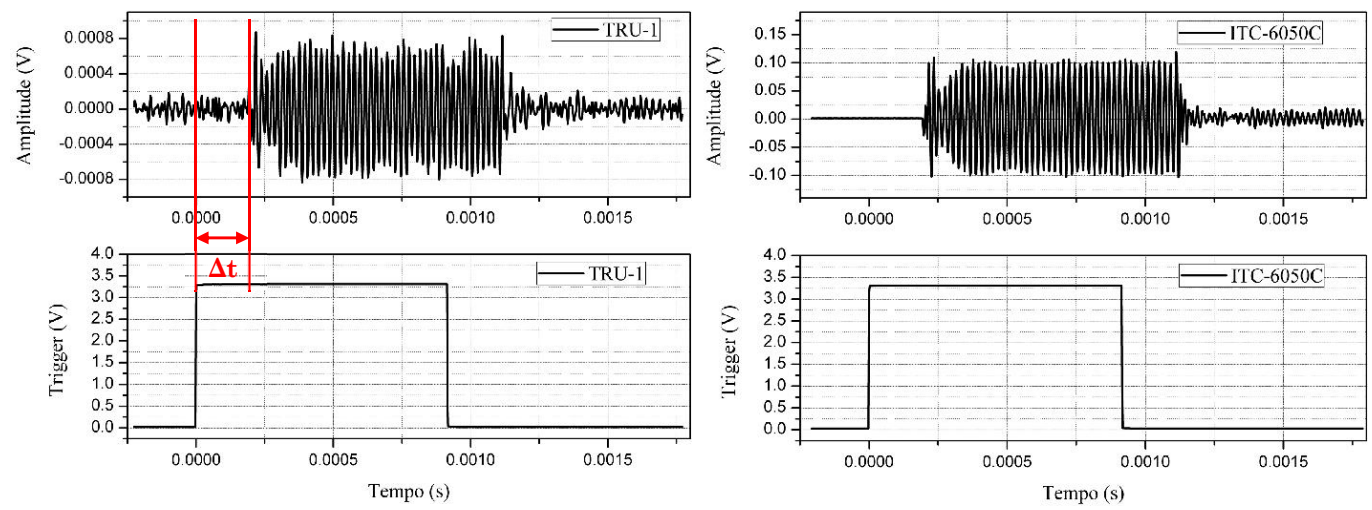

Figura 5.13 - Medidas em burst evidenciando o momento do disparo do conjunto de senoides (dado pelo sinal de trigger) e momento em que o hidrofone começa a captar as primeiras ondas. Exemplo em 50kHz.

Nota-se que, no momento da ativação do sinal de trigger, o hidrofone demora um intervalo de tempo $\Delta t$ para começar a responder. Essa grandeza equivale ao tempo de voo da onda ultrassônica desde o transdutor confocal até ser percebida pelo hidrofone. Ao fazer uso dessa variação de tempo, pode-se calcular a distância entre a fonte confocal e o hidrofone em atividade.

De acordo com o exemplo supramencionado, os tempos de voo para o TRU-1 e para o ITC-6050C foram, respectivamente, $1,92 \times 10^{-4}$ e $1,94 \times 10^{-4}$ segundos. Ao considerar que a velocidade do som na água $\left(a 0^{\circ} \mathrm{C}\right.$ ) é de aproximadamente $1480 \mathrm{~m} / \mathrm{s}$, chega-se a distâncias de $28,41 \mathrm{~cm}$ e $28,71 \mathrm{~cm}$, nesta ordem, para o TRU-1 e ITC-6050C, até a fonte.

\subsection{Padrão de Diretividade}

Os testes para a verificação do padrão de diretividade (ou sensibilidade polar) do TRU-1 foram executados também em modo burst. Os parâmetros oriundos da configuração dos equipamentos envolvidos na excitação da fonte e as características do batimento são exibidos na Tabela 5.2. 
Tabela 5.2 - Parâmetros do modo burst no estudo do Padrão de Diretividade nas frequências de 40 e $50 \mathrm{kHz}$.

\begin{tabular}{ccccccc}
\hline $\boldsymbol{f 1}(\mathbf{M H z})$ & $\boldsymbol{f 2}(\mathbf{M H z})$ & $\boldsymbol{\Delta f}(\mathbf{k H z})$ & Ciclos em $\mathbf{~ M H z}$ & Tb $(\mathbf{s})$ & Ciclos em $\mathbf{~ H z z}$ & $\boldsymbol{\lambda}$ do burst $(\mathbf{m})$ \\
\hline 3.22 & 3.18 & 40 & 1500 & $4.717 \mathrm{E}-04$ & 18.87 & 0.698 \\
3.225 & 3.175 & 50 & 1500 & $4.724 \mathrm{E}-04$ & 23.62 & 0.699 \\
\hline
\end{tabular}

As medidas feitas nas frequências de 40 e $50 \mathrm{kHz}$ são apresentadas na Figura 5.14. Os eixos do gráfico correspondem ao seguinte: coordenadas polares (eixo X), amplitude do sinal (eixo Y) e Z coincide com o eixo do hidrofone de piezoeletreto. Os dados foram plotados mediante normalização de acordo com a amplitude máxima (em volts) das aquisições feitas com intervalos de 1 grau.
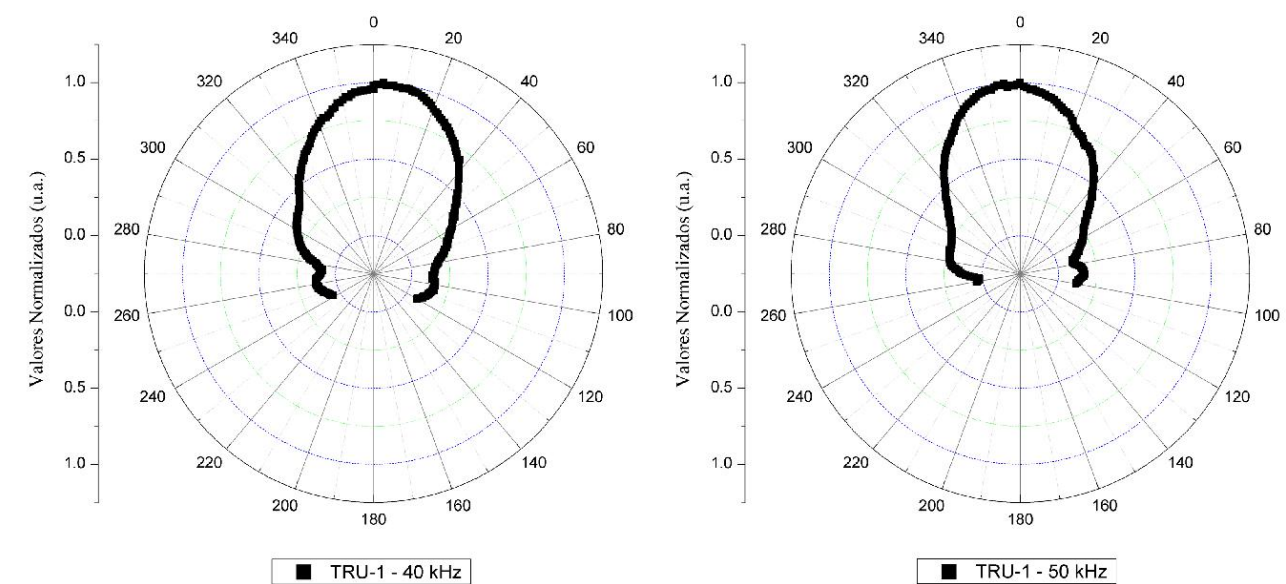

Figura 5.14 - Curvas representativas do Padrão de Diretividade do TRU-1 em 40 kHz (1) e 50 kHz (2), feitas em modo Burst.

Nos gráficos precedentes, principalmente no de $40 \mathrm{kHz}$, observa-se a presença de pequenas descontinuidades laterais presentes simetricamente em $90^{\circ}$ e $270^{\circ}$. Essas regiões são provenientes dos lóbulos laterais produzidos pelo transdutor de PZT. Este fenômeno trata-se de pequenos feixes acústicos em torno do feixe principal do transdutor confocal. Os lóbulos laterais são gerados a partir das bordas do elemento cerâmico e projetados em direções diferentes do eixo primário. Embora a maior parte da energia gerada pelo transdutor seja concentrada no feixe ao longo do eixo central do transdutor, os feixes secundários foram também perceptíveis ao TRU-1.

Como já eram esperadas pelo padrão unidirecional do dispositivo, as respostas tiveram maior amplitude na parte frontal do hidrofone onde se situa o elemento ativo. Os maiores valores registrados foram de $1,878 \mathrm{mV}$ (posição $360^{\circ}$ ) e 1,554mV (posição $3^{\circ}$ ), para 50 e $40 \mathrm{kHz}$, respectivamente. 
Nesse estudo, o tempo de voo da onda foi sempre observado para que não variasse em relação à aquisição inicial em $0^{\circ}$, cuja região sensível do hidrofone foi mantida frente às emissões sonoras emitidas pelo alvo metálico. O fato é que se, em outras posições do goniômetro, diferente de $0^{\circ}$, o tempo de voo fosse diferente daquele inicial, isso seria um indício de que ondas provenientes de reflexões no interior do tanque poderiam ser captadas e, desse modo, influenciariam negativamente na sensibilidade.

\subsection{Análise de Ruído}

Durante os experimentos realizados com os hidrofones até aqui, em particular com o TRU-1, observou-se que o ruído envolvido nas medidas apresentava uma banda de frequência relativamente larga. Ademais, o ruído apresenta uma característica dinâmica e aleatória o que dificulta sobremaneira conhecê-lo.

Nessa fase de medidas, antes mesmo do cálculo da SNR foi necessária uma análise prévia para determinar o ruído intrínseco do hidrofone de piezoeletreto. Como descrito anteriormente na metodologia dos experimentos, esse teste foi realizado em uma sala anecóica fechada, sem interferência de equipamentos elétricos locais e presença humana. Para alcançar um espectro mais abrangente, as aquisições foram configuradas com taxas de amostragem diferentes. Os gráficos da Figura 5.15 ilustram esses dados.
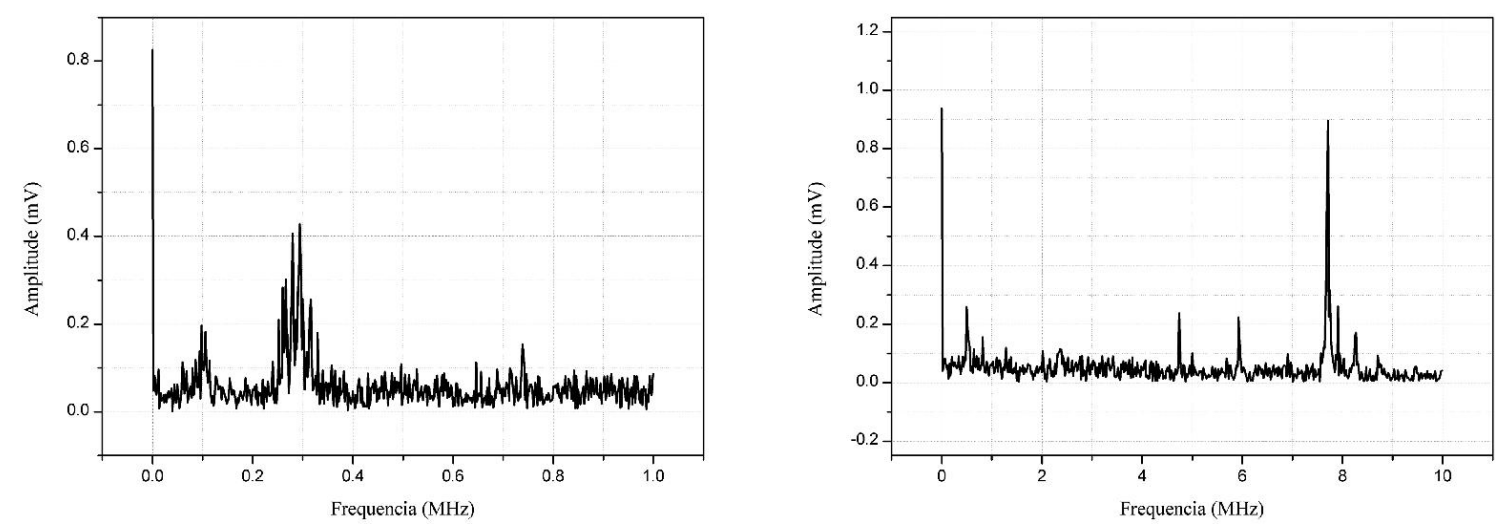

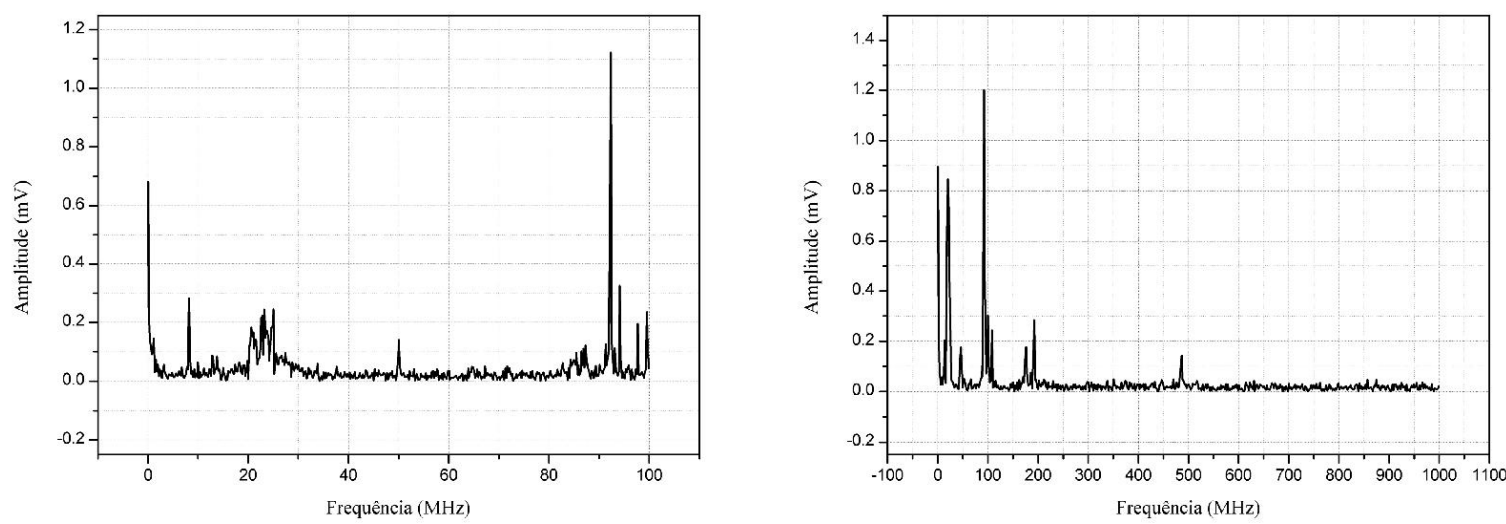

Figura 5.15 - Espectro de frequências do ruído percebido pelo TRU-1, sem fonte de US atuando e dentro de uma sala anecoica totalmente isolada de outras fontes de sinal.

No espectro de todas as medidas foi encontrado um nível DC considerável com amplitude média de $0.85 \mathrm{mV}$. As componentes de ruído mais evidentes e menos invariantes foram na faixa de $250-350 \mathrm{kHz}, 7-8 \mathrm{MHz}, 20-30 \mathrm{MHz}$ e $90-100 \mathrm{MHz}$. A maior amplitude de ruído intrínseco foi em aproximadamente $93 \mathrm{MHz}$, com média de $1,15 \mathrm{mV}$.

As prováveis fontes desses ruídos são atribuídas à própria estrutura (blindagem eletrostática) e circuito eletrônico do TRU-1, bem como a perdas dielétricas do filme piezoelétrico na conversão eletroacústica. Fontes externas, tais como o ruído ambiental e interferências eletromagnéticas da rede de alimentação dos instrumentos de medidas, também podem ter contribuído. Esses dois últimos, podem ter sido causados por possíveis falhas na isolação acústica da sala anecóica e a uma não total eficiência da malha de aterramento do laboratório, respectivamente.

A grande interferência do ruído ocorreu nos experimentos em modo burst, onde os valores médios lidos pelo TRU-1 foram em torno de 0,35mV. Comparando o valor de $1,15 \mathrm{mV}$, proveniente de ruído, com a maior tensão lida em modo burst, pôde-se verificar que a componente do ruído é aproximadamente $70 \%$ maior que amplitude líquida de uma leitura do sinal fundamental.

Contudo a existência desse sinal indesejado não foi o maior problema nas medidas comparativas, porque se conseguiu parcialmente eliminá-lo da informação fundamental com o uso do lock-in nos experimentos em CW e programar o osciloscópio para aquisições no modo "médias" nas demais medidas.

No subitem subsequente, considerações foram feitas com relação à potência do sinal desejado e à potência do ruído existente nesse sinal. 


\subsubsection{Relação Sinal-Ruído (SNR)}

O procedimento para calcular a relação sinal-ruído teve duas etapas. Primeiro, foram adquiridos sinais em 32 médias com o TRU-1. Em seguida, no mesmo ambiente, o protótipo permaneceu ligado, porém sem a fonte de US, sem médias, como se estivesse adquirindo apenas sinais ruidosos próprios e do ambiente (o mesmo das primeiras medidas).

Aos sinais amostrados com médias foi aplicado FFT e calculado valor RMS da onda frequência fundamental, ou seja, a de batimento. O próximo passo foi obter o valor RMS do ruído de fundo e, por último, aplicar com esses valores a Equação 4.7. Os resultados dessa relação são apresentados na Figura 5.16.

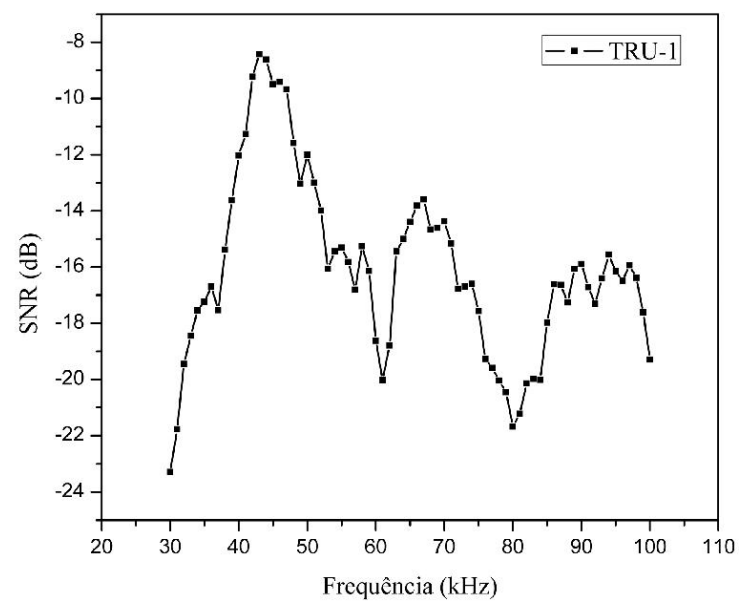

Figura 5.16 - Curva da Relação Sinal-Ruído do TRU-1, dado em função das frequências no qual ele foi caracterizado anteriormente.

De acordo com essa curva, em nenhum momento, a potência do sinal foi superior a do ruído. A melhor SNR verificada esteve na frequência de $43 \mathrm{kHz}$ com um valor absoluto de 0,144 (-8.41dB). Em 30kHz, mediu-se o menor valor equivalente a 0,00468 (-23.29dB), enquanto que a média esteve em torno de $0.169(-15,43 \mathrm{~dB})$.

Portanto, é possível inferir que esses valores não são exagerados para um protótipo que não apresente em sua eletrônica nenhuma etapa de filtragem do sinal, apenas amplificação. Além do mais, atenuações dos sinais indesejados já foram verificadas no TRU1 em testes posteriores a este. Melhorias no sistema de aterramento, melhor conservação do eletrodo da amostra de piezoeletreto e condições ambientais mais resguardadas, ajudaram a melhorar a SNR. 


\subsection{Imagens por VA}

Os testes de caracterização do TRU-1 foram importantes para estabelecer os pontos positivos e negativos da sua operação como hidrofone, assim, pôde-se concluir que o protótipo alcançou alguns requisitos que o habilitam para metodologias de geração de imagens ultrassônicas. A seguir, foram discutidos os resultados provenientes dessa primeira fase de aplicações que fez uso da técnica de vibroacustografia.

\subsubsection{Esfera metálica colada em película}

O objeto de imagem nessa aplicação foi representado pela esfera metálica mencionada no item 4.6.1, e ilustrada na Figura 4.20. Uma frequência de batimento de $37 \mathrm{kHz}$ foi configurada para a excitação do alvo e sua vibração característica mapeada pelos hidrofones TRU-1 e ITC-6050C.

O mapeamento proveniente das emissões acústicas da pequena esfera é apresentado na Figura 5.17. Os gráficos exibem imagens construídas a partir da amplitude do sinal (barra lateral), pela profundidade de pixels $(\mathrm{mm})$.
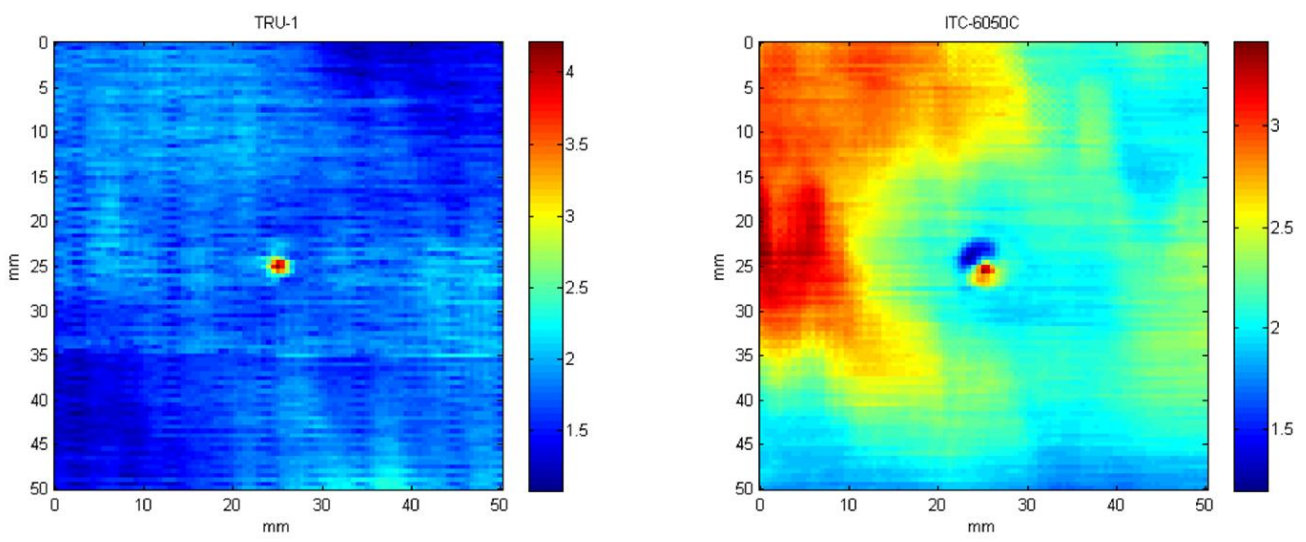

Figura 5.17 - Imagens por VA da esfera de 1mm de diâmetro, colada em um filme de PVC. Imagem à esquerda do TRU-1 e à direita do ITC-6050C.

Observa-se na imagem gerada pelo TRU-1, que o filme de PVC gerou pouca resposta acústica em comparação à esfera, conferindo um alto contraste entre estes elementos. Já no mapa do ITC-6050C, o imageamento foi prejudicado por pontos de saturação que dificultaram a definição da esfera perante o filme. 
Essa diferença de contraste pode ainda ser verificada no gráfico da Figura 5.18, no qual são exibidos os perfis do centro das imagens dos mapas acústicos adquiridos por ambos os hidrofones. No gráfico, nota-se que no TRU-1 o sinal da esfera foi significativamente maior do que o da membrana, enquanto que no ITC-6050C a diferença de sinal entre o filme de PVC e a esfera foi menor.

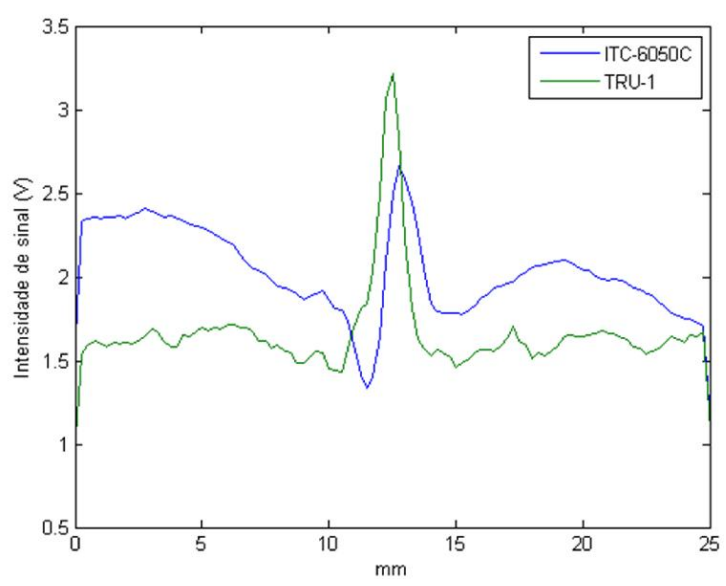

Figura 5.18 - Perfis na linha de centro das imagens adquiridas pelo TRU-1 e ITC-6050C.

O ITC-6050C foi mais sensível à vibração do filme de PVC e aos padrões de ondas estacionárias formadas no tanque acústico. Isso devido à sua maior sensibilidade e ao seu padrão de diretividade ôhmico. Essa característica, no entanto, prejudicou o contraste da imagem, como ilustrado na Figura 5.19.
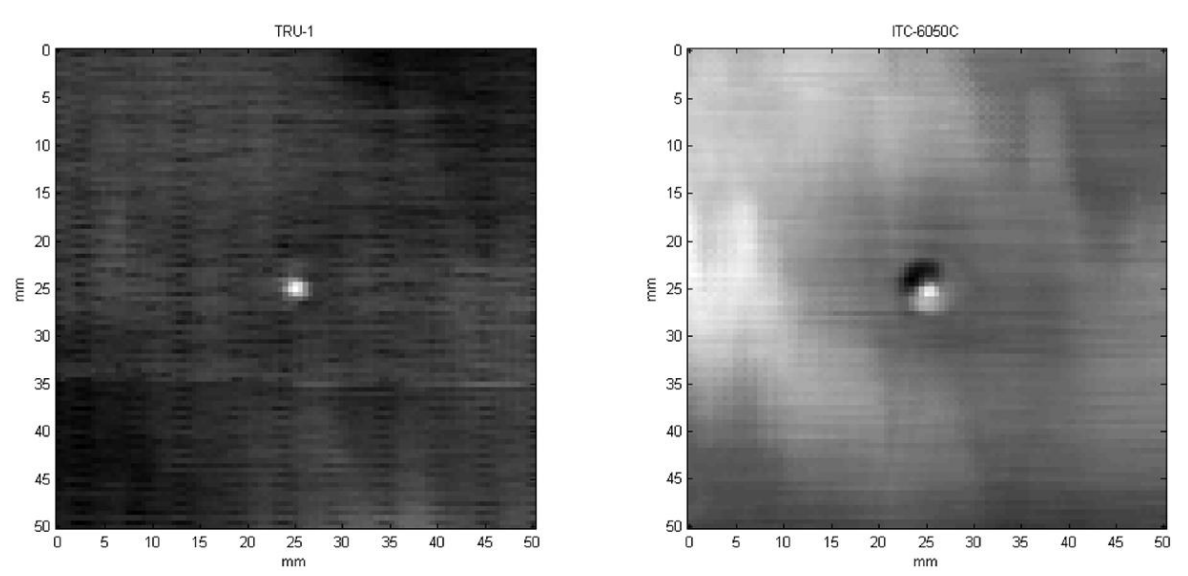

Figura 5.19 - Imagens adquiridas pelo TRU-1 e ITC-6050C, em escala de cinza para melhor definição de contraste.

Outra observação importante é com relação à região sensível do TRU-1, que se encontra localizada na frente de seu encapsulamento devido à configuração do hidrofone. 
Isso, embora represente uma limitação no seu padrão de diretividade, restrito à região frontal, permite que as ondas reverberantes dentro do tanque pouco influenciem na leitura do sinal do objeto. Os padrões de reverberação também ocorrem em aquisições fora do tanque, que normalmente são evitadas através do uso de diferentes beamformings e pós-processamento das imagens.

\subsubsection{Esfera metálica fixada por fios de cabelo}

O mapeamento anterior foi repetido mantendo o mesmo objeto de imagem, mas agora na frequência de $50 \mathrm{kHz}$. A película de PVC que segurava o alvo metálico foi substituída por fios de cabelo fixados no mesmo aro de PVC rígido, com o intuito de que a vibração do elemento de apoio da esfera pouco influenciasse no contraste da imagem. Esse aparato encontra-se ilustrado na fotografia da Figura 4.22; e a imagem resultante desse mapeamento acústico é visualizada na Figura 5.20.
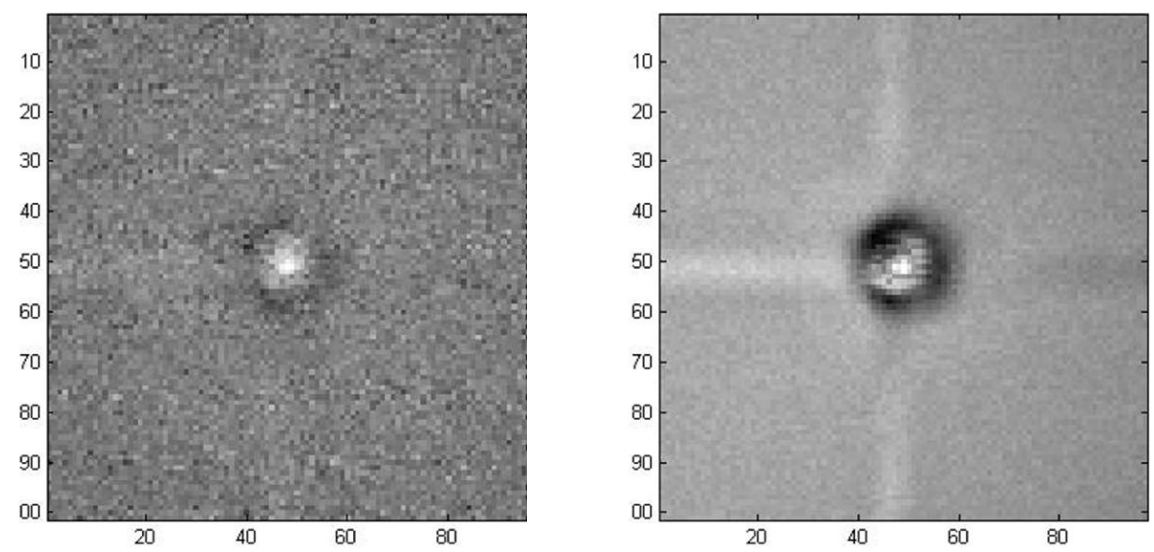

Figura 5.20 - Imagens por VA da esfera de $1 \mathrm{~mm}$ de diâmetro, colada em um filme de PVC. Imagem (1) TRU-1 e (2) ITC-6050C.

Em ambos os resultados verificou-se que a vibração da pequena esfera e até dos fios de cabelo foi perceptível aos hidrofones. Isso reforça o quanto o TRU-1 é sensível à vibração de minúsculos corpos oscilantes, pois os fios de cabelo, em média, apresentam diâmetro na faixa de 60 a $120 \mu \mathrm{m}$.

Na imagem do ITC-6050C, apesar da possível distinção dos objetos, existe uma "falsa ideia" de um mapeamento mais rico em detalhes. Isso se justifica por uma imagem prejudicada por pontos de saturação que além de distorcerem o tamaho real, exibiram pontos sombreados em torno da esfera e do fio de cabelo. Novamente pode-se inferir, que a 
diretividade desse hidrofone contribuiu para que ele fosse mais sensível aos padrões de ondas estacionárias formadas dentro do taque.

\subsubsection{Estrutura óssea}

Mantendo o mesmo arranjo dos equipamentos utilizados no rastreio vibroacústico anterior, a esfera metálica utilizada até então foi substituída por uma estrutura óssea animal. Esse objeto de imagem foi ilustrado na Figura 4.23. As imagens produto desse mapeamento são visualizadas na Figura 5.21.
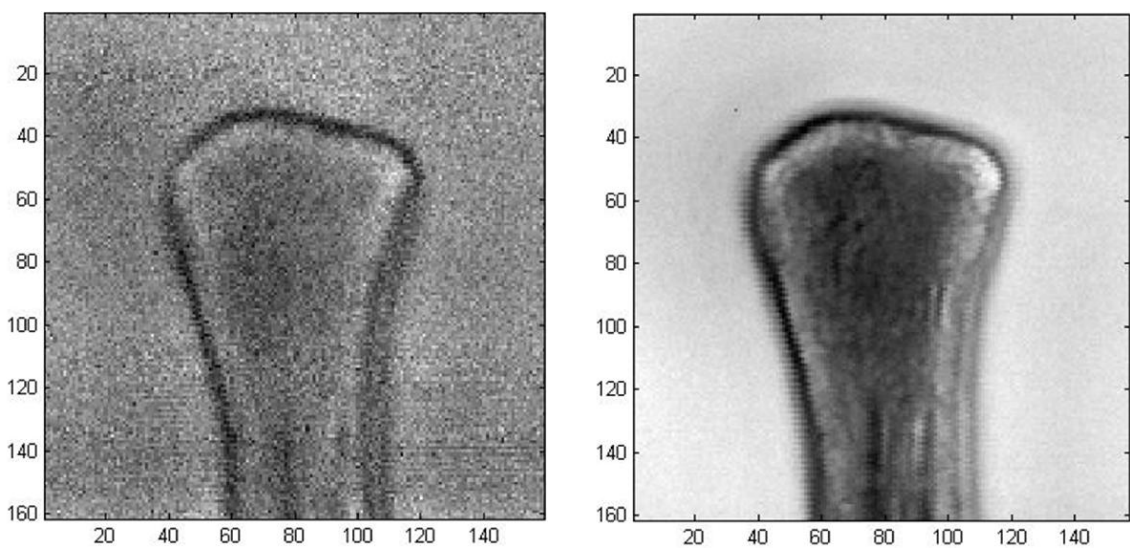

Figura 5.21 - Imagens por VA da estrutura óssea mapeada pelos hidrofones. Imagem (1) TRU-1 e (2) ITC$6050 \mathrm{C}$.

Nessas imagens por VA, nota-se que o TRU-1 foi sensível às oscilações do objeto ósseo, inclusive sendo capaz de exibir detalhes também existentes na imagem com o sensível ITC-6050C, porém com uma resolução da imagem bastante inferior, fato que prejudicou a maior riqueza nos detalhes. O padrão ôhmico do hidrofone comercial, nesse caso, não prejudicou a definição do osso na imagem, pelo fato de não existirem suportes vibrantes ao redor desse alvo.

A baixa qualidade vista nas imagens com o TRU-1 pode ser atribuída principalmente ao alto índice de ruído e à baixa sensibilidade inerentes ao hidrofone. Melhorias tanto estruturais como no circuito eletrônico devem aperfeiçoar esse quesito, pois a atividade piezoelétrica do piezoeletreto empregado é relativamente alta quando comparada com os demais materiais do mesmo segmento.

No capítulo seguinte, são expostas as conclusões baseadas nos resultados comentados até aqui, bem como as propostas futuras para aperfeiçoá-los. 


\section{Capítulo 6}

\section{Considerações Finais}

Nas etapas preliminares das medidas com o modo AM, as curvas resultantes permitiram conhecer os pontos de saturação precoce recorrentes da disposição dos sensores sob intensa radiação ultrassônica. Posteriormente a estas medidas, todos os outros experimentos com os hidrofones foram realizados utilizando um alvo que, depois de irradiado por um feixe de US, passou a vibrar com a frequência de interesse e numa menor intensidade.

$\mathrm{Na}$ análise dos resultados comparativos foi possível verificar a sensibilidade do TRU1 em três diferentes abordagens experimentais, mas em duas delas, $C W$ e Burst, em um maior espectro de frequências. $\mathrm{O}$ fato de o modo Burst operar com ondas emitidas em pacotes temporalmente controlados coibiu múltiplas reflexões no interior do tanque de medidas, que consequentemente, causariam alterações no resultado efetivo. Portanto, foram verificados os valores de $0,142 \mathrm{mV} / \mathrm{Pa}(-196,93 \mathrm{~dB}$ re $1 \mathrm{~V} / \mu \mathrm{Pa})$ como sendo a sensibilidade do protótipo e a ressonância em $40 \mathrm{kHz}$ com uma sensibilidade $1,698 \mathrm{mV} / \mathrm{Pa}$ ($175,4 \mathrm{~dB}$ re $1 \mathrm{~V} / \mu \mathrm{Pa})$.

Nas medidas para verificar o padrão de diretividade polar do hidrofone de piezoeletreto, o padrão unidirecional verificado já era esperado pelas características plana e frontal da região sensível que mantém o filme eletromecânico. Esse padrão teve sua importância nos experimentos em CW por ficar mais imune aos padrões de ondas estacionários, fato este que contribuiu principalmente no contraste das imagens por VA.

A relação sinal-ruído não transmitiu resultados satisfatórios, mas serviu para apontarmos pontos falhos principalmente na blindagem do TRU-1. Os ruídos com componentes de maior amplitude foram verificados em altas frequências, acima de $1 \mathrm{MHz}$, longe da banda de interesse em $\mathrm{kHz}$. A existência de nível DC também se mostrou, por vezes, um empecilho no processamento de sinal. No entanto, em posse dessas informações, o projeto de um filtro adequado a resolver esses problemas pode ser projetado. 
A geração de imagem de VA utilizando-se o hidrofone proposto se mostrou viável com o uso de piezoeletretos termoformados. Esses dispositivos são mais acessíveis devido ao menor custo e representam uma tecnologia nacional. A construção destes dispositivos a partir da tecnologia de piezoeletretos também permite a adequação de diversos formatos de sensores acústicos às diferentes regiões anatômicas, na patologia clínica, devido à flexibilidade dos filmes piezoelétricos, o que favorece o sinal de VA.

A análise dos resultados dos testes de calibração, caracterização e dos experimentos aplicados a VA, permitiram inferir que o TRU-1 mostrou-se viável e com potencial para já ser empregado como uma ferramenta de apoio ao diagnóstico clínico. Esses valores foram evidenciados, perante estudos comparativos do protótipo TRU-1, com um hidrofone padrão de calibração e com renome na área militar, pesquisa e comercial.

\subsection{Trabalhos futuros}

Os estudos futuros pretendidos com os filmes eletromecânicos baseados na tecnologia dos piezoeletretos, desenvolvidos pelo GATM, compreendem:

- Projetar e desenvolver novos dispositivos que operem como sensores e atuadores, simultaneamente, no mesmo equipamento, de maneira a agregar novas aplicações.

- Aplicar à região sensível novas morfologias adequadas ao ambiente de rastreio, , principalmente, na área de patologia clínica com aplicação em VA.

- Aumentar a sensibilidade do sensor, empilhando mais de um filme eletromecânico.

- Estudos dos componentes estruturais do transdutor que tratem da camada de backing e de casamento de impedância acústica e envolvam simulações computacionais.

- Projetar novos dispositivos amplificadores que atuem também como filtros passabanda, com rejeição das altas frequências indesejadas e melhoramento da SNR.

- Executar os testes de diretividade em outro plano de varredura.

- Verificar aplicações também em alta frequência, em casos de pulso-eco. 


\section{Capítulo 7}

\section{Referências}

ALTAFIM, R. A. C. et al. Piezoelectricity of multi-layers space-charge electrets from Teflon FEP film with homogeneous voids distributed on its surfaceConference on Electrical Insulation and Dielectric Phenomena (CEIDP). Anais...2003

ALTAFIM, R. A. C. et al. Piezoelectricity in multi-air voids electretsConference on Electrical Insulation and Dielectric Phenomena (CEIDP). Anais...2005

ALTAFIM, R. A. C. et al. Piezoelectrets from thermo-formed bubble structures of fluoropolymer-electret films. IEEE Transactions on Dielectrics and Electrical Insulation, v. 13, n. 5, p. 979-985, 2006.

ALTAFIM, R. A. C.; GIACOMETTI, J. A.; JANISZEWSKI, J. M. A novel method for electret production using impulse voltages. IEEE Transactions on Electrical Insulation, v. 27, n. 4, p. 739-743, 1992.

ALTAFIM, R. A. P. Análise e implementação de métodos para a caracterização de eletretos termo-formados. [s.l: s.n.].

ALTAFIM, R. A. P. et al. Discharge patterns in three-layer ferroelectret systems with perforated polymer films13th International Symposium on Electrets (ISE). Anais...2008

ALTAFIM, R. A. P. et al. Template-based fluoroethylenepropylene piezoelectrets with tubular channels for transducer applications. Journal of Applied Physics, v. 106, n. 1, p. 014106, 2009.

ALTAFIM, R. A. P. Novos piezoeletretos: desenvolvimento e caracterização. [s.l.] Escola de Engenharia de São Carlos, Universidade de São Paulo, São Carlos, 2010.

APC INTERNATIONAL, L. Piezoelectric constants. Disponível em: $<$ http://www.americanpiezo.com/knowledge-center/piezo-theory/piezoelectric-

constants.html>. Acesso em: 1 maio. 2012.

BAGGIO, A. L. Imagens acústicas geradas pela interação da radiação ultrassônica com o meio material. [s.l.] Faculdade de Física, Ciência e Letras de Ribeirão Preto, Universidade de São Paulo, 2011.

BASSI, D. W. Princípios Básicos de Ensaios Dielétricos em Alta Tensão. São Paulo - SP: [s.n.]. 
BASSO, H. C. et al. Piezoelectricity of a single bubble formed by two oppositely charged Teflon ${ }^{\circledR}$-FEP filmsIEEE Conference on Electrical Insulation and Dielectric Phenomena (CEIDP). Anais...2006

BAUER, S. et al. Modern electretsIEEE Symposium on Ultrasonics (IUS). Anais...2003

BAUER, S. et al. Ferroelectrets: polymer-foam space-charge electrets with ferroelectric-like behaviour12th International Symposium on Electrets (ISE). Anais...2005

BAUER, S.; GERHARD-MULTHAUPT, R.; SESSLER, G. M. Ferroelectrets: Soft Electroactive Foams for Transducers. Physics Today, v. 57, n. 2, p. 37-43, fev. 2004.

BERLINCOURT, D. A.; CURRAN, D. R.; JAFFE, H. Piezoelectric and Piezomagnetic materials and their function in transducers. In: MASON, W. P. (Ed.). Physical Acoustics. New York: Academic Press, 1964.

BIERMAN, W. Ultrasound in the treatment of scars. Arch Phys Med Rehabil, v. 35, n. 4, p. 209-214, 1954.

BOVTUN, V. et al. Ferroelectret non-contact ultrasonic transducers. Applied Physics A, v. 88, n. 4, p. 737-743, 2007.

BROADHURST, M. G. et al. Piezoelectricity and pyroelectricity in polyvinylidene fluoride-A model. Journal of Applied Physics, v. 49, n. 10, p. 4992-4997, 1978.

BROWN, L. F. New ferroelectric polymer ultrasound contact transducers for nondestructive testing applicationsIEEE 7 th International Symposium on Applications of Ferroelectrics. Anais...1990

BROWN, L. F. et al. Ferroelectric nylon materials and their feasibility for ultrasound transducers. IEEE Transactions on Ultrasonics, Ferroelectrics and Frequency Control, v. 44, n. 5, p. 1049-1059, 1997.

BROWN, L. F. Design considerations for piezoelectric polymer ultrasound transducers. IEEE Transactions on Ultrasonics, Ferroelectrics and Frequency Control, v. 47, n. 6, p. 1377-1396, 2000.

CAPRON, B.; HESS, D. Microscopic models of piezoelectric polymers. IEEE Transactions on Ultrasonics, Ferroelectrics and Frequency Control, v. 33, n. 1, p. 33-40, jan. 1986.

CHEN, S. et al. Comparison of stress field forming methods for vibro-acoustography. IEEE Transactions on Ultrasonics, Ferroelectrics and Frequency Control, v. 51, n. 3, p. 313-321, 2004.

CHILOWSKY, C.; LANGEVIN, P. Procedes et appareils pour la production de signaux sous-marins diriges et pour la localisation a distance d'obstacles sousmarinsFrance, 1916. 
CHILOWSKY, C.; LANGEVIN, P. Production of submarine signals and the location of submarine objectsFranceUnited States Patent Office, , 1917.

COSTA-FÉLIX, R. P. B.; MACHADO, J. C. Métodos de calibração de hidrofones. Journal of Biomedical Engineering, v. 23, n. 3, p. 277-292, 2007.

CURIE, J.; CURIE, P. Développement par compression de l'électricité polaire dans les cristaux hémièdres à faces inclinées. Comptes Rendus des Séances de l'Académie des Sciences, v. 91, p. 294-295, 1880.

DUSSIK, K. T. Hyperphonography of the Brain. Physical Therapy, n. 1, p. 9-10, 1948.

FALCONI, D. R. et al. Piezoelectric sensor based on electret thermoforming technology10th IEEE International Conference on Solid Dielectrics (ICSD). Anais...2010

FALCONI, D. R. et al. Multi-layers fluoroethylenepropylene (FEP) films bounded with adhesive tape to create piezoelectrets with controlled cavitiesConference on Electrical Insulation and Dielectric Phenomena (CEIDP). Anais...2011

FATEMI, M.; GREENLEAF, J. F. Ultrasound-stimulated vibro-acoustic spectrography. Science (New York, N.Y.), v. 280, n. 5360, p. 82-5, 3 abr. 1998.

FATEMI, M.; GREENLEAF, J. F. Vibro-acoustography: An imaging modality based on ultrasound-stimulated acoustic emission. Proceedings of the National Academy of Sciences, v. 96, n. 12, p. 6603-6608, 8 jun. 1999.

FIGLABS PESQUISA E DESENVOLVIMENTO LTDA. '. Disponível em: $<$ http://www.fig-labs.com.br/home/>. Acesso em: 18 jan. 2014.

FUKADA, E. History and recent progress in piezoelectric polymers. IEEE Transactions on Ultrasonics, Ferroelectrics and Frequency Control, v. 47, n. 6, p. 1277-1290, 2000.

FURUKAWA, T. Piezoelectricity and pyroelectricity in polymers. IEEE Transactions on Electrical Insulation, v. 24, n. 3, p. 375-394, 1989.

GALLEGO-JUAREZ, J. Piezoelectric ceramics and ultrasonic transducers. Journal of Physics E: Scientific Instruments, v. 22, p. 804-816, 1989.

GALTON, F. Inquiries into human faculty and its development. [s.l.] Macmillan and Co., 1883. p. 288

GERHARD-MULTHAUPT, R. Less can be more. Holes in polymers lead to a new paradigm of piezoelectric materials for electret transducers. IEEE Transactions on Dielectrics and Electrical Insulation, v. 9, n. 5, p. 850-859, 2002.

GOODFELLOW. Fluorinated Ethylene Propylene Copolymer - Film (FP341050). Disponível em: <ttps://www.goodfellowusa.com/catalog/GFCat4J.php?ewd_token=iP8qyY0fWvNSdXm3g tMAsgNkI2ERnN\&n=KW4ucmLyaCkJFZi7EbUPMWrOHstYJU>. Acesso em: 18 abr. 2012. 
HILL, M. N.; ROBINSON, A. R. Physical Oceanography. [s.l.] Harvard University Press, 1962. p. 882

HILLENBRAND, J. et al. Pressure-treated cellular polypropylene with large piezoelectric coefficientsAnnual Report - Conference on Electrical Insulation and Dielectric Phenomena (CEIDP). Anais...2003

IEC. Ultrasonics - Hydrophones - Part 2: Calibration for ultrasonic fields up to $40 \mathrm{MHz}$. In: IEC - Internacional Electrotechnical Commision. Geneva: [s.n.]. p. 83.

INTERNATIONAL TRANSDUCER CORPORATION. ITC-6050C. Disponível em: $<$ http://www.itc-transducers.com/pdf/6050C.pdf $>$.

JAFFE, B.; COOK, W. R.; JAFFE, H. Piezoelectric ceramics. 3. ed. New York: Academic Press, 1971. v. 20p. 317

KAMIMURA, H. Vibroacustografia na avaliação tridimensional de artroplastia total de quadril. [s.l.] Faculdade de Filosofia, Ciências e Letras de Ribeirão Preto, Universidade de São Paulo, 2011.

KAWAI, H. The Piezoelectricity of Poly (vinylidene Fluoride). Japanese Journal of Applied Physics, v. 8, n. 7, p. 975-976, 1969.

KOGA, K.; OHIGASHI, H. Piezoelectricity and related properties of vinylidene fluoride and trifluoroethylene copolymers. Journal of Applied Physics, v. 59, n. 6, p. 21422150, 15 mar. 1986.

KUWATA, J.; UCHINO, K.; NOMURA, S. Dielectric and Piezoelectric Properties of $0.91 \mathrm{~Pb}(\mathrm{Zn} 1 / 3 \mathrm{Nb} 2 / 3) \mathrm{O} 3-0.09 \mathrm{PbTiO} 3$ Single Crystals. Japanese Journal of Applied Physics, v. 21, n. Part 1, No. 9, p. 1298-1302, 1982.

LANGEVIN, P. Procédé et appareils d'émission et de réception des ondes élastiques sous-marines à l'aide des propriétés piézo-électriques du quartzFrança, 1918.

LERCH, R.; SESSLER, G. M. Microphones with rigidly supported piezopolymer membranes. The Journal of the Acoustical Society of America, v. 67, n. 4, p. 13791381, 1980.

LIPPMAN, G. Sur le principe de la conservation de l'électricité, ou second principe de la théorie des phénomènes électriques. Comptes Rendus des Séances de l'Académie des Sciences, v. 92, p. 1049-1051, 1881.

MANBACHI, A.; COBBOLD, R. S. C. Development and application of piezoelectric materials for ultrasound generation and detection. Ultrasound, v. 19, n. 4, p. 187-196, 3 nov. 2011.

NALWA, H. S. Ferroelectric Polymers: Chemistry, Physics, and Applications. New York: M. Dekker, Incorporated, 1995. p. 63-182 
OLIPHANT, T.; EHMAN, R.; GREENLEAF, J. Estimation of complex-valued stiffness using acoustic waves measured with magnetic resonance. Imaging of complex media with acoustic and seismic waves, p. 277-295, 2002.

OMOTE, K.; OHIGASHI, H.; KOGA, K. Temperature dependence of elastic, dielectric, and piezoelectric properties of "single crystalline" films of vinylidene fluoride trifluoroethylene copolymer. Journal of Applied Physics, v. 81, n. 6, p. 2760-2769, 15 mar. 1997.

PAAJANEN, M.; LEKKALA, J.; KIRJAVAINEN, K. ElectroMechanical Film (EMFi) - a new multipurpose electret material. Sensors and Actuators A: Physical, v. 84, n. 1-2, p. 95-102, 1 ago. 2000.

QIU, X. et al. Penetration of sulfur hexafluoride into cellular polypropylene films and its effect on the electric charging and electromechanical response of ferroelectrets. Journal of Physics D: Applied Physics, v. 38, n. 4, p. 649, 2005.

QIU, X. et al. Barrier discharges in cellular polypropylene ferroelectrets: How do they influence the electromechanical properties? Journal of Applied Physics, v. 101, n. 10, p. 104112-1041127, 2007.

QIU, X. Patterned piezo-, pyro-, and ferroelectricity of poled polymer electrets. Journal of Applied Physics, v. 108, n. 1, p. 011101, 2010.

QUANLU, L. et al. Multipurpose piezoelectrical ceramic materials and high performance transducers are used for the ultrasonic medicine27th Annual International Conference of the Engineering in Medicine and Biology Society (IEEEEMBS). Anais...2005

RAHMAN, M. F. B. A. Underwater Acoustic Transducer: Receive Sensitivity and Transmit Response. Disponível em: $<$ http://urrg.eng.usm.my/index.php?option=com_content\&view=article\&id=115:underwat er-acoustic-transducer-receive-sensitivity-and-transmit-

response\&catid=31:articles\&Itemid=70>. Acesso em: 20 abr. 2012.

RHIM, S. M. et al. A 6.0 $\mathbf{M H z} 0.15 \mathrm{~mm}$ pitch phased array ultrasonic probe using PMN-PT single crystalIEEE Ultrasonics Symposium (IUS). Anais...2005

RHIM, S. M.; JUNG, H. Piezoelectric Single Crystal for Medical Ultrasound Transducer. Ultrasonics, p. 300-304, 2007.

ROBERTS, M. J. Fundamentos em Sinais e Sistemas. 2009. ed. [s.l: s.n.]. p. 753

RUPITSCH, S. J. et al. Ultrasound transducers based on ferroelectret materials. IEEE Transactions on Dielectrics and Electrical Insulation, v. 18, n. 1, p. 69-80, fev. 2011.

SCHWODIAUER, R. et al. Preparation and characterization of novel piezoelectric and pyroelectric polymer electrets. IEEE Transactions on Dielectrics and Electrical Insulation, v. 7, n. 4, p. 578-586, 2000. 
SEITZ, F. The cosmic inventor: Reginald Aubrey Fessenden (1866-1932). [s.l.] American Philosophical Society, 1999. p. 77

SESSLER, G. M. Piezoelectricity in polyvinylidenefluoride. The Journal of the Acoustical Society of America, v. 70, n. 6, p. 1596-1608, 1981.

SESSLER, G. M. Electrets. Berlin: Springer-Verlag, 1987. p. 453

SESSLER, G. M.; HILLENBRAND, J. Electromechanical response of cellular electret films. Applied Physics Letters, v. 75, n. 21, p. 3405-3407, 22 nov. 1999.

SHERMAN, C.; BUTLER, J. Transducers and Arrays for Underwater Sound. [s.l.] Springer, 2007. p. 610

SHIRANE, G.; SAWAGUCHI, E.; TAKAGI, Y. Dielectric Properties of Lead Zirconate. Physical Review, v. 84, n. 3, p. 476-481, 1 nov. 1951.

SHROUT, T. R.; EITEL, R.; RANDALL, C. High Performance, High Temperature Perovskite Piezoelectric Ceramics. In: SETTER, N. (Ed.). Piezoelectric Materials in Devices. Switzerland: Lausanne, 2002. p. 413-432.

STREICHER, A. et al. Broadband ultrasonic transducer for a artificial bat headIEEE Symposium on Ultrasonics. Anais...2003

SUGIMOTO, T.; UEHA, S.; ITOH, K. Tissue hardness measurement using the radiation force of focused ultrasoundIEEE Ultrasonics Symposium. Anais...1990

TEXAS INSTRUMENTS INCORPORATED. Precision, Low Power INSTRUMENTATION AMPLIFIERS FEATURES. Disponível em: <http://www.ti.com/lit/ds/sbos051b/sbos051b.pdf>. Acesso em: 20 mar. 2012.

US FOOD AND DRUG ADMINISTRATION (FDA). Guidance for industry and FDA staff-information for manufacturers seeking marketing clearance of diagnostic ultrasound systems and transducers. 2012.

VOIGT, W. Lehrbuch der kristallphysik (mit ausschluss der kristalloptik). Berlin: Leipzig, B.G. Teubner, 1910.

WADA, Y.; HAYAKAWA, R. Piezoelectricity and Pyroelectricity of Polymers. Japanese Journal of Applied Physics, v. 15, n. 11, p. 2041-2057, 1976.

WALLER, D.; CHEN, J.; GURURAJA, T. R. Requirements of piezoelectric materials for medical ultrasound transducersIEEE International Symposium on Applications of Ferroelectrics (ISAF). Anais...1996

WANG, T. T.; HERBERT, J. M.; GLASS, A. M. The applications of ferroelectric polymers. In: ROUTLEDGE; CHAPMAN; HALL (Eds.). Ultrasonics transducers in the megahertz range. New York: [s.n.]. p. 237-273.

WEGENER, M. et al. Piezoelectric two-layer stacks of cellular polypropylene ferroelectrets: transducer response at audio and ultrasound frequencies. IEEE 
Transactions on Ultrasonics, Ferroelectrics and Frequency Control, v. 52, n. 9, p. 1601-1607, 2005.

WILD, J. J.; REID, J. M. Application of echo-ranging techniques to the determination of structure of biological tissues. Science, v. 115, n. 2983, p. 226-230, 1952.

WOO, J. A short history of the development of ultrasound in obstetrics and gynecology. History of Ultrasound in Obstetrics and Gynecology, v. 1, 2002.

ZHANG, P. et al. Influence of charging parameters on piezoelectricity for cellular polypropylene film electrets 12 th International Symposium on Electrets (ISE). Anais...2005

ZHANG, S.; YU, F. Piezoelectric Materials for High Temperature Sensors. Journal of the American Ceramic Society, v. 94, n. 10, p. 3153-3170, 2011.

ZHANG, X.; HILLENBRAND, J.; SESSLER, G. M. Thermally stable fluorocarbon ferroelectrets with high piezoelectric coefficient. Applied Physics A: Materials Science \& Processing, v. 84, n. 1, p. 139-142, 2006.

ZHANG, X.; HILLENBRAND, J.; SESSLER, G. M. Ferroelectrets with improved thermal stability made from fused fluorocarbon layers. Journal of Applied Physics, v. 101, n. 5, p. 54114-54118, 1 mar. 2007. 